\title{
Bruno Oliveira Mororó
}

\section{Modelagem Sistêmica do Processo de Melhoria Contínua de Processos Industriais Utilizando o Método Seis Sigma e Redes de Petri}

\author{
Dissertação apresentada à Escola \\ Politécnica da Universidade de São \\ Paulo para obtenção do Título de \\ Mestre em Engenharia.
}

São Paulo 
Bruno Oliveira Mororó

\title{
Modelagem Sistêmica do Processo de Melhoria Contínua de Processos Industriais Utilizando o Método Seis Sigma e Redes de Petri
}

\author{
Dissertação apresentada à Escola \\ Politécnica da Universidade de São \\ Paulo para obtenção do Título de \\ Mestre em Engenharia.
}

Área de Concentração:

Engenharia de Controle e Automação

Mecânica

Orientador:

Prof. Dr. José Reinaldo Silva

São Paulo 
Este exemplar foi revisado e alterado em relação à versão original, sob responsabilidade única do autor e com a anuência de seu orientador.

São Paulo, 20 de Novembro de 2008

Assinatura do autor

Assinatura do orientador

\section{FICHA CATALOGRÁFICA}

Mororó, Bruno Oliveira

Modelagem Sistêmica do Processo de Melhoria Contínua de Processos Industriais Utilizando o Método Seis Sigma e Redes de Petri / B.O. Mororó. - São Paulo, 2008. Edição Revisada $171 \mathrm{p}$.

Dissertação (Mestrado) - Escola Politécnica da Universidade de São Paulo. Departamento de Engenharia Mecatrônica e de Sistemas Mecânicos.

1. Engenharia de produção 2. Modelagem de manufatura 3. Suporte da Rede de Petri no Método Seis Sigma I.Universidade de São Paulo. Escola Politécnica. Departamento de Engenharia Mecatrônica e de Sistemas Mecânicos Il.t. 
À minha esposa Claudia, exemplo de persistência, força e coragem, tão raros nos dias atuais. 


\section{Agradecimentos}

Agradeço a Deus pela força que não me deixa faltar e pela constante inspiração ao longo da minha existência.

Aos meus filhos que são os grandes motivadores na busca dos meus objetivos.

Aos meus pais Raimundo e Vilma e às minhas irmãs Caroliny e Ivna que ratificam a importância da família na formação do caráter e do espírito vencedor.

Ao meu orientador José Reinaldo Silva pela larga compreensão, suporte e exigência tão necessários no desenvolvimento e conclusão deste trabalho.

Aos colegas do laboratório Design Lab, pelo companheirismo e amizade durante as minhas permanências em São Paulo, particularmente ao Pedro, Jean e Tiago pelo auxílio constante. 


\section{Resumo}

A globalização reforça a necessidade das empresas aprimorarem seus processos e produtos continuamente para se manterem competitivas e atenderem às expectativas de um mercado dinâmico e de acionistas cada vez mais exigentes, que buscam maximizar seus lucros. A melhoria contínua acima mencionada não se refere apenas à qualidade percebida pelo consumidor final, mas também à qualidade e confiabilidade dos processos de produção. Desta forma, quando as empresas têm melhores processos, melhores são os produtos originados e também os seus custos. Porém, a questão é como esses processos são modelados na fase de projeto e como ferramentas de qualidade, sobretudo o Seis Sigma - metodologia mais em voga na atualidade - podem utilizar tais modelos para obter melhores resultados. Essa dissertação propõe a utilização de ferramentas de modelagem e simulação tais como as Redes de Petri para modelagem de processos produtivos - fornecem um modelo formal para a representação de sistemas de produção, capturando aspectos inerentes a tais sistemas como concorrência, paralelismo e sincronização - suportando a aplicação da metodologia Seis Sigma, a qual geralmente atua somente no nível de melhoria do processo produtivo e não do projeto que o originou. Dessa forma, essa dissertação trás uma proposta de integração entre os times que projetam o processo e os que executam a produção, demonstrando tal viabilidade

por meio da análise dos projetos/modelos durante a aplicação da metodologia Seis Sigma. É realizado um estudo de caso na estamparia de uma indústria automotiva que ilustra a aplicação da metodologia proposta.

Palavras-chaves: Modelagem do Processo de Manufatura, Seis Sigma, Redes de Petri, Melhoria Contínua, Documentação do Projeto. 


\begin{abstract}
The globalization strengthens the necessity for companies to improve its processes and products in order to remains competitive and to attend expectations of a dynamic market and shareholders each time more demanding and eager to maximize their profits. The continuous improvement mentioned above, is not related only to the quality perceived by the final consumer, but also to the quality and reliability of the production processes. Therefore, as better processe the company gets, as better would be their final products and as lower would be the costs. However, the question is wheter a continuous improvement using Six Sigma could benefit from the design documentation for the target process returning also an improved documentation after the cycle is completed. This work considers the use of Petri Nets for production processes modeling - even if any other design and modeling representation would return similar results - supporting the Six Sigma methodology application. The main result is a proposition of continuous improvement life cycle that maintains the design documentation consistent and up-to-date. Thus, this work pursuits the integration between the teams that design processes and those who implement them in the manufacturing plant. To show the potential of the models analysis during Six Sigma projects a case study is analyzed for the Press Shop area in an Automotive Industry.
\end{abstract}

Key-words: Manufacturing Process Modeling, Six Sigma, Petri Nets, Continuous Improvement, Design Documentation. 


\section{Lista de Figuras}

FiguRA 2.1 - Elementos do Sistema DE ProduÇão (GIRAULT; VALK, 2003) .............................................. 24

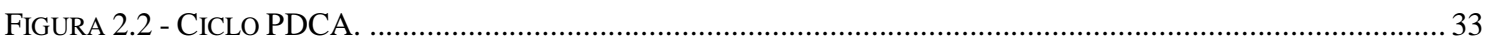

FIGURA 2.3 - CURVA NoRMAL EM UM PROCESSO SEIS SIGMA CENTRADO ………............................................ 34

FIGURA 2.4 - CURVA NORMAL EM UM PROCESSO CUJA MÉDIA ESTÁ DESVIADA 1,5 SIGMA DA NOMINAL ................ 35

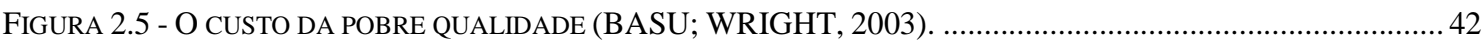

FiguRA 2.6 - Custos RELACIONADOS À QUALIDADE. AdAPTADO DE BASU; Wright, 2003.................................. 43

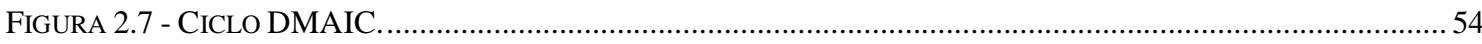

FiguRA 2.8 - O CICLO DE HIPÓTESE/ANÁLISE DA CAUSA-RAIZ (ADAPTADA DE PANDE $E T$ AL, 2001) ........................ 61

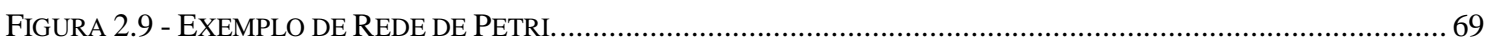

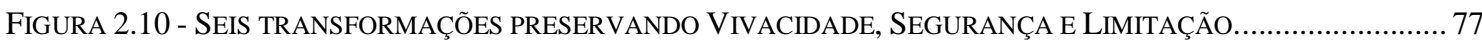

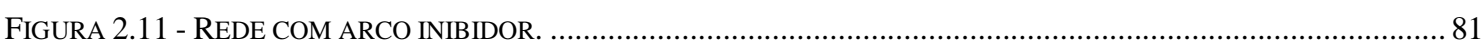

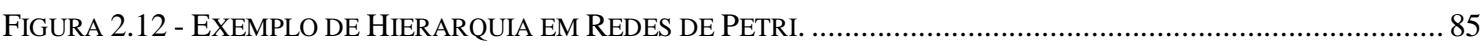

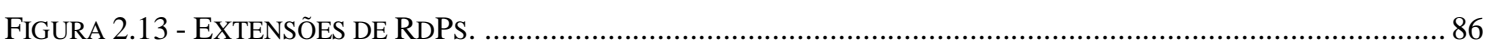

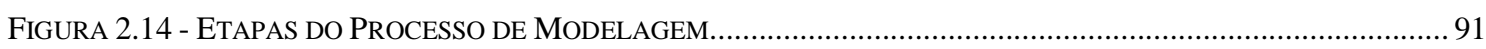

FIGURA 2.15 - CONCEITUAÇÃO DE UMA FÁBRICA VIRTUAL (PORTO; PALMA, 2000)........................................... 93

FigURA 2.16 - AMBIENTE DA MANUfATURA ViRTUAL (PORTO; PALMA, 2000). …….......................................... 94

FigURA 3.1 - FluXOGRAMA DA METODOLOGIA DE SIMULAÇÃO. FonTE: ANDRADE (1989) .................................... 113

FigURA 3.2 - Proposta dE FLUXOGRAMA DA METODOLOGIA DE SIMULAÇÃo. FonTE: AUTOR............................... 114

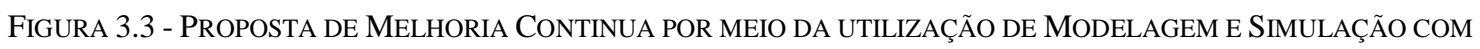
FOCO NA ATUALIZAÇÃO DAS DOCUMENTAÇÕES. FONTE: AUTOR. ...................................................... 117

FIGURA 3.4 - GERAÇÃO DA DOCUMENTAÇÃO DO PROCESSO POR MEIO DO PROGRAMA WITNESS.......................... 121

FiguRA 3.5 - FluXOGRAMA DO DMAIC ATRELADO AO CICLO DE MELHORIA PROPOSTO. FONTE: AUTOR............. 123

FiguRA 3.6 - EXEMPLO A - PROJETO DE UMA LINHA DE MONTAGEM MODELADA E SIMULADA EM REDES DE PETRI. FONTE: AUTOR. 124

FiguRA 3.7 - EXEMPLO B - PROCESSO REAL DIVERGENTE DO PROCESSO PROJETADO. FONTE: AUTOR. ................. 125

FigURA 3.8 - EXEMPLO C - MODELO DO PROCESSO MELHORADO DURANTE UM PROJETO SEIS SigMA. FONTE:

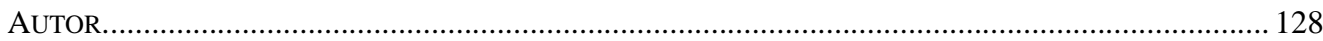

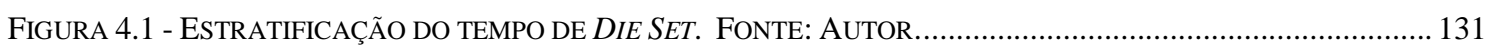

Figura 4.2 - MAPEAMENTO MACRO do PROCESSO DE DIE SET. FonTE: AUTOR…………................................. 131

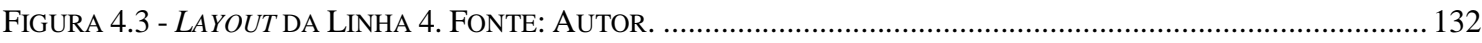

Figura 4.4 - TEMPo MÉdio de Troca do FerRamental Por CÉlula. Fonte: Autor....................................... 135

Figura 4.5 - ANÁliSE ESTATÍSTICA DO TEMPO DE TROCA DO FERRAMENTAL. FonTE: AUTOR............................. 135

Figura 4.6 - MAPA DETALHADO do PROCESSO dE TROCA Do FERRAMENTAL NA CÉlULA 1. FonTE: AUTOR........ 136

Figura 4.7 - Modelo em Redes de Petri do PROCESSO De troca De estampos Com os Die CARS. Fonte:

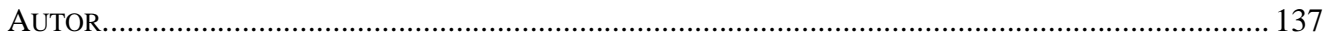

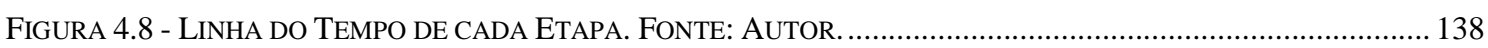

Figura 4.9 - Espinha-de-Peixe: alto tempo de Troca do FerRamental na linha 4. Fonte: Autor......... 138 
FIGURA 4.10 - MAPEAMENTO DO PROCESSO DE MOVIMENTAÇÃO DOS DIE CARS ANTES DA MELHORIA. FONTE:

AUTOR. 139

Figura 4.11 - MOVIMENTO do CARRO PRINCIPAL, PARA FRENTE E PARA TRÁS : VELOCIDAdE ALTA 10,05 M/MIN.; VELOCIDADE BAIXA 1,52 M/MIN. FONTE: HIDRAULIC SCHEMATIC DA ATLAS TECHNOLOGIES K11500.013. 141

Figura 4.12 - MOVIMENTO dO CARRO DO PUSH PUll ( PARAFUSO DE BOLA ) PARA DIREITA OU PARA ESQUERDA: VELOCIDADE 4,57 M/MIN. FONTE: HIDRAULIC SCHEMATIC DA ATLAS TECHNOLOGIES K11500.013. ...... 141

Figura 4.13 - PARTe do MOdelo DesenVOlVIdo EM POWER POINT PElo BLACK BELT. 143

FIGURA 4.14 - MODELO DO PROCESSO MELHORADO DE MOVIMENTAÇÃO DOS ESTAMPOS PELOS DiE CARS. FONTE: AUTOR.

Figura 4.15 - CARTA DE CONTROLE I-MR DO PROCESSO DE MOVIMENTAÇÃO DOS DIE CARS NA TROCA DO FERRAMENTAL ANTERIOR A MELHORIA. FONTE: AUTOR. 153

Figura 4.16 - CARTA DE CONTROLE I-MR DO PROCESSO DE MOVIMENTAÇÃo DOS DIE CARS NA TROCA DO FERRAMENTAL APÓS IMPLEMENTAÇÃO DA MELHORIA. FONTE: AUTOR. 153

Figura A. 1 - Modelo EM WITNESS COM TELA DE RESUlTAdOS MOSTRANDO o NÍVEL SigMA 164

FIGURA A. 2 - ESTÁGIOS DA MODELAGEM. 168

Figura A. 3 - Modelo DE SimulaçÃo NAVEGANDO NO WITNESS. 169 


\section{Lista de Tabelas}

TABela 2.1 - Classificação dos Sistemas de ProduÇão (SILVA, 2005) .

TABELA 2.2 - ESCALA SIGMA E NÚMERO DE DEFEITOS CORRESPONDENTES, CONSIDERANDO RESULTADOS DE UM PROCESSO CENTRADO NO VALOR NOMINAL (WERKEMA, 2000)

TABELA 2.3 - EXEMPLO COMPARATIVO ENTRE UM PROCESSO QUATRO SigMA E UM PROCESSO SEIS SigMA (WERKEMA, 2000) 36

TABELA 2.4 - TRADUÇÃo DO NÍVEL DA QUALIDADE PARA A LINGUAGEM FINANCEIRA. FONTE: WERKEMA (2000)

.

TABELA 2.5 - RELAÇÃO ENTRE OS NÍVEIS SIGMA E O CP, CPK E PPM ASSUMINDO: NORMALIDADE, ESTABILIDADE E

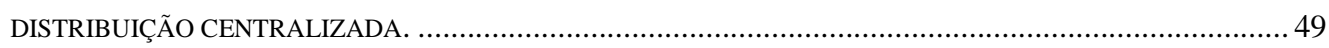

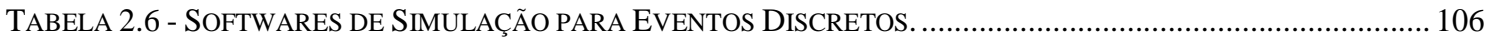

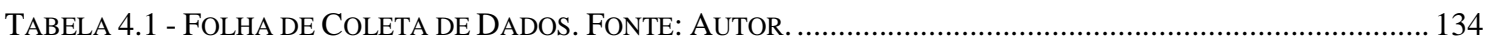

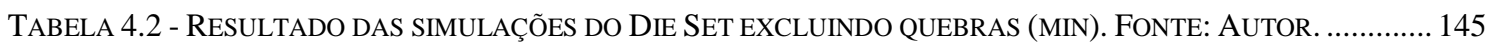

TABEla 4.3 - Resultado DAS SIMULAÇÕES DO Die SET CONSIDERANDO-SE QUEBRAS OU ATRASOS. FonTE:

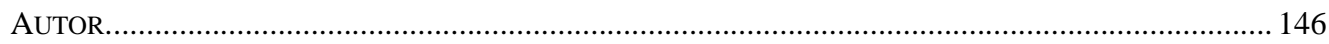

TAbela 4.4 - Resultado das Simulações do novo Processo de Die Set SEM Quebras. FonTE: Autor. .. 148

TABela 4.5 - Resultado das SimUlaÇões do NOVo Die SET CONSIDERANDO-SE QUEBRAs. FonTE: AUTOR. . 150 


\section{Glossário}

Baseline - conjunto de especificações ou produtos de trabalho que foram formalmente revisados e sobre os quais foi feito um acordo, que serve como base para desenvolvimento posterior e que pode ser modificado somente através dos procedimentos de controle de mudanças.

Benchmarking - é um processo contínuo de comparação dos produtos, serviços e práticas empresarias entre os mais fortes concorrentes ou empresas reconhecidas como líderes. É um processo de pesquisa que permite realizar comparações de processos e práticas "companhia-acompanhia" para identificar o melhor do melhor e alcançar um nível de superioridade ou vantagem competitiva.

Brainstorming - é uma metodologia de exploração de idéias, visando a obtenção das melhores soluções de um grupo de pessoas.

Check-lists - lista com pontos chaves do que deve ser feito ou observado.

Deadlock - caracteriza uma situação em que ocorre um impasse e dois ou mais processos ficam impedidos de continuar suas execuções, ou seja, ficam bloqueados.

Just in Time - Just in Time é um sistema de administração da produção que determina que nada deve ser produzido, transportado ou comprado antes da hora exata. Pode ser aplicado em qualquer organização, para reduzir estoques e os custos decorrentes.

Milestones - pontos de checagem ou marcos de desenvolvimento.

Run Chart - gráfico de seqüência que permite que seja avaliada a evolução de um conjunto de dados ao longo do tempo

Shell - É um componente de software - geralmente um programa em separado - que faz a comunicação direta entre o usuário e o sistema operacional. 


\section{Lista de Siglas e Abreviaturas}

\begin{tabular}{|c|c|c|}
\hline$A P Q P$ & - & Advanced Product Quality Planning \\
\hline$C E P$ & - & Controle Estatístico do Processo \\
\hline$C O P Q$ & - & Cost of Poor Quality \\
\hline$C T Q$ & - & Critical to Quality \\
\hline DFMEA & - & Design Failure Mode and Effect Analysis \\
\hline DMAIC & - & Define-Measure-Analyze-Improve-Control \\
\hline$D O E$ & - & Design of Experiments \\
\hline$D P$ & - & Desenvolvimento de Produtos \\
\hline$D P U$ & - & Defeito por Unidade \\
\hline FMEA & - & Failure Mode and Effect Analysis \\
\hline$M R P$ & - & Material Requirement Planning \\
\hline$M S A$ & - & Measurement System Analysis \\
\hline$N A S A$ & - & National Aeronautics and Space Administration \\
\hline$P D C A$ & - & Plan-Do-Check-Act \\
\hline$P D V$ & - & Processo de Desenvolvimento de Veículos \\
\hline$P \& D$ & - & Pesquisa e Desenvolvimento \\
\hline PFMEA & - & Process Failure Mode and Effect Analysis \\
\hline$P P M$ & - & Partes por Milhão \\
\hline$P S W$ & - & Part Submission Warranty \\
\hline$Q F D$ & - & Quality Fuction Deployment \\
\hline QPS & - & Quality Process Sheet \\
\hline VOC & - & Voice of Costumer \\
\hline
\end{tabular}




\section{Sumário}

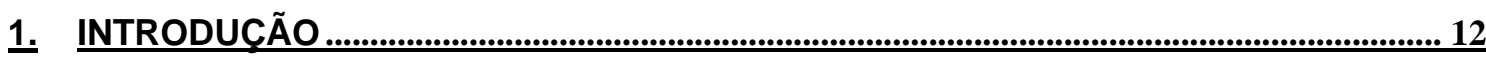

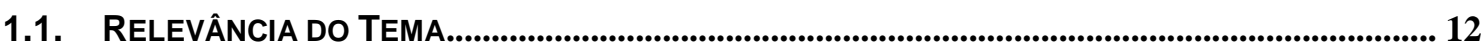

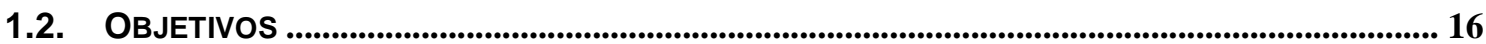

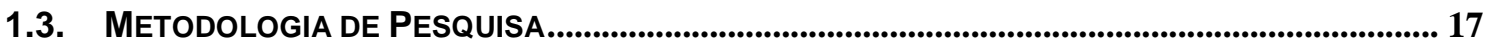

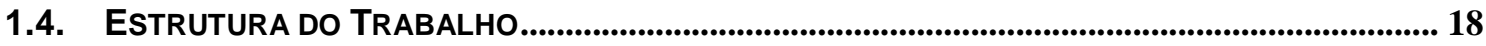

2. REVISÃO DA LITERATURA $\ldots$

2.1. Desenvolvimento de Produtos e de Processos............................................................ 19

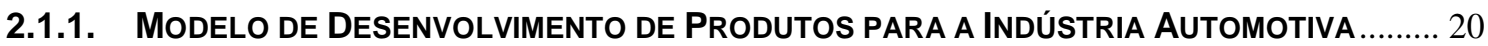

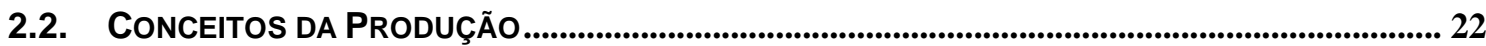

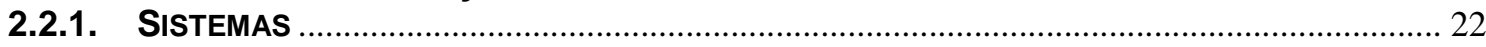

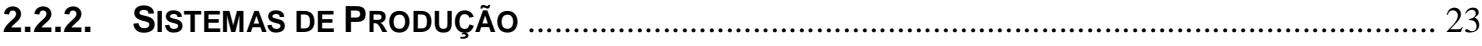

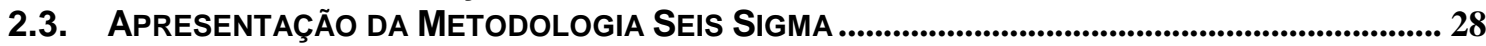

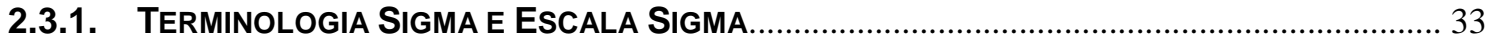

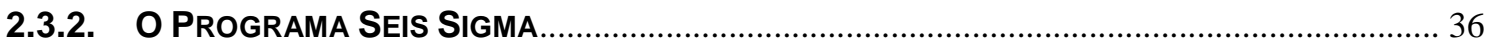

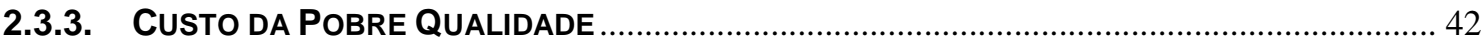

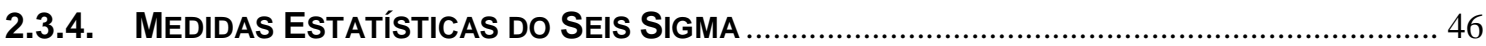

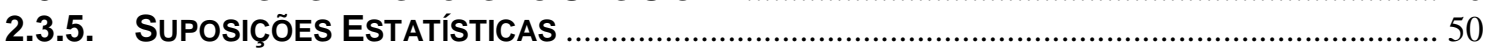

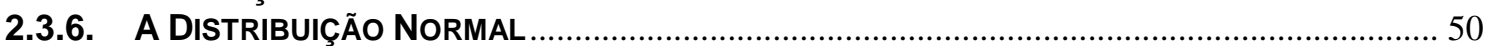

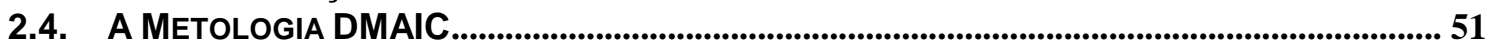

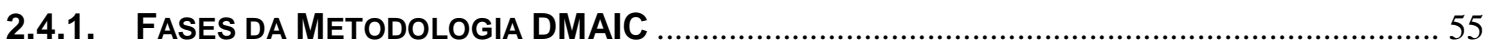

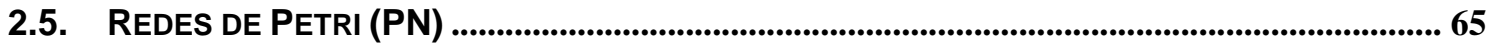

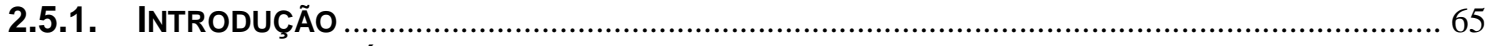

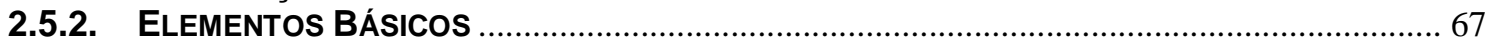

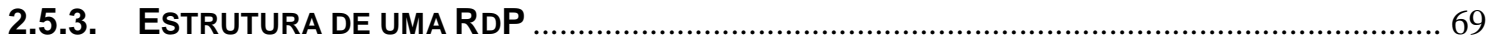

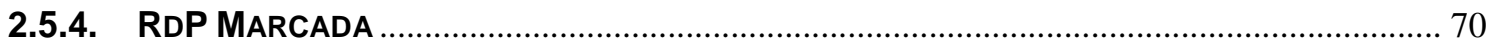

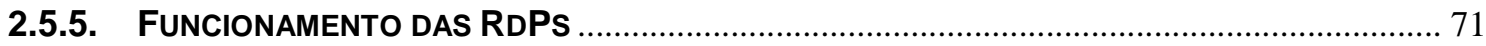

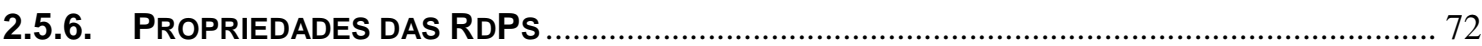

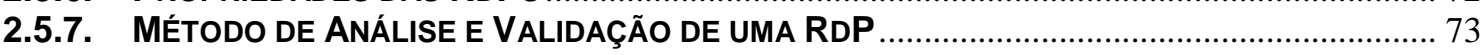

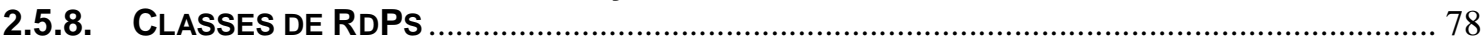

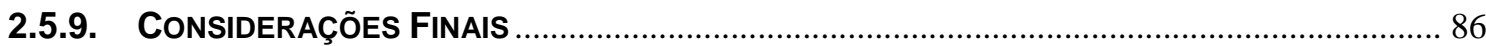

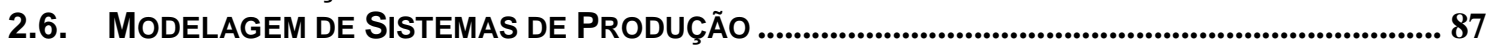

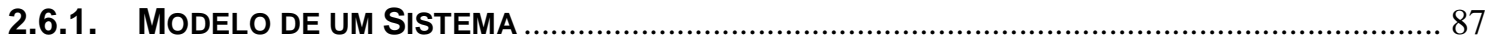

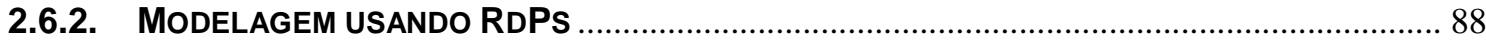

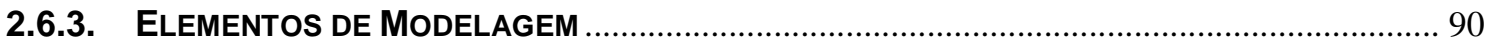

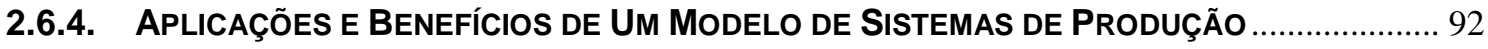

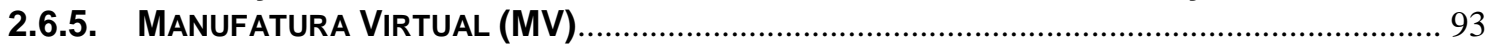

2.7. Manufatura ViRtual, Processo de Melhoria Contínua e Seis Sigma ................... 110

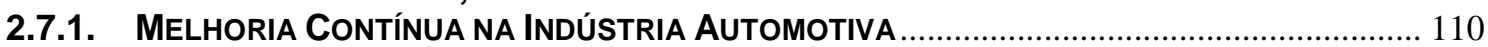

3. PROPOSTA DE UTILIZACÃO DE FERRAMENTAS DE MODELAGEM E SIMULACÃO EM PROJETOS DE MANUFATURA E NO CICLO DE MELHORIA CONTÍNUA ................ 113 


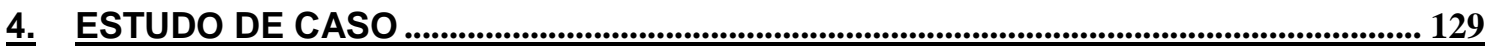

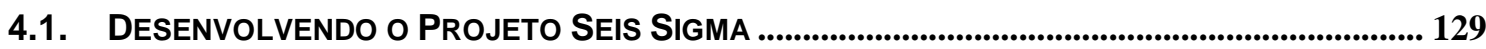

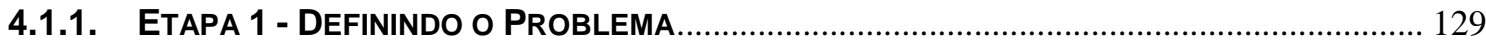

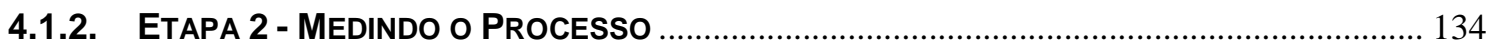

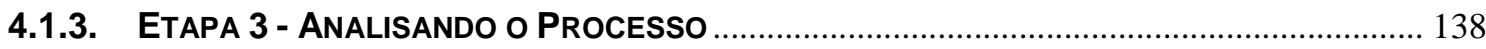

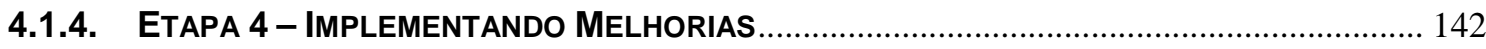

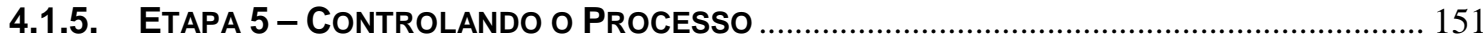

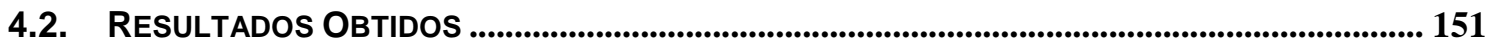

5.

6. REFERÊNCIAS BIBLIOGRÁFICAS $\ldots$

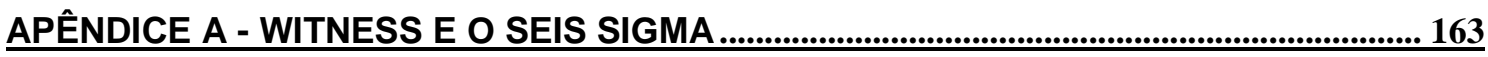

- SuPoRTe À DefiniçÃo do ProJeto SeIS Sigma ...................................................................... 165

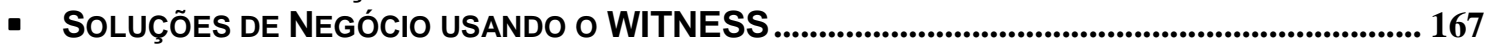




\section{Introdução}

\subsection{Relevância do Tema}

Desde os anos 90, no final do século passado, o mundo da manufatura convive com os requisitos de precisão e qualidade inerentes tanto aos processos industriais quanto aos produtos finais. A motivação está em buscar o estado da arte, alcançando a cada dia um novo padrão de evolução. A essência da melhoria contínua está nessa busca rumo à evolução constante e consciente, superando os obstáculos, solucionando problemas, aprendendo com erros e acertos, ensinando, conhecendo, compartilhando cada conhecimento, contribuindo, assim, não somente para o crescimento pessoal e individual, mas também profissional e organizacional. O que se vê atualmente é o dinamismo de mercados, clientes, técnicas, metodologias, enfim, do ambiente.

Há um ritmo acelerado de mudanças. E, para acompanhar esse ambiente em constante transformação, torna-se essencial ter pensamentos e ações voltados para a melhoria contínua, desenvolvendo uma cultura com base nela. Sua prática facilita a criação de um ambiente de aprendizagem continuada, buscando o melhor uso do conhecimento existente na organização e potencializando a capacidade de criação de novos conhecimentos. Isso posiciona a melhoria contínua como uma prática útil nessa era do conhecimento.

A idéia de melhoria contínua está relacionada à capacidade de resolução de problemas (BESSANT et al., 2001) por meio de pequenos passos, alta frequiência e ciclos curtos de mudança (BESSANT et al., 1994). Esses ciclos de mudança são causados pela alternância de momentos de ruptura e de controle do desempenho dos processos.

Ruptura (do inglês, breakthrough) significa mudar os padrões de desempenho para níveis melhores, e controle pode ser conceituado como a aderência ao padrão, levando à 
manutenção do status quo. Com significados opostos, essas duas atividades, complementares entre si e partes do mesmo ciclo, são vitais para a sobrevivência da maioria das organizações na medida em que elas possibilitam a esta organização implementar mudanças e perpetuá-las ao longo do tempo (JURAN, 1995).

As atividades de ruptura e controle formam a base do processo de melhoria contínua, que pode ser caracterizado por esforços sistemáticos e iterativos que causam impactos positivos e acumulativos no desempenho da organização. A melhoria é sistemática porque utiliza uma abordagem científica, ou seja, o processo de resolução de problemas é estruturado em etapas como a identificação das causas, escolha, planejamento e padronização da solução. A melhoria é iterativa porque o ciclo de resolução de problemas é realizado indefinidamente para buscar uma solução ou melhorar algo já atingido.

O conceito Seis Sigma foi inicialmente desenvolvido e implementado pela Motorola, em 1986, sendo adotado, na seqüência, por outras grandes empresas como a General Electric, Texas Instrumentos, Allied e Hewlett-Packard.

Seis Sigma é, acima de tudo, uma iniciativa estratégica de alto nível. É um processo científico que procura focar no desenvolvimento e entrega de produtos e serviços próximos da perfeição. Do ponto de vista dos processos, trata-se de uma abordagem sistemática para reduzir falhas que afetam pontos críticos para o cliente, aumentando a sua satisfação e reduzindo custos.

Porém, as falhas tratadas nos projetos Seis Sigma voltados à manufatura e as soluções advindas da aplicação dessa metodologia, resolvem o problema apenas em nível de chão de fábrica, enquanto que diversos problemas surgem numa fase anterior que é a elaboração do projeto do processo, suas especificações e requisitos. Atualmente, é razoável admitir haver carência nas empresas quanto à coordenação das atividades de melhoria dentro de uma visão 
sistêmica dos processos existentes. As atividades normalmente focam a solução necessária para se adequar a um ou outro indicador de desempenho, e não estendem a análise para implicações em outros processos. A falta de análise das falhas que deveriam ser vistas durante o projeto corroboram com a afirmação anterior, sendo pouca a integração e compartilhamento de informações entre equipes de produção e projeto, não gerando um conhecimento integrado entre áreas e conseqüentemente não havendo uma análise crítica das documentações de projeto existentes. Isto pode levar a três problemas principais:

1. Perda de tempo no desenvolvimento de um projeto Seis Sigma quando o problema estiver na adesão aos padrões, ou seja, o processo não estar implementado conforme projetado, o que é um problema de disciplina e cultura, onde não cabe a demanda de um time aplicando o método Seis Sigma.

2. Possibilidade de se tentar implementar ações as quais já foram testadas anteriormente e não deram certo, porém o time não sabe. Isso pode ocorrer ou pela verificação da documentação não ser uma das etapas realizadas pelo time, ou pelo fato da inexistência de uma documentação "viva" onde todas as melhorias implementadas no chão-de-fábrica devem estar devidamente registradas.

3. Time de projetos continuar cometendo os mesmos erros e propondo processos que outrora já precisaram ser modificados na manufatura devido a sua ineficácia e levando o time de processo a manter engenheiros trabalhando em melhorias que deveriam ser vistas antes da implementação no chão-de-fábrica.

É importante atentarmos para o fato de que a globalização da economia ocorrida nos últimos tempos levou a profundas mudanças no processo produtivo, fazendo surgir novas formas de fabricação e comunicação. Os sistemas de produção modernos requerem grandes investimentos e são muito complexos. Eles são usualmente compostos de produtos, máquinas, 
sistemas de transporte etc. $\mathrm{O}$ adequado projeto de tais sistemas tem um grande impacto no desempenho, e em última análise no seu sucesso econômico. Devido a sua complexidade, é freqüentemente difícil prever o comportamento de tais sistemas com relativa precisão sem o auxílio de técnicas de modelagem e avaliação qualitativa e quantitativa.

Em vista disso, outro aspecto que será tratado nesta dissertação proposta são as Redes de Petri (RdPs) que têm sido utilizadas com sucesso na modelagem de sistemas de produção devido a sua capacidade de descrever e analisar características inerentes a tais sistemas, como sincronização, compartilhamento de recursos e atividades concorrentes. É importante ressaltar que na maioria dos projetos de manufatura os processos não são projetados utilizando ferramentas adequadas de modelagem e simulação, cujo uso poderia ser um poderoso recurso para abertura, verificação, análise crítica e desenvolvimento de projetos Seis Sigma, servindo como base documental para o mesmo.

O autor da dissertação atua há oito anos na área de produção tendo recebido treinamento de Black Belt em Seis Sigma e conhecendo os problemas de integração entre os times de projeto e produção. Com base nisso, vemos com entusiasmo a possibilidade da aplicação prática dessa dissertação.

A importância do tema deste trabalho pode ser justificada pelos seguintes aspectos:

1. Inicialmente por estar relacionado à melhoria do processo decisório e dos requisitos de projetos através da utilização do Seis Sigma. Segundo Eckes (2001), o Seis Sigma depende quase exclusivamente da coleta e análise de dados dos processos individuais e por essa afirmativa é possível notar a carência na análise da integração com outros processos e, portanto, limitação da metodologia.

2. Por fortalecer a metodologia Seis Sigma promovendo uma análise não só em nível de implementação no chão de fábrica, mas também em nível de projeto. 
3. Pela utilização das redes de Petri como ferramenta de modelagem nesta nova abordagem e visto que a mesma, foi de grande relevância durante o curso de Mestrado em Engenharia Mecânica. Ademais, Perez-Wilson (1999) afirma que uma das deficiências do Seis Sigma é a falta de controle utilizada para sustentar melhorias alcançadas, visto que o Seis Sigma utiliza processos manuais para este fim, uma abordagem que carece de eficácia. As redes de Petri na proposta desse trabalho são utilizadas como ferramenta de controle e como documentação robusta do processo.

\subsection{Objetivos}

Este trabalho tem como objetivo principal propor um ciclo de melhoria contínua mais robusto e que preserve a documentação, isto é, que tenha a especificação dos processos como ponto de partida e resulte em uma nova especificação, também consistente, como substituta da anterior.

Os objetivos secundários da proposta são:

- Propor a modelagem e simulação de processos (seja qual for o modelo básico utilizado) como um meio de estabelecer o processo como especificado inicialmente e melhorar o seu entendimento pela equipe Seis Sigma.

- Propor a análise do design dos processos pelo time Seis Sigma, comparando o processo com a especificação original, antes mesmo da elaboração do mapeamento do processo em alto nível, e discutir as vantagens dessa sistemática.

- Propor um método onde os times de projeto e produção estejam totalmente integrados pela documentação, estando o projeto do processo disponível ao time de produção e que as melhorias efetuadas no chão-de-fábrica sejam corretamente documentadas e atreladas à 
documentação original do projeto - como uma nova versão desta - garantindo assim que sempre sejam questionados os requisitos de projeto e o processo decisório, bem como adequando os mesmos de forma a evitar futura repetição da falha;

- Tomar como estudo de caso a aplicação da presente proposta na estamparia de uma indústria automotiva, podendo assim validar sua eficácia utilizando Redes de Petri como modelo básico de simulação.

\subsection{Metodologia de Pesquisa}

Conforme citado por Silva e Menezes (2000) as pesquisas podem ser classificadas de diversas maneiras:

1. Pela natureza, em básica ou aplicada. Sendo o trabalho em questão uma pesquisa aplicada, pois os conhecimentos gerados são de possível aplicação em problemas práticos. O tema também foi inspirado em dificuldades encontradas no ambiente industrial, embora tenha sido tratado à luz dos métodos de modelagem e design de sistemas.

2. De acordo com a forma de abordagem, em quantitativa ou qualitativa. A abordagem qualitativa é a mais adequada para o trabalho em questão, pois as avaliações e discussões são subjetivas e baseadas na interpretação de fenômenos.

3. Pelo seu objetivo, em exploratória, descritiva ou explicativa. O objetivo da dissertação é exploratório, pois visa analisar as atuais aplicações do Seis Sigma e das redes de Petri em relação aos projetos de produção, conhecendo suas particularidades, seus conceitos e assim propor hipóteses para que estes sejam otimizados. 
4. Em relação aos procedimentos técnicos, a pesquisa pode ser bibliográfica, documental, experimental, levantamento, estudo de caso, expost-facto, pesquisa-ação e pesquisa participante. Devido ao seu caráter exploratório e prático, a dissertação será baseada em pesquisa bibliográfica e estudo de caso.

\subsection{Estrutura do Trabalho}

- No capítulo 1 é apresentada a introdução com considerações acerca da relevância do tema e objetivos desse trabalho.

- O capítulo 2 é formado pela fundamentação teórica, com conceitos de Desenvolvimento de Produtos e de Processos, Conceitos de Produção, Seis Sigma, Redes de Petri e Modelagem de Sistemas de Produção.

- O capítulo 3 é constituído pela proposta de utilização de ferramentas de modelagem e simulação em projetos de manufatura e no ciclo de melhoria contínua.

- O capítulo 4 apresenta o estudo de caso na área da estamparia de uma indústria automotiva.

- O capítulo 5 apresenta as conclusões e a proposta de trabalhos futuros. 


\section{Revisão da Literatura}

\subsection{Desenvolvimento de Produtos e de Processos}

A nova competição industrial que apresenta dois dos seus focos no processo de desenvolvimento de produtos e no desenvolvimento da manufatura considera três forças que surgiram nas empresas nas últimas duas décadas. Uma competição internacional intensa proveniente da globalização, consumidores mais sofisticados provenientes da fragmentação de mercados e mudanças constantes na tecnologia combinaram-se levando o processo de desenvolvimento de produtos ao centro do jogo de competição entre as empresas. (CLARK e FUJIMOTO, 1991).

Em um ambiente competitivo que é global, intenso e dinâmico, o desenvolvimento de novos produtos e processos tornou-se um ponto de foco da competição. Empresas que conquistam mercados mais rápida e eficientemente com produtos que encontram e excedem às expectativas dos clientes criam uma significativa alavancagem competitiva.

O processo de desenvolvimento de produtos encontra-se na interface entre a empresa e o mercado cabendo a ele: desenvolver um produto que atenda às expectativas de mercado, em termos de qualidade total do produto; e desenvolver o produto no tempo adequado, ou seja, mais rápido que os concorrentes, e a um custo de projeto compatível. Além disso, deve também assegurar a manufaturabilidade do produto, ou seja, a facilidade de produzi-lo, atendendo aos requisitos de custo e qualidade (FLORENZANO, 1999).

O desempenho de uma empresa no desenvolvimento de produtos pode ser avaliado por três parâmetros básicos: qualidade, tempo e produtividade, que devem ser otimizados para 
capacitar uma empresa a atrair e satisfazer seus clientes, aumentando a competitividade de seus produtos (CLARK e FUJIMOTO, 1991).

O desenvolvimento de produto (DP) pode ser definido como um processo pelo qual uma organização transforma as informações de oportunidade de mercado e de possibilidades técnicas em informações para a fabricação (CLARK e FUJIMOTO, 1991). Essa definição tem como objetivo romper as barreiras para que o desenvolvimento do produto esteja apenas relacionado aos departamentos de manufatura e P\&D (pesquisa e desenvolvimento). Este desenvolvimento é muito mais amplo, englobando todo o ambiente interno (marketing, logística etc.) e externo (mercado) à empresa, devendo agregar às equipes de processo de desenvolvimento de produtos outros departamentos (marketing e financeiro), por meio de informações que se originam em pesquisas de mercado.

Outros autores defendem que o desenvolvimento do produto seria a transformação de uma oportunidade de mercado, adicionado a um conjunto de possibilidades, onde o emprego de uma nova tecnologia resultaria em um produto disponível para a venda. As duas mais importantes entidades envolvidas na tomada de decisão para desenvolver um produto são a empresa e o mercado, sendo o último sempre dinâmico. Existem, ainda, outros fatores que são considerados secundários como leis políticas econômicas e o estado da tecnologia.

\subsubsection{Modelo de Desenvolvimento de Produtos para a Indústria Automotiva}

O Processo de Desenvolvimento de Veículos (PDV) surgiu em decorrência da necessidade das indústrias automobilísticas se estruturarem melhor, disciplinando e organizando seus métodos de trabalho face ao considerável aumento da competição de mercado evidenciado, principalmente, pela forte empreitada das indústrias do bloco oriental, como as japonesas e 
coreanas, em aumentar a participação no mercado com produtos inovadores, com um ótimo nível de qualidade e, principalmente, com custos mais baixos (FIORAVANTI, 2005).

A colocação do parágrafo acima pode ser atribuída a um PDV que passou a figurar no cenário automobilístico como uma ferramenta estratégica de grande valor para os fabricantes de automóveis, porém, não se pode deixar de citar que o PDV, de fato, passou a existir preliminarmente quando as primeiras fábricas de automóveis de produção seriada começaram a operar. Naquela época, a preocupação em se ter um PDV estava relacionada basicamente ao fato de se documentar os métodos e as técnicas empregadas na construção dos automóveis.

Segundo Fioravanti (2005), o campo de atuação desta concorrência atual deixou de ser limitado à melhoria da qualidade do produto e dos processos de fabricação vigentes. Este passou a ser mais consistente, mais abrangente, ou seja, passou a exigir e ditar regras em direção às etapas mais preliminares do produto, penetrando nas até então, restritas e estanques atividades de desenvolvimento de produto. Estava sendo este o grande diferencial que as indústrias asiáticas vinham proporcionando, pois além das vantagens em custo e qualidade, passou também a ser levado em consideração a variável tempo como mais uma importante vantagem competitiva perante as demais.

Fioravanti (2005) ainda cita que face a esta situação de ameaça de perda de mercado, as grandes indústrias automobilísticas americanas e européias foram obrigadas a criar processos de desenvolvimento mais flexíveis e eficazes, para garantir que seus produtos continuassem a entusiasmar o consumidor, através do lançamento de produtos mais competitivos em preço, qualidade e tempo de desenvolvimento.

Para tanto, todas as áreas da empresa, principalmente a engenharia, passaram a utilizar recursos tecnológicos de ponta em diversos segmentos para assegurar que não haveria desperdícios, principalmente de tempo e dinheiro, além de uma nova postura disciplinar que 
assegurasse o alcance dos objetivos de projeto previamente determinados. A questão "dinheiro" citada acima se refere ao fato da empresa utilizar recursos, como por exemplo, simulações virtuais durante a fase de desenvolvimento de produto, o que é sensivelmente mais econômico do que a construção de um protótipo físico. Esta economia também pode vir por meio de processos otimizados de fabricação e também através da redução do custo de garantia do produto durante o seu ciclo de vida.

\subsection{Conceitos da Produção}

\subsubsection{Sistemas}

Um sistema pode ser conceitualmente definido como um conjunto de partes inter-relacionadas que existem para atingir um determinado objetivo. As inter-relações entre as partes integrantes do sistema são os canais de comunicações ou as interdependências.

Um sistema pode ser decomposto em uma coleção de subsistemas, um conjunto de elementos organizados para a realização de um propósito específico e descrito por um conjunto de modelos, provavelmente sob diferentes pontos de vista.

Uma empresa, por exemplo, pode ser considerado um sistema composto de vários departamentos (subsistemas) e fazendo parte de um sistema maior, que é a própria sociedade.

Um sistema é geralmente composto dos seguintes componentes (TUBINO, 1997):

- Fronteira - representa o limite do sistema;

- Subsistema - agrupamento de elementos que compõem o sistema; 
- Entrada (input) - representa os insumos ou variáveis independentes do sistema;

- Saídas (outputs) - representa os produtos ou variáveis dependentes do sistema;

- Processamento - engloba as atividades desenvolvidas pelos subsistemas que interagem entre si para converter as entradas em saídas;

- Realimentação - é a influência que as saídas do sistema exercem sobre as suas entradas no sentido de ajustá-las ou regulá-las ao funcionamento do sistema.

\subsubsection{Sistemas de Produção}

Produção é o processo de transformação pelo qual insumos (material, energia, trabalho, equipamentos etc) são transformados em produtos ou serviços. Naturalmente, os produtos ou serviços resultantes têm um valor econômico maior que o dos elementos utilizados como entrada. A produção segundo a sua natureza, pode ser classificada em três tipos: Produção primária (ou extrativa), secundária (ou de transformação) e terciária (ou prestadora de serviço) (TUBINO, 1997).

Um Sistema de Produção é um conjunto de atividades e operações inter-relacionadas envolvidas na produção de bens (caso da indústria) ou serviços. Ele é composto por dois subsistemas principais (GIRAULT;VALK,2003):

- O subsistema físico - composto dos recursos físicos tais como correias transportadoras, robôs, buffers, estações de trabalho etc.

- O subsistema de controle - Determina como utilizar o subsistema físico para organizar e otimizar o processo produtivo. 
Em um sistema de produção, alguns elementos fundamentais podem ser identificados. São eles os insumos, o processo de criação ou conversão, os produtos ou serviços, e o subsistema de controle, seguindo o fluxo mostrado na Figura 2.1.

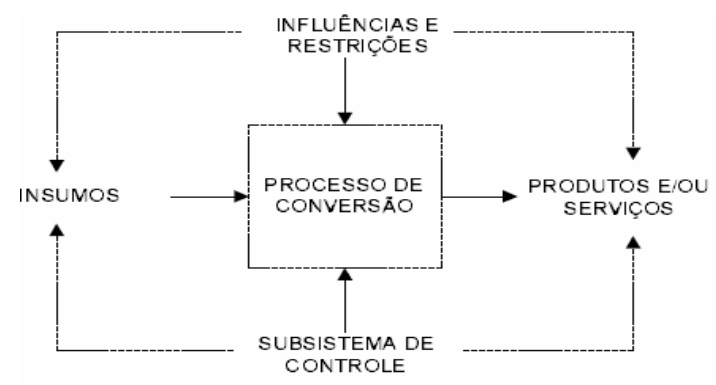

Figura 2.1 - Elementos do Sistema de Produção (GIRAULT; VALK, 2003)

Os insumos são os elementos que entram no processo de produção de mercadorias ou serviços, tais como matéria-prima, mão-de-obra, capital, máquinas, equipamentos, instalações, conhecimento técnico etc.

O processo de conversão, no caso da manufatura, modifica a forma da matéria-prima ou muda a composição dos recursos. Em serviços não há propriamente transformação: o serviço é criado. O processo de transformação geralmente envolve uma seqüência de passos chamados operações de produção. Cada operação de produção é um processo de transformação das entradas em saídas, com uma adição de valor ao produto final. Intercaladas a estas operações que adicionam valor ao produto final existem operações tais como transporte, armazenagem e inspeção que não adicionam valor ao produto e devem, portanto, ser minimizadas ou mesmo eliminadas.

O sistema de controle monitora os demais elementos do sistema de produção. Trata-se de um conjunto de atividades que visam assegurar que o que foi programado seja cumprido, que padrões sejam obedecidos, que a qualidade desejada seja obtida e que os recursos sejam utilizados de forma eficaz. 
Finalmente, é importante citar as influências tanto internas quanto externas as quais o sistema de produção está sujeito, e que afetam o seu desempenho. No caso do ambiente interno, o sistema de produção está sujeito a outras áreas funcionais da empresa tais como marketing, finanças e recursos humanos. Como influências externas podem ser citadas as condições econômicas do país, as políticas e regulamentações governamentais, a competição e a tecnologia.

\subsubsection{Classificação dos Sistemas de Produção}

Existem várias classificações para os sistemas de produção. Na Tabela 2.1 são apresentadas três das classificações mais conhecidas: pelo grau de padronização dos produtos, pelo tipo de operação a que são submetidos os produtos e pela natureza do produto (TUBINO, 1997).

Tabela 2.1 - Classificação dos Sistemas de Produção (SILVA, 2005)

\begin{tabular}{|c|c|c|}
\hline Critério & Classificação & Características \\
\hline \multirow{5}{*}{$\begin{array}{l}\text { Pelo grau de } \\
\text { padronização } \\
\text { dos produtos }\end{array}$} & \multirow{3}{*}{$\begin{array}{l}\text { Sistemas que produzem } \\
\text { produtos padronizados }\end{array}$} & " Alto grau de uniformidade \\
\hline & & Produção em grande escala \\
\hline & & $\begin{array}{l}\text { Produtos facilmente encon- } \\
\text { trados no mercado }\end{array}$ \\
\hline & \multirow{2}{*}{$\begin{array}{l}\text { Sistemas que produzem } \\
\text { produtos sob medida }\end{array}$} & Cliente define o produto \\
\hline & & Lotes normalmente unitários \\
\hline \multirow[t]{2}{*}{$\begin{array}{l}\text { Pelo tipo das } \\
\text { operações }\end{array}$} & Processos contínuos & $\begin{array}{l}\text { Produtos não podem ser in- } \\
\text { dividualmente identificados }\end{array}$ \\
\hline & Processos discretos & $\begin{array}{l}\text { Os produtos podem ser iden- } \\
\text { tificados individualmente }\end{array}$ \\
\hline \multirow[t]{2}{*}{$\begin{array}{l}\text { Pela natureza } \\
\text { do produto }\end{array}$} & Manufatura de bens & $\begin{array}{l}\text { Produtos que são tangíveis } \\
\text { (e.x. rádio, carro) }\end{array}$ \\
\hline & Prestador de serviços & $\begin{array}{l}\text { Produtos que são intangíveis } \\
\text { (e.x. consulta médica) }\end{array}$ \\
\hline
\end{tabular}

Produtos padronizados são bens ou serviços com alto grau de uniformidade e produção em grande escala, com o objetivo de tornarem-se amplamente disponíveis para os clientes. Dentro deste grupo estão incluídas as fabricações de bens como automóveis, 
eletrodomésticos, roupas etc ou prestação de serviços, como planos de saúde, serviços bancários, entre outras.

Produtos sob medidas visam atender um cliente em particular. Por depender dos clientes para a definição dos produtos, estes normalmente não são produzidos para estoque e os lotes são normalmente unitários. Em decorrência da baixa quantidade produzida, a automação dos processos é menos aplicável, por não justificar os investimentos. Sistemas que se enquadram nesta categoria normalmente possuem grande capacidade ociosa e dificuldade de padronizar os métodos de trabalho e recursos produtivos, gerando produtos mais caros que os padronizados. Como exemplo de produção sob medida pode-se citar a construção civil, estaleiros etc, e a prestação de serviços tais como táxis, restaurantes, clínica médicas entre outros. Os processos contínuos são empregados quando existe alta uniformidade na produção de bens e prestação de serviços e os produtos e processos produtivos são totalmente independentes, favorecendo a automação. Não há flexibilidade no sistema.

Segundo Silva (2005), os processos discretos de produção podem ser divididos em:

- Processos Repetitivos em Massa - produção em grande escala de produtos altamente padronizados;

- Processos Repetitivos em Lote - volume médio de produção, onde cada lote segue uma série de operações que necessitam ser programada à medida que as operações anteriores forem realizadas; e

- Processos por Projeto - têm como objetivo atender uma necessidade específica do cliente, com todas as suas atividades voltadas para esta meta. O produto tem uma data específica para ser concluído e uma vez concluído o sistema produtivo se volta para um novo projeto. Exemplos de processos por projeto estão na fabricação de 
bens como navios, aviões, hidroelétricas etc, e na prestação de serviços como escritórios de advocacia, agências de propagandas etc.

Um sistema de produção pode ainda ser classificado em relação à natureza do produto. Quando o produto fabricado é algo tangível, tem-se uma manufatura de bens; quando o produto é intangível, tem-se uma prestação de serviços. Embora ambos os conceitos sejam similares no sentido de transformar insumos em produtos com valor agregado, uma diferença básica reside no fato da manufatura de bens ser orientada ao produto enquanto a prestação de serviços é orientada à ação.

\subsubsection{Planejamento Estratégico da Produção}

O principal objetivo da estratégia de produção é fazer com que uma empresa consiga atingir uma vantagem competitiva de longo prazo. Esta vantagem competitiva é conseguida através do adequado gerenciamento dos recursos de produção.

Segundo Silva, W. (2005), há cinco prioridades competitivas principais baseadas nas quais a produção pode contribuir para a competitividade da empresa.

- Fazer os produtos gastando menos que os concorrentes, obtendo vantagens em custos.

- Fazer produtos melhores que os concorrentes, obtendo vantagem em qualidade.

- Fazer os produtos mais rápido que os concorrentes, obtendo vantagens em velocidade de entrega.

- Fazer os produtos no prazo prometido, obtendo vantagens em confiabilidade de entrega.

- Ser capaz de mudar muito e rápido o que se está fazendo, obtendo vantagens em flexibilidade. 
A importância relativa de cada um dos objetivos citados varia conforme o mercado particular em que a empresa está competindo.

\subsection{Apresentação da Metodologia Seis Sigma}

O Seis Sigma nasceu no departamento de garantia da qualidade da Motorola, fruto da aplicação dos conceitos de Deming sobre variação de processos, cujo objetivo era atacar as causas destas variações como forma de melhorá-los. Tais variações eram medidas por meio seu desvio padrão (medida estatística representada pela letra sigma) e a meta de melhoria adotada por essa empresa foi de Seis Sigma, que representa uma variação das características de resposta do processo analisado, de seis desvios padrões em torno de seu valor central, e que também foi adotada como nome desta abordagem de melhoria. Embora esta fosse uma abordagem que originalmente destinava-se à parte operacional, o presidente da Motorola, Bob Galvin, atento ao potencial dessa abordagem, logo a adaptou a todas as atividades de negócio, elegendo esta como a maneira de fazer negócio de sua empresa (ECKES, 2001).

Parte da popularidade do programa é devido ao seu foco na redução de custos e na melhoria da lucratividade. Essa melhoria é obtida através do rastreamento e eliminação das causas raiz dos defeitos, assim como na melhoria da eficiência em todas as operações, desde o chão-de-fábrica até os níveis gerenciais. A eliminação de falhas em processo e produtos no Seis Sigma envolve a medição e melhoria da capacidade do processo na produção de itens conformes.

Os métodos de Taguchi produziram fruto no programa Seis Sigma. Os programas de qualidade anteriores focavam na conformidade às especificações do produto mesmo que isso implicasse em retrabalho, refugo, teste e inspeção final. Tais programas, geralmente, 
consideravam o fato de um produto ou serviço ser constituídos de um único elemento (HARRY; SCHROEDER, 2000). Na visão do Seis Sigma, conforme proposto por Taguchi, na redução da variabilidade do processo um produto ou serviço é composto por vários elementos que individualmente podem atender às especificações, mas que, uma vez utilizados em conjunto, podem não atender às especificações devido ao somatório das variações dos processos e produtos. Aparentemente, pequenas variações nas condições ambientais, operador, matéria prima, maquinário, podem causar problemas de qualidade significativos.

Freqüentemente, indicadores de desempenho real de empresas e processos são descritos em termos de médias. Exemplos são os custos médios, tempo de ciclo médio e tempo médio de entrega de um item ou processo. O desempenho do processo escrito em termo de valores médios pode esconder problemas, por não considerar a variação inerente do processo.

Os conceitos fundamentais do Seis Sigma consideram o fato de que a variação dos produtos e processos deve ser conhecida por ser um fator que afeta tempos de fabricação, custos de produto e processo, qualidade do produto, e finalmente, a satisfação do cliente. A etapa crucial do Seis Sigma consiste na definição e medição da variação dos processos, com o objetivo de descobrir suas causas, desenvolvendo meios operacionais eficientes para controlar e reduzir essa variação.

A estratégia de aplicação do programa Seis Sigma envolve o uso de técnicas estatísticas dentro de uma metodologia estruturada, a fim de adquirir o conhecimento necessário para a obtenção de produtos ou serviços mais baratos, melhores e mais rápidos do que a concorrência.

Seguem algumas definições do Seis Sigma segundo Eckes (2001):

- Seis Sigma - o "Benchmark" 
O Seis Sigma é usado como um parâmetro para comparar o nível de qualidade de processos, operações, produtos, características, equipamentos, máquinas, divisões e departamentos, entre outros.

- Seis Sigma - a Meta

O Seis Sigma também é uma meta de qualidade. A meta do Seis Sigma é chegar muito próximo de zero defeitos, erros ou falhas, tendo o objetivo de 3,4 defeitos por milhão de oportunidades.

\section{Seis Sigma - a Medida}

O Seis Sigma é uma medida para determinado nível de qualidade. Quando o número de sigmas é baixo, tal como em processos 1 sigma, implicando mais ou menos 1 sigma $( \pm 1 \sigma)$ dentro das especificações, o nível de qualidade é muito baixo, visto que, neste processo, apenas $68,27 \%$ dos produtos ou serviços estão dentro do especificado e teremos cerca de 317.300 defeitos por milhão de oportunidades, enquanto que em processos seis sigma, temos $99,9997 \%$ dos produtos ou serviços dentro do especificado e teremos cerca de 3,4 defeitos por milhão de oportunidades (em processos descentralizados em 1,5 $\sigma$ ).

\section{Seis Sigma - a Filosofia}

O Seis Sigma é uma filosofia de melhoria contínua do processo (máquina, mão-de-obra, método, metrologia, matérias, meio ambiente) e redução de sua variabilidade na busca interminável do zero defeito.

- Seis Sigma - a Estratégia

O Seis Sigma é uma estratégia baseada na inter-relação que existe entre o projeto de um produto, sua fabricação, sua qualidade final e sua confiabilidade, ciclo de controle, 
inventários, reparos no produto, sucata, defeitos, assim como falhas em tudo o que é feito no processo de entrega de um produto a um cliente e o grau de influência que eles possam ter sobre a satisfação do mesmo.

- Seis Sigma - o Valor

O Seis Sigma é um valor composto, derivado da multiplicação de 12 vezes um dado valor sigma, assumindo 6 vezes o valor do sigma dentro dos limites de controle para a esquerda da média e 6 vezes o valor do sigma dentro dos limites de controle para a direita da média em uma distribuição normal.

Seis Sigma - a Visão

O Seis Sigma tem a visão de levar uma organização a ser a melhor do ramo. É uma viagem intrépida em busca da redução da variação, defeitos, erros e falhas. É estender a qualidade para além das expectativas do cliente.

Os resultados esperados a partir da adoção do programa Seis Sigma são:

a) desenvolvimento de produtos mais robustos de forma mais rápida;

b) obtenção de processos de manufatura mais eficientes e capazes;

c) obtenção de um resultado financeiro global mais confiável.

Segundo Pande et al. (2001), os benefícios do Seis Sigma são: a) visão de processo e controle, relacionando as variáveis do mesmo com o resultado, sejam objetivos estratégicos, como lucro ou requisitos do cliente; conhecimento de quais variáveis no processo têm maior influência, monitoramento das mesmas e tomada de ação para correção e melhoria dos resultados do processo; b) determinar uma meta de desempenho comum aos diferentes processos, comparando-os com a capacidade Seis Sigma, ou seja, 99,9997\% produtos 
conformes; c) acelerar a taxa de melhoria; d) promover a aprendizagem; e) executar mudanças estratégicas.

Para a obtenção dos resultados Seis Sigma, a implantação com sucesso do programa envolve: a) desenvolvimento do pensamento crítico e da integração do conhecimento e experiência atuais com as ferramentas do Seis Sigma; b) educação do gerenciamento na filosofia, métodos, aplicações e seus papéis; c) suporte para as metas estabelecidas como meios, oportunidades, e mecanismos para atendê-las; c) integração de todas as iniciativas concorrentes e comunicação através da organização sobre como cada iniciativa se alinha com os planos e objetivos estratégicos; e) tradução dos objetivos internos e relacionamento com as necessidades dos clientes externos; f) alinhamento das metas do projeto com as metas do departamento e então com as metas da organização; g) valorização e recompensa no atendimento de conhecimento sobre o processo/produto além do atendimento de economia em um projeto.

As propostas metodológicas para a implantação do programa Seis Sigma focam em projetos de melhoria contínua baseado em técnicas estatísticas voltado para o atendimento do nível de qualidade Seis Sigma. O ciclo de melhoria amplamente utilizado no Seis Sigma, denominado de Definir-Medir-Analisar-Melhorar-Controlar (DMAIC), é baseado no ciclo PDCA que é um método gerencial de tomada de decisão que pretende, como um dos seus principais objetivos, garantir o alcance das metas necessárias à sobrevivência e crescimentos das organizações. O método PDCA., contém quatro etapas bem definidas, conforme mostra a

\section{Figura 2.2.}




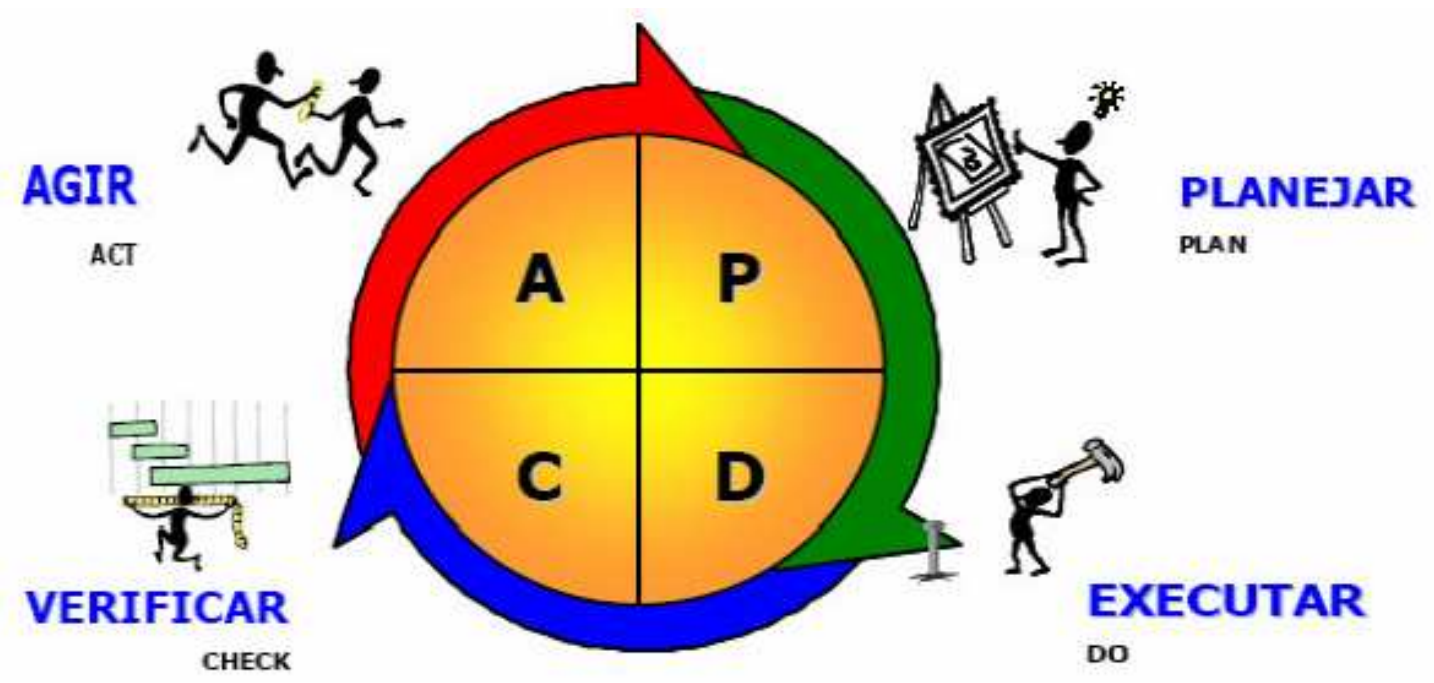

Figura 2.2 - Ciclo PDCA.

\subsubsection{Terminologia Sigma e Escala Sigma}

O conceito sigma $(\sigma)$ foi criado em 1980 como forma de desenvolver uma métrica universal de qualidade para mensurar o desempenho de processos independentemente de sua complexidade (HARRY; SCHROEDER, 2000). O índice $6 \sigma$ mede a capacidade do processo em atender às especificações de projeto, analogamente aos tradicionais $\mathrm{Cp}$ e Cpk utilizados no Controle Estatístico do Processo (CEP).

Um processo é definido como sendo Seis Sigma quando estiver com a média da população centrada no valor nominal da especificação, e os limites de especificação estiverem distantes seis desvios padrões da média da população.

No Seis Sigma tem-se 99,9999998\% de produtos perfeitos, isto é, dois defeitos por bilhão de unidades produzidas num processo centrado cuja curva normal é mostrada na Figura 2.3. 


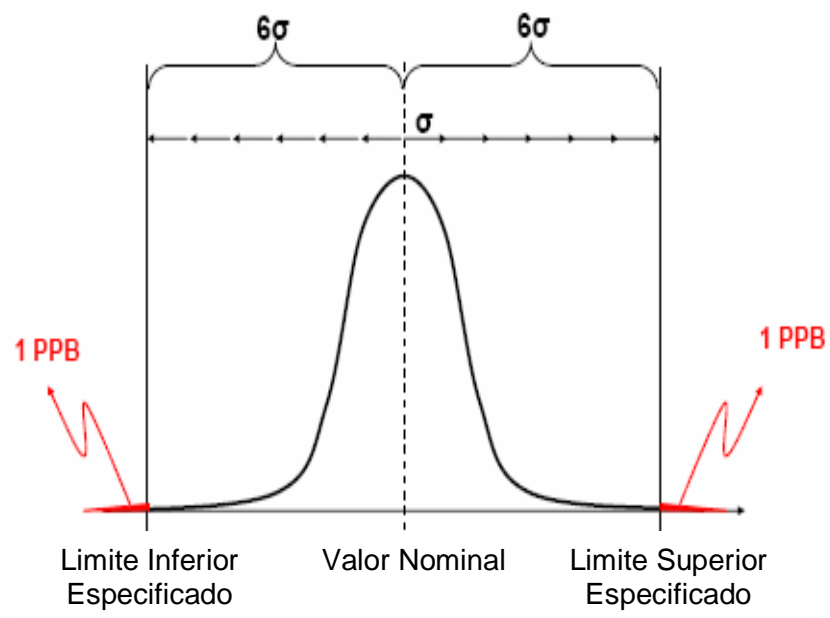

Figura 2.3 - Curva Normal em um processo Seis Sigma centrado

A escala sigma é uma medida que quantifica a variação existente entre os resultados de qualquer processo ou procedimento, sendo utilizada para medir o nível de qualidade associado a um processo, transformando a quantidade de defeitos por milhão em um número na escala sigma. Quanto maior o valor alcançado na escala sigma, maior o nível de qualidade (WERKEMA, 2000). A relação entre a escala sigma e o número de defeitos gerados no processo vem explicitado na Tabela 2.2. Atentar para o fato desses valores serem para um processo centrado, ou seja, com sua média na nominal. Ainda nesta tabela, verifica-se que, quanto mais alto o valor na escala sigma, menor a probabilidade de um processo produzir defeitos. Cada ponto na escala sigma produz uma redução exponencial de defeitos. Como resultado, a necessidade de testes e inspeções diminui, os custos baixam, os tempos de ciclo diminuem e a satisfação dos clientes aumenta (HARRY; SCHROEDER, 2000). 
Tabela 2.2 - Escala sigma e número de defeitos correspondentes, considerando resultados de um processo centrado no valor nominal (WERKEMA, 2000)

\begin{tabular}{c|c}
\hline Escala Sigma & Defeitos (ppm) \\
\hline 1 & 317,400 \\
\hline 2 & 45,600 \\
\hline 3 & 2,700 \\
\hline 4 & 63 \\
\hline 5 & 0,57 \\
\hline 6 & 0,002 \\
\hline 7 & 0,000003 \\
\hline
\end{tabular}

Evidente que na prática é impossível que todos os processos estejam exatamente no centro da tolerância e estudos realizados pela Motorola mostram que esse deslocamento do centro, normalmente, não ultrapassa $1,5 \sigma$ seja para o lado inferior ou superior da especificação. Este mesmo resultado tem sido verificado e, portanto, utilizado pela maioria das empresas que adotam o Seis Sigma. Mas, mesmo se o valor médio dos resultados do processo se afastar do valor ideal em 1,5 sigma, não se espera obter mais do que 3,4 produtos defeituosos por milhão de unidades (ppm) fabricadas, conforme é mostrada na Figura 2.4.

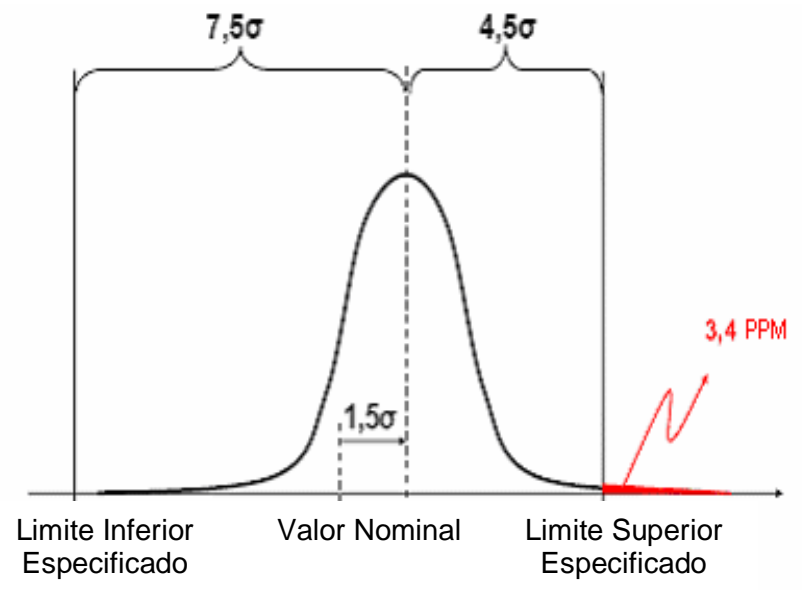

Figura 2.4 - Curva Normal em um processo cuja média está desviada 1,5 sigma da nominal. 
A Tabela 2.3 mostra em exemplos práticos a diferença de desempenho entre um processo $6 \sigma$ já com o desvio de $1,5 \sigma$ e um processo $4 \sigma$.

Tabela 2.3 - Exemplo comparativo entre um processo Quatro Sigma e um processo Seis Sigma (WERKEMA, 2000)

\begin{tabular}{l|l|l}
\hline Quatro Sigma (99,38\%conforme) & Seis Sigma (99,99966\%conforme) \\
\hline $\begin{array}{l}\text { Sete horas de falta de energia elétrica por } \\
\text { mês }\end{array}$ & $\begin{array}{l}\text { Uma hora de falta de energia elétrica } \\
\text { a cada } 34 \text { anos }\end{array}$ \\
\hline $\begin{array}{l}\text { 5.000 operaçð̃es cirúrgicas incorretas por } \\
\text { semana }\end{array}$ & $\begin{array}{l}1,7 \text { operação cirúrgica incorreta por } \\
\text { semana }\end{array}$ \\
\hline $\begin{array}{l}\text { 3.000 cartas extraviadas para cada } \\
\text { Quinze minutos de fornecimento de água } \\
\text { não potável por dia }\end{array}$ & $\begin{array}{l}1 \text { carta extraviada para cada 3000,000 } \\
\text { cartas postadas }\end{array}$ \\
\hline $\begin{array}{l}\text { Uma aterrisagem de emergência no } \\
\text { aeroporto de Guarulhos por dia }\end{array}$ & $\begin{array}{l}\text { Um minuto de fomecimento de água } \\
\text { não potável a cada sete meses }\end{array}$ \\
\hline $\begin{array}{l}\text { Um canal de TV } 1,68 \text { horas fora do ar } \\
\text { por semana }\end{array}$ & $\begin{array}{l}\text { Uma aterrisagem de emergência em } \\
\text { todos os aeroportos do Brasil a cada } \\
\text { cinco anos }\end{array}$ \\
\hline
\end{tabular}

\subsubsection{O Programa Seis Sigma}

Um programa Seis Sigma visa de maneira estruturada incrementar a qualidade por meio da melhoria contínua dos processos envolvidos na produção de um bem ou serviço, considerando todos os aspectos importantes de um negócio. O objetivo do Seis Sigma é conseguir a excelência na competitividade pelo aprimoramento contínuo dos processos (ROTONDARO, 2002).

Segundo Harry e Shroeder (1998), Seis Sigma é um processo de negócio que permite às empresas ampliar seus lucros com a otimização das operações, o aumento da qualidade e a eliminação de defeitos, de falhas e de erros, pois está relacionado à melhoria da lucratividade. As empresas que implementam o programa o fazem com a meta de melhorar seus lucros. 
A integração e a participação de todos os níveis e funções da organização é o fatorchave para o sucesso da implantação do programa Seis Sigma. Esse envolvimento completo, no entanto, não é suficiente. Outros fatores de extrema importância são um sólido compromisso da alta administração e uma atitude pró-ativa, organizada e sistemática em busca da satisfação das necessidades e dos objetivos dos clientes e da própria organização.

Em resumo, pode-se dizer que o diferencial do Seis Sigma é que ele promove uma mudança na cultura da empresa. Após sua implantação, a organização modifica seu posicionamento em relação aos problemas e à forma de identificá-los e resolvê-los. Segundo Aguiar (2002), as principais mudanças obtidas com a implantação do Seis Sigma são:

- A atuação da empresa volta-se principalmente para o atendimento às necessidades dos clientes;

- Todo projeto ou meta a ser desenvolvido deve enfatizar os resultados financeiros, possibilitando aos funcionários participar mais do processo, pois estes conseguem visualizar onde seus esforços surtem efeitos de fato.

- Todos os funcionários devem buscar o aperfeiçoamento na condução de seu trabalho, além de procurar eliminar operações que não agregam valor ao produto final;

- Os problemas da empresa são considerados problemas de todos os seus funcionários;

- A forma de condução da solução de um problema é padronizada em todos os setores da empresa. 


\subsubsection{Fatores Determinantes do Programa}

Os elementos-chave que suportam o programa Seis Sigma e asseguram uma adequada aplicação de suas ferramentas e o êxito dessa iniciativa como estratégia de negócios são:

$\checkmark$ Identificação dos elementos críticos para a qualidade (CTQ), relacionados com os clientes externos e internos, pois um elemento do produto ou processo é considerado crítico quando seu impacto sobre os requisitos do cliente, o desempenho, a qualidade e a confiabilidade são relevantes;

$\checkmark$ A seleção correta do projeto de melhoria pode ser extremamente significante no negócio, uma vez que seu processo pode tornar-se mais eficiente num horizonte de tempo de três a seis meses. Conseqüentemente, seus funcionários ficarão satisfeitos e poderão apreciar seus esforços para melhoria do processo e os acionistas ficarão satisfeitos por verem resultados financeiros advindos desses esforços.

$\checkmark$ Avaliação dos erros de processos por meio da realização da Análise dos Modos e Efeitos das Falhas (FMEA). Essa análise é usada para entender os tipos potenciais de falhas, o que pode causá-las e como prevenir ou conter as suas consequiências. FMEA é um procedimento utilizado para identificar modos potenciais de falha e os efeitos dela resultantes, de forma a avaliar a causa-raiz e implantar medidas para contê-la ou eliminála;

$\checkmark$ Identificação das variáveis críticas, por meio da utilização de Projetos de Experimentos (DOE). Os Projetos de Experimentos modelam os efeitos principais e as interações das variáveis consideradas. O enfoque estatístico para a experimentação permite uma forma ordenada para coletar, analisar e interpretar dados a fim de satisfazer os objetivos do estudo; 
Realização de "benchmarking" permanente e estabelecimento sem ambigüidades dos objetivos a serem alcançados.

Além dos elementos-chave mencionados, existem também alguns fatores que são determinantes para a implementação e sustentação do programa. Pande et al. (2001) enumeram seis pontos-chave para se obter êxito no Seis Sigma:

Foco genuíno sobre o cliente, que consiste na superação dos modismos e promessas sem nenhuma fundamentação estratégica de satisfazer as necessidades dos clientes e assegurar, por meio das medidas de desempenho do programa Seis Sigma, a satisfação e os valores da clientela;

$\checkmark$ Gerenciamento dirigido por dados e fatos, que supõe a aplicação de uma rígida disciplina, destacando a importância das medidas como suporte para avaliar o desempenho dos negócios e a aplicação de dados e análises para construir e compreender as variáveischaves que otimizam os resultados;

Foco em processo, gestão e melhoria, pois o Seis Sigma considera os processos como o centro das ações e o veículo-chave para o sucesso. Portanto, o domínio sobre os processos é a maneira mais segura de garantir a obtenção de vantagens competitivas que oferecem valor para os clientes;

$\checkmark$ Gestão proativa, que é o exercício do gerenciamento dinâmico, que define objetivos, determina prioridades, estabelece a prevenção de problemas e questiona a prática das diferentes atividades da empresa;

Colaboração e compartilhamento, que é a compreensão das necessidades dos usuários das etapas do processo e do fluxo, ou da cadeia de fornecimento desse processo, por todos que desenvolvem atividades na empresa; 
Busca da perfeição e tolerância ao fracasso, que é o equilíbrio entre a implementação de novas idéias e métodos e o gerenciamento dos riscos até serem atingidos os objetivos do programa Seis Sigma. A aplicação dos pontos-chave do Seis Sigma permite uma mudança de enfoque das empresas em todos os elementos de desempenho, principalmente nas áreas de projeto de produto e de operações comerciais.

\subsubsection{Benefícios do Programa}

O principal benefício do programa Seis Sigma é minimizar custos, por meio da redução ou da eliminação de atividades que não agregam valor ao processo e da maximização da qualidade, para obter lucro em níveis ótimos. Em segundo lugar, implementar o Seis Sigma em uma organização cria uma cultura interna de indivíduos educados em um programa padronizado de caracterização, otimização e controle de processos, definindo-se processo como a atividade repetitiva envolvida no fornecimento de um serviço ou na confecção de um produto.

A otimização de processos faz com que eles sejam simplificados, reduzindo o número de passos e tornando-os mais rápidos e eficientes. Ao mesmo tempo, esses processos são otimizados para que não gerem defeitos nem apresentem oportunidades de erros. A eliminação de defeitos gera duas conseqüências. Primeiro, diminui custos, porque defeitos tornam os produtos e serviços mais caros; em segundo lugar, defeitos, erros e falhas desapontam os clientes, e clientela insatisfeita devolve os produtos ou não compra mais serviços.

Quanto maior o número de clientes insatisfeitos com produtos e serviços, maior a tendência de se perder espaço no mercado. Ao se perder parte do mercado, perde-se também parte da receita bruta. Se a receita bruta diminui, a organização não consegue contratar ou 
manter seus funcionários. Sem funcionários e receita, a empresa não se mantém mais no mercado (PEREZ-WILSON, 2000).

De um ponto de vista prático, é possível analisar os benefícios do Seis Sigma enumerando as histórias de sucesso do programa, que está levando diversas empresas, tanto as proeminentes quanto as modestas, a adotá-lo (PANDE et al., 2001).

O Seis Sigma pode ser aplicado a todos os processos e atividades econômicas. Nos processos administrativos, em especial na área de prestação de serviços e transações comerciais, existem determinadas etapas que são intangíveis. Portanto, entendê-los melhor e determinar suas características, promover a otimização, o controle e a eliminação de falhas e erros são benefícios possíveis com a implementação de um programa Seis Sigma. Por exemplo, gerar um orçamento é um processo administrativo, vender um produto por telefone é um processo de serviço, assim como fazer um financiamento imobiliário é um processo de transação comercial.

Determinados processos administrativos podem ter um número excessivo de etapas, causando, eventualmente, variações em seu resultado final. Daí a vantagem de aplicar o Seis Sigma visando diminuir ou eliminar a variação dos processos (ROTONDARO., 2002).

Contudo, para alcançar e manter os benefícios do programa Seis Sigma em processos administrativos, a metodologia DMAIC deve estar estruturada de modo a assegurar a manutenção das conquistas obtidas, pois ela permite alcançar melhorias de desempenho elevadas (AGUIAR, 2002).

Vejamos a seguir os custos associados à pobreza da qualidade dentro de uma empresa, custos estes cuja redução é o principal objetivo do Seis Sigma. 


\subsubsection{Custo da Pobre Qualidade}

Segundo Basu e Wright (2003), o Custo da Pobre Qualidade (COPQ) é derivado de atividades que não agregam valor ao processo ampliando os custos associados com:

a) Falhas Internas

b) Falhas Externas

c) Avaliação

d) Prevenção

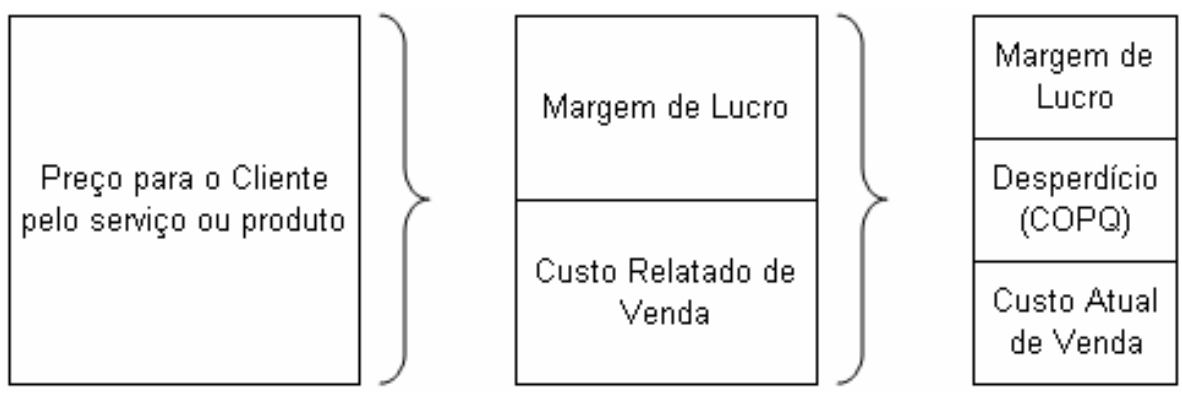

Figura 2.5 - $O$ custo da pobre qualidade (BASU; WRIGHT, 2003).

A Figura 2.5 ilustra como se forma o preço para o Cliente e ratifica a importância do controle do desperdício ou custo da pobre qualidade (COPQ) para a maximização da margem de lucro pelas empresas. Eckes (2001) demonstra uma divisão similar de COPQ, conforme a Figura 2.6: 


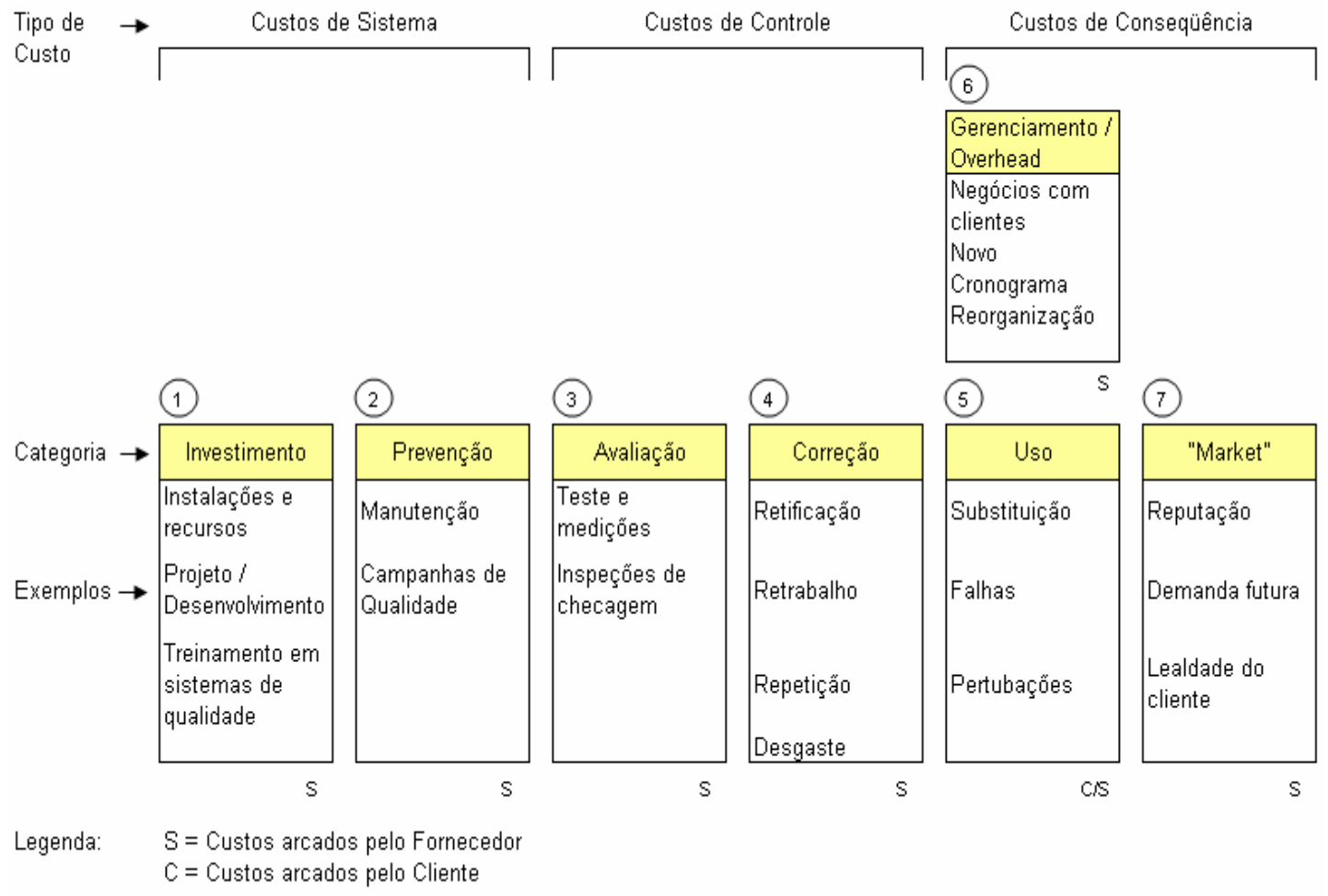

Figura 2.6 - Custos relacionados à qualidade. Adaptado de Basu; Wright, 2003.

Custos de Falha Interna ocorre antes do produto ou serviço ser entregue, e inclui:

- Ação corretiva no projeto;

- Custos com falhas de compras;

- Retrabalhos da produção;

- Perdas de material;

- Perdas de energia;

- Máquinas paradas;

- Custos com mão-de-obra e horas extras;

- Custos de inspeção e supervisão;

- Custos de gerenciamento de overheads. 
Custos de Falhas Externas são aqueles que ocorrem após a entrega e tempo de garantia do produto e incluem:

- Custos de "recalls";

- Investigação de reclamações dos clientes;

- Perda da confiança e lealdade do cliente;

- Efeitos na reputação/demanda futura/percepção do mercado;

- Substituição/retorno de mercadorias;

Custos de Avaliação são associados com medição, avaliação, testes e auditorias nos produtos e serviços para garantir conformidade junto aos padrões de qualidade desejáveis e requisitos de desempenho. Estes custos incluem:

- Custos de avaliação da compra;

- Recebimento e inspeção de mercadorias;

- Custos de avaliação da manufatura;

- Recursos de inspeção (supervisores, inspetores, auditores);

- Suporte do laboratório;

- Custos de avaliação externa e custos de auditorias externas.

Custos de Prevenção incluem todos os custos associados a atividades projetadas para garantir que produtos e serviços correspondam aos requisitos dos clientes. Isto inclui eliminar provisões extras indesejadas e garantir que o provisionado seja o que o cliente realmente necessita. Estes custos incluem:

- Pesquisas de mercado

- Pesquisas de percepção do cliente

- Revisões do fornecedor 
- Validação do processo

- Testes de campo

- Educação na qualidade

- Controle estatístico do processo pelo operador

- Checagem contínua dos trabalhadores e processos deixando claro que não existem desvios de especificação para mercadorias e serviços.

Os custos da pobre qualidade (COPQ) devem ser reportados tanto em dinheiro quanto em índices e taxas. Cada custo pode ser reportado separadamente. O somatório dos custos com Falhas Internas, Falhas Externas, Avaliação e Prevenção são expressos como Custo Total de Qualidade em dinheiro (\$).

\section{Taxa de COPQ = Custo Total de Qualidade \$ / Custos Mensais de Vendas \$}

A Tabela 2.4 mostra os custos da pobre qualidade em relação ao nível de qualidade de uma empresa. Notar que em níveis Seis Sigma o custo é menor que um porcento.

Tabela 2.4 - Tradução do nível da qualidade para a linguagem financeira. Fonte: WERKEMA (2000)

\begin{tabular}{|c|c|c|c|}
\hline $\begin{array}{c}\text { Nível de } \\
\text { Qualidade }\end{array}$ & $\begin{array}{c}\text { Defeitos por } \\
\text { Milhão (ppm) }\end{array}$ & $\begin{array}{c}\text { Fator } \\
\text { Percentual }\end{array}$ & $\begin{array}{c}\text { Custo de } \\
\text { Qualidade }\end{array}$ \\
\hline 2 sigma & 308.537 & 69,15 & Não se aplica \\
\hline 3 sigma & 66.807 & 93,32 & 25 a $40 \%$ \\
\hline 4 sigma & 6.210 & 99,379 & 15 a $25 \%$ \\
\hline 5 sigma & 233 & 99,9767 & 5 a $15 \%$ \\
\hline 6 sigma & 3 & 99,99966 & $<1 \%$ \\
\hline
\end{tabular}




\subsubsection{Medidas Estatísticas do Seis Sigma}

As medidas e os coeficientes são extremamente importantes, pois permitem o acompanhamento da organização, produtos e serviços, tanto internamente quanto em relação aos concorrentes. Porém o Seis Sigma não se trata de medidas, trata-se de melhorias (PEREZWILSON, 1999). As medidas são necessárias, mas são um meio e não um fim.

\subsubsection{Coeficientes de Capacidade do Processo}

Capacidade se define pela habilidade que um processo possui de confeccionar produtos que estejam dentro dos limites de especificação. O Cpk é o coeficiente de capacidade do processo. O Cp é o coeficiente de potencial do processo. Ambos são utilizados em processos técnicos e raramente em processos administrativos, de serviços ou de transações.

\section{- Coeficiente de Potencial do Processo (Cp)}

Mede a capacidade real do processo que é definida pela razão entre a dispersão permitida e a dispersão real. A dispersão permitida é a diferença entre o limite de controle superior e inferior. A dispersão real é determinada pelos dados coletados do processo e é calculada multiplicando-se o desvio padrão $\mathrm{S}$, por 6 . O desvio padrão quantifica a variabilidade de um processo. À medida que o desvio padrão aumenta de valor em um processo, o Cp diminui de valor e vice-versa.

Por convenção, quando um processo possui um valor de Cp menor do que 1, ele é considerado potencialmente incapacitado para satisfazer as exigências das especificações.

Idealmente, o $\mathrm{Cp}$ deve ser o maior possível, visto que tanto quanto maior for este valor, menor a variabilidade com respeito aos limites de especificação. Num processo 
qualificado como Seis Sigma (isto é, um que permite mais ou menos seis desvios padrão dentro dos limites de especificação), o Cp é maior ou igual a 2,0.

$$
\mathrm{Cp}=\frac{L S E-L I E}{6 S}
$$$$
\mathrm{S}=\sqrt{\frac{\sum_{i=1}^{n}\left(\mathrm{X}_{i}-\overline{\mathrm{X}}\right)^{2}}{n-1}}
$$

Onde:

$$
\begin{aligned}
& L S E=\text { Limite Superior de Especificação } \\
& L I E=\text { Limite Inferior de Especificação } \\
& S=\text { Desvio Padrão }
\end{aligned}
$$

$$
\begin{aligned}
& \mathrm{X}_{i}=\text { Valor de cada Amostra } \\
& \overline{\mathrm{X}}=\text { Valor Médio das Amostras } \\
& n=\text { Quantidade Total de Amostras }
\end{aligned}
$$

Porém, um alto valor de Cp não garante que um processo de produção caia dentro dos limites de especificação, porque o valor de Cp não implica que a dispersão real coincida com a permitida (isto é, os limites de especificação). Por este motivo, o Cp é chamado de potencial do processo (PEREZ-WILSON, 1999).

\section{- Coeficiente de Capacidade do Processo (Cpk)}

O coeficiente de capacidade do processo, ou Cpk mede a habilidade do processo criar um produto dentro dos limites de especificação. O Cpk representa a diferença entre a média aritmética real do processo e o limite de especificação mais próximo, dividido por três vezes o desvio padrão.

$$
\mathrm{Cpk}=\left\{\text { menor de } \frac{\overline{\mathrm{X}}-L S E}{3 S} \text { ou } \frac{L I E-\overline{\mathrm{X}}}{3 S}\right\}
$$

Por convenção, quando o Cpk é menor do que 1, diz-se que o processo é incapacitado. Quando o Cpk é maior do que 1, o processo é considerado capacitado para atender às especificações. Num processo Seis Sigma, o Cpk é igual a 2,0. 
O Cpk é inversamente proporcional ao desvio padrão, ou à variabilidade de um processo. Quanto maior for o $\mathrm{Cpk}$, mais estreita será a distribuição do processo em comparação aos limites de especificação, e mais uniforme será o produto. À medida que o desvio padrão aumenta de valor, o coeficiente Cpk diminui. Ao mesmo tempo, o potencial de criar um produto fora dos limites de especificação aumenta.

O Cpk somente pode assumir valores positivos. Ele será igual a zero quando a média real do processo coincidir com os limites de especificação ou quando estiver fora destes. O coeficiente $\mathrm{Cpk}$ nunca pode ser maior do que o $\mathrm{Cp}$, somente igual a ele. Isto ocorre quando a média real do processo cai no centro dos limites de especificação (PEREZ-WILSON, 1999).

\subsubsection{Partes por Milhão (PPM)}

A medida partes por milhão refere-se a produtos ou peças defeituosas, assim como defeitos, erros e falhas.

O PPM estima o número de unidades, partes de peças ou produtos que serão defeituosos, se um milhão de produtos forem produzidos, oferecendo maior resolução para quantificar as falhas, defeitos ou erros. A relação entre Cp, Cpk e PPM, encontra-se demonstrada na Tabela 2.5. 
Tabela 2.5 - Relação entre os níveis sigma e o Cp, Cpk e PPM assumindo: normalidade, estabilidade e distribuição centralizada.

\begin{tabular}{|c|c|c|c|}
\hline Nível Sigma $( \pm x \sigma)$ & $\mathbf{C p}$ & $\mathbf{C p k}$ & PPM \\
\hline $\pm 1 \sigma$ & 0,33 & 0,33 & 317.320 \\
\hline $\pm 2 \sigma$ & 0,67 & 0,67 & 45.500 \\
\hline $\pm 3 \sigma$ & 1,0 & 1,0 & 2.700 \\
\hline $\pm 4 \sigma$ & 1,33 & 1,33 & 63,5 \\
\hline $\pm 4.5 \sigma$ & 1,50 & 1,50 & 6,9 \\
\hline $\pm 5 \sigma$ & 1,67 & 1,67 & 0,6 \\
\hline $\pm 6 \sigma$ & 2,0 & 2,0 & 0,002 \\
\hline
\end{tabular}

\subsubsection{Defeitos por Milhão de Oportunidades (DPMO)}

É uma medida para quantificar o número total de defeitos, se um milhão de unidades forem produzidas, dividido pelo número total de oportunidades de defeitos.

Na fórmula de DPMO, o numerador é o nível de desempenho ppm (defeitos por milhão) do processo ou operação, e o denominador é um fator de peso que representa a dificuldade do processo ou operação. Este fator de peso - o número total de oportunidades de defeitos - permite que o DPMO seja utilizado na comparação entre processos ou operações com diferente níveis de complexidade.

$$
\mathrm{DPMO}=\frac{p p m}{N T O D}
$$

Onde: $\mathrm{ppm}=\mathrm{dpu} \times 1.000 .000$

NTOD = Número total de oportunidades de defeitos

$\mathrm{dpu}=$ Defeitos por unidade 


\subsubsection{Suposições Estatísticas}

O Seis Sigma compartilha de certas suposições básicas, a saber:

- Normalidade: A resposta ou a distribuição da característica segue ou pode ser aproximada pela distribuição Normal ou Gaussiana;

- Estabilidade: O padrão que resulta da plotagem dos dados da resposta ou característica contra o tempo está sob controle estatístico;

Estas suposições devem ser testadas antes de qualquer previsão ou inferência, especialmente na aplicação do Seis Sigma a processos técnicos.

\subsubsection{A Distribuição Normal}

A distribuição Normal possui um importante papel no Seis Sigma, que é seu modelo estatístico fundamental. A distribuição normal é a distribuição de probabilidade contínua mais importante no ramo da Estatística. Também é conhecida como Curva de Gauss ou distribuição Gaussiana (PEREZ-WILSON, 1999)

Muitas características de fenômenos físicos e de engenharia podem ser aproximadas pela distribuição Normal. Em muitos outros casos, quando as características não seguem inerentemente a distribuição Normal, mas uma outra distribuição como a Binomial ou de Poisson, ainda pode-se usar a distribuição Normal para estimá-las (PEREZ-WILSON, 1999).

A função de probabilidade normal relaciona os valores das características com sua probabilidades de ocorrência. Saber que a distribuição amostral segue uma distribuição Normal possibilita a previsão da ocorrência de eventos. Isto também possibilita a previsão de a quantos sigma determinada observação se encontra em relação à média. 


\subsection{A Metologia DMAIC}

DMAIC é uma metodologia de qualidade baseada em dados para melhoria de processos. Esta metodologia mais característica do Seis Sigma, universalmente reconhecida, será descrita a seguir, detalhadamente, relacionando-a as ferramentas mais utilizadas em cada uma de suas fases. O conhecimento prévio das técnicas e ferramentas é necessário para se determinar quais destas é a mais apropriada, ressaltando que a aplicação apropriada das ferramentas é crítica para a eficácia do projeto Seis Sigma em curso. Vale dizer que as ferramentas são utilizadas pelo Seis Sigma, mas não foram criadas por este programa, aliás, vieram muito antes deste. O Seis Sigma apenas utiliza estas ferramentas (gráficos, ferramentas estatísticas, FMEA, QFD, Diagrama de Causa e Efeito etc) de uma forma diferenciada e que tem se mostrado eficaz em sua aplicação.

Segundo Rotondaro (2002), a metodologia DMAIC significa seguir determinadas etapas na condução de um estudo no qual deseja-se otimizar processos e produtos (com a conseqüente redução de custos e aumento de produtividade) e que são compostas por:

- D - Define (Definir): Definir com precisão o escopo do projeto Seis Sigma que está sendo aberto, o time de trabalho, o detalhamento do problema e sua interface com o cliente, bem como seu objetivo.

- M - Measure (Medir): Determinar a localização ou foco do problema.

- A - Analyze (Analisar): Determinar as causas de cada problema prioritário.

- I - Improve (Melhorar): Propor, avaliar e implementar soluções para cada problema prioritário.

- C - Control (Controlar): Garantir que o alcance da meta seja mantido a longo prazo. 
Na fase Definir ("Define"), são identificados os projetos que se enquadram no programa Seis Sigma e que serão desenvolvidos na empresa com o objetivo de satisfazer as expectativas dos clientes em termos de qualidade, preço e prazo de entrega. Tem-se nesta fase o início do ciclo de melhoria contínua que deve ser direcionado pelos indicadores chaves da empresa. A habilidade da organização em atender a essa expectativa está intimamente ligada à variação de seus processos, sejam eles processos produtivos, administrativos ou transacionais, como os de serviços e de vendas. A variação de processos tem um impacto direto nos resultados financeiros da empresa, em termos de custo, tempo de ciclo e número de defeitos, de falhas e de erros que afetam a satisfação do cliente. A identificação de projetos aos quais se aplicam o Seis Sigma permite à organização reconhecer como os seus processos afetam a lucratividade e definir quais processos são críticos para o negócio da empresa. Neste ponto, apesar da habilidade do Seis Sigma em correlacionar seus projetos às expectativas do cliente, há uma brecha a ser discutida posteriormente nesta dissertação, pois o sistema de melhoria, neste caso, ainda é um sistema de loop aberto no qual a empresa pode encontrar as exigências do cliente de hoje, mas não estar pronta para as de amanhã.

A fase Medir ("Measure") abrange ações relacionadas à mensuração do desempenho de processos e à quantificação da variabilidade dos mesmos. Por meio de consenso entre os integrantes da equipe que trabalha no programa Seis Sigma da empresa, são identificadas as Variáveis de Entrada de Processos-Chave (KPIVs) e as Variáveis de Saída de ProcessosChave (KPOVs). Nessa fase, são utilizadas ferramentas básicas existentes há tempos, como por exemplo:

- Ferramentas estatísticas: cartas de controle, capacidade do processo, estatística descritiva etc.

- Análise de Sistemas de Medição (MSA - Measurement System Analysis): O primeiro manual MSA surgiu em 1990, elaborado pelo MSA Group, uma força tarefa com o apoio 
da ASQ (American Society for Quality) e do AIAG (Automotive Industry Action Group) e foi sancionada pelas Big Three (Ford, General Motors e DaimlerChrysler) através do Supplier Quality Requirements Task Force. Trata-se de metodologia estatística desenvolvida para estudar e analisar o comportamento do sistema de medição e, proporcionar o aumento de confiança e certeza na leitura obtida nos instrumentos (AIAG, 1995).

- Análise de Modos e Efeitos de Falhas (FMEA - Failure Mode and Effects Analysis): Método criado por volta de 1963 pela NASA durante a missão Apollo para identificar de forma sistemática falhas potenciais em sistemas, processos ou serviços antes que as mesmas ocorram (PUENTE, 2001).

- Desdobramento da Função Qualidade (QFD - Quality Function Deployment): Método criado em 1978 pelos professores Shigeru Mizuno e Yoji Akao para operacionalizar o processo de Planejamento da Qualidade e que consiste basicamente em uma série de relações causa e efeito representadas por meio de matrizes e que visa transformar expectativas e necessidades do cliente em requisitos do produto e processo (CHEN, 1995; AKAO, 1990).

$\mathrm{Na}$ fase Analisar ("Analyze"), são analisados os dados levantados relativos aos processos estudados, com o objetivo principal de se conhecer as relações causais e as fontes de variabilidade e de desempenho insatisfatório desses processos, visando a sua melhoria. Nessa etapa, as ferramentas utilizadas incluem visualização de dados, testes de hipótese, análise de correlação e regressão e análise de variância.

A fase Melhorar ("Improve") consiste, fundamentalmente, no desenvolvimento de Projetos de Experimentos (DOE), com o objetivo de conhecer a fundo cada processo, por meio da mudança estrutural de níveis das operações e dos diversos fatores associados. As 
informações obtidas com o DOE auxiliam a identificar os ajustes necessários das variáveischaves para modificar e otimizar o referido processo.

$\mathrm{Na}$ fase Controlar ("Control"), são implementados diversos mecanismos para monitorar continuamente o desempenho de cada processo. Entre as técnicas adotadas, destacam-se as cartas de controle, os planos de controle, os testes de confiabilidade e os processos à prova de erros.

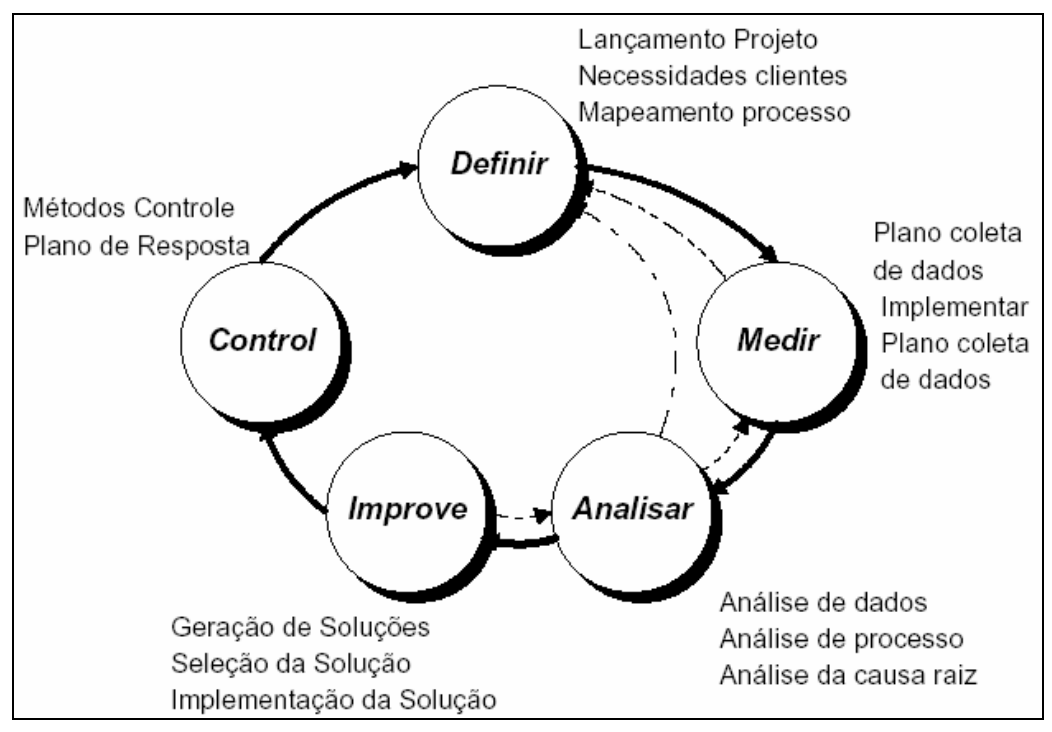

Figura 2.7 - Ciclo DMAIC.

O Seis Sigma aprimora a abordagem tradicional propondo a resolução de problemas dividida em etapas bem distintas dentro do PDCA, ou DMAIC, com a utilização de ferramentas específicas, conforme pode-se observar na Figura 2.7.

A seguir a disposição das ferramentas em cada fase segundo Werkema (2000), conforme o DMAIC:

a) Fase Definir: métrica Seis Sigma, gráficos seqüenciais, carta de controle, análise de séries temporais, análise econômica, mapa de raciocínio; 
b) Fase Medir: análise do sistema de medição, estratificação, plano para coleta de dados, folha de verificação, amostragem, pareto, histograma, "boxplot", capacidade de processo, análise multivariada;

c) Fase Analisar: fluxograma, mapa de processo, mapa de produto, FMEA, FTA, Brainstorming, diagrama de dispersão, diagrama de causa e efeito, diagrama de afinidades, teste de hipóteses, análise de variância, planejamento e análise de experimentos (PAE), análise de tempos de falha, teste de vida acelerado, regressão;

d) Fase Melhorar: matriz de priorização, pesquisa de mercado, pesquisa operacional, operação evolutiva (EVOP), diagrama de processo decisório (PDPC), diagrama de Gantt;

e) Fase Controlar: procedimento operacional padrão, "poka-yoke", relatório de anomalias, plano de ação.

\subsubsection{Fases da Metodologia DMAIC}

\subsubsection{Fase Definir ("Define")}

Na fase da definição é determinado o que é importante para o cliente e ao estabelecidos os fundamentos dos projetos Seis Sigma.

Pande et al. (2001) defendem que nesta fase deve ser definido o problema ou oportunidade a ser trabalhada, a meta, o cliente a ser atendido e qual o processo a ser investigado. As metas e parâmetros do projeto devem ser definidos num documento 
denominado carta de projeto e, tipicamente, pode incluir: descrição do projeto, objetivos, dados da equipe, principais medidores, datas-chave e aprovações dos responsáveis.

Neste trabalho é proposto que antes da definição do problema devem ser verificados todos os pontos relevantes da documentação do processo, entendendo como o mesmo foi projetado para funcionar, quais as especificações e requisitos e se os mesmos estão sendo seguidos na prática. Após essa verificação da documentação e do processo real, é possível se definir o problema, excluindo dessa forma qualquer variação por não cumprimento dos padrões estabelecidos no projeto inicial - ou em último nível - podendo-se, dessa forma, atuar em problemas cujas variáveis são outras que não falta de disciplina ou de implementação adequada, pois nesses casos é necessário apenas colocar o que foi projetado em prática.

É importante ressaltar que caso o processo real esteja diferente do projetado, deve-se entender o motivo pelo qual isso ocorre, pois melhorias não sistêmicas podem estar sendo implementadas sem conhecimento do time da engenharia responsável pelos projetos, sem aval deste e, portanto sem retroalimentação das documentações do projeto do processo. Essa falha é muito comum e é objeto de análise dessa dissertação.

Uma das ferramentas que auxilia na sistemática de documentação é a modelagem do processo em redes de Petri, conforme veremos mais em detalhe posteriormente. Essa modelagem auxilia sobremaneira na visualização dos gargalos, entendimento do processo e definição do problema. 


\subsection{Construção da Equipe}

Ainda que se trate de uma estratégia que implica o desdobramento de toda a organização, é necessária a criação de uma infra-estrutura humana, da qual fazem parte as seguintes entidades:

Alta Direção: Estabelece objetivos, cria a infra-estrutura organizacional necessária, seleciona os projetos e as equipes, presta o apoio necessário e faz as perguntas adequadas durante as fases do projeto.

Champion: Membro da gestão de topo responsável pela logística e aspectos do negócio do programa. Oferece a sua capacidade de gestão, liderança, apoio e guia aos Black Belts.

Black Belts: São os líderes da equipe responsável pela medição, análise, melhoria e controle dos processos que influenciam a satisfação do Cliente e/ou o crescimento da produtividade. São os impulsionadores que dirigem a organização para a excelência.

Green Belts: São os indivíduos que apóiam a implementação e aplicação das ferramentas Seis Sigma, através da participação nas equipes de projeto.

- Master Black Belt: É o professor e mentor dos Black Belts. Fornece apoio, revê projetos e supervisiona os projetos. Atua como consultor interno, formador e perito.

Os membros da Equipe são selecionados com base nas competências técnicas em relação ao projeto e têm como maior responsabilidade a implementação das etapas do modelo de qualidade.

Conforme estamos propondo nesse trabalho, com a análise crítica da documentação do processo, é imprescindível que quaisquer trabalho de melhoria Seis Sigma aplicado à 
manufatura tenha como membro da equipe, ao menos uma pessoa da Engenharia, responsável pelo projeto do processo e pela documentação do mesmo.

\subsection{Iniciando o Trabalho de Definição}

Segundo Eckes (2001), os três estágios da definição são:

1. Criação do Estatuto da Equipe

- O caso do negócio

- A definição do problema

- O escopo do projeto

- Metas e objetivos

- Etapas cumpridas

- Papéis e responsabilidades

2. Identificação dos clientes do projeto, suas necessidades e exigências:

Elaborar a árvore do CTQ (Critical to Quality - Crítico para o Cliente), seguindo os passos a seguir:

- Identificar o cliente

- Identificar as necessidades do cliente

- Identificar o primeiro conjunto de requisitos da necessidade

- Continuar a ramificação a partir do conjunto de requisitos já identificados (se necessário)

- Validar os requisitos junto ao Cliente:

$\checkmark$ Entrevistas individuais com os clientes

$\checkmark$ Enquetes 
$\checkmark$ Grupos de foco

$\checkmark$ Colocar-se no lugar do cliente / Observar o Cliente

$\checkmark$ Reclamações do cliente

3. Criação de um Mapa de Processo de alto nível para o projeto em questão

Nesta última etapa da Definição, cria-se um mapa de alto nível que represente como o processo em questão opera no momento, de modo a termos condições de determinar, posteriormente, o que não está funcionando como deveria.

- Definir o processo a ser mapeado

- Estabelecer os pontos de início e fim do processo (fronteiras)

- Determinar o resultado do processo

- Determinar os clientes do processo

- Determinar as exigências dos clientes

- Identificar os fornecedores do processo e obter o acordo sobre as entradas do processo

Em caso de processos modelados em, por exemplo, redes de Petri, é importante que o Black Belt demonstre através de simulações o problema definido e que todo o time tenha o mesmo nível de entendimento.

\subsubsection{Fase Medir ("Measure")}

Os objetivos da fase Medir são a medição dos processos e conversão dos resultados em informações que indiquem soluções. Essa fase tipicamente inclui a identificação das variáveis-chaves de saída e sua quantificação e sua relação com as variáveis-chaves de entrada 
A fase de medição é uma fase de transição, que serve para validar ou refinar a definição do problema, e para começar a busca pelas causas raiz - que é o objetivo da fase seguinte (Analyze), as medições devem responder a duas perguntas chave:

Qual o foco e extensão do problema, com base nas medições do processo e/ou output?

Quais dados chave podem ajudar a relacionar o problema a seus principais fatores, ou causas principais "Vitais"?

$\checkmark$ Existem dados que levam a entender o problema?

Para planejar as medições que serão feitas, é preciso que haja dados que auxiliem a entender o problema, caso contrário, o time necessitará desenvolver um plano de coleta de dados. Em esforços para melhoria do processo, a necessidade de coletar dados em diversas fases é uma das principais razões para que os projetos demorem meses para serem concluídos.

O principal requisito de preparação para a fase "Analisar", é ter pelo menos uma medição sólida e repetível, confirmando o problema ou oportunidade. Esta deve ser a medição a ser repetida durante a implementação das soluções, e depois, para acompanhar os efeitos de suas melhorias.

\subsubsection{Fase Analisar ("Analyze")}

Os dados coletados na fase anterior devem, nesta fase, ser analisado estatisticamente para que se possam determinar as causas raiz dos problemas. Aqui, as causas óbvias e não-óbvias (os X's - entradas do processo) que influenciam o processo devem ser determinadas. Feito isto, determina-se a capacidade sigma atual do processo e se estabelece os objetivos de melhoria para o mesmo. 
Nesta fase tem-se o objetivo de se identificar a lacuna existente entre o desempenho do processo atual e o desempenho do processo desejado, priorizando problemas e identificando as causas desses problemas (PORTER, 2000).

Pande et al. (2001) considera esta fase como sendo a mais imprevisível do DMAIC, pois ele afirma que não existe certeza absoluta de uma causa raiz. As ferramentas que se devem usar e a maneira como aplicá-las vão depender muito do problema a ser estudado, bem como processo envolvido. Ele ainda apresenta a fase Analisar como um ciclo aplicado na melhoria de processo. O ciclo é impulsionado através da geração e da avaliação de "hipóteses" (ou "estimativas") quanto à causa do problema. Pode-se entrar em um ciclo ou no ponto (a), examinando-se o processo e os dados para se identificar causas possíveis; ou no ponto (b), onde se começa com a suspeita de uma causa e procura confirmá-la ou rejeitá-la através de uma análise, conforme mostrado na Figura 2.8. Quando se encontra uma hipótese que não seja correta, pode-se ter que voltar ao início do ciclo para se obter uma explicação completamente diferente. Mas, mesmo as causas incorretas, na verdade, são oportunidades para refinar e estreitar a explicação do problema.

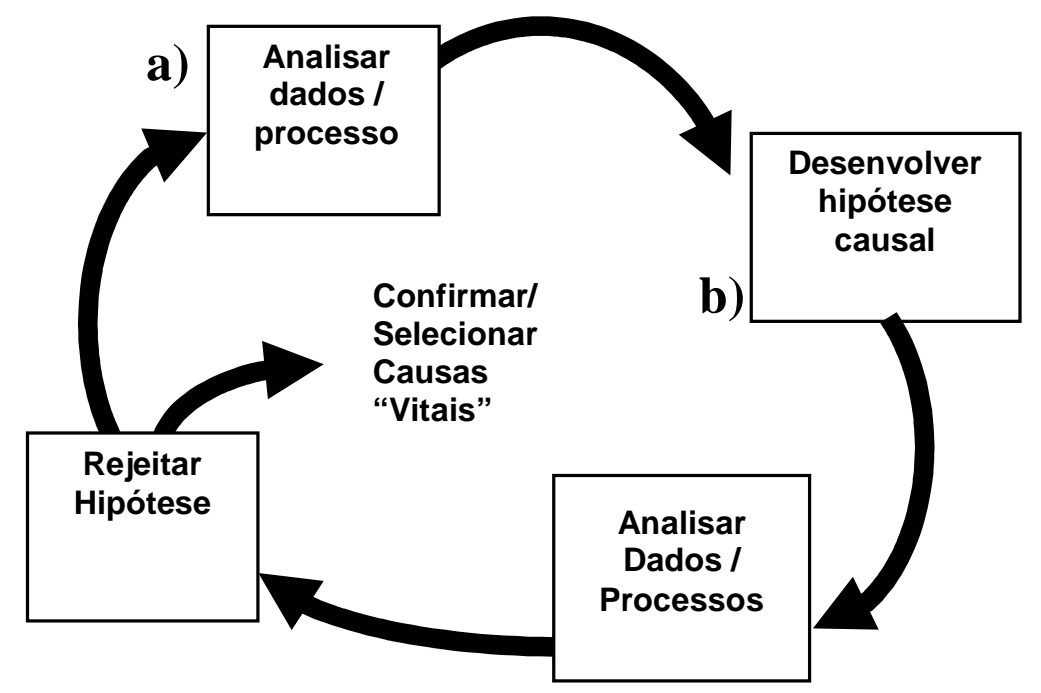

Figura 2.8 - O ciclo de hipótese/análise da causa-raiz (adaptada de Pande et al, 2001). 
Eckes (2001), considera essa fase como a mais importante, pois é nela que ocorre a descoberta da razão da existência do problema. Contudo, muitas vezes a equipe tem uma noção preconcebida da razão do problema, e passa pela etapa da análise superficialmente, antecipando soluções precipitadas de melhoria.

O objetivo da análise é solucionar a seguinte equação:

$$
\mathrm{Y}=f\left(X_{1}, X_{2}, X_{3} \ldots X_{n}\right)
$$

Onde Y é a medida de resultado sobre o qual calcula-se o sigma. Essa equação define que Y (seja um desempenho sigma alto ou baixo) é uma função $(f)$ de uma série de $X s$, que se referem aos elementos do processo (ECKES, 2001)

A expectativa é sair da etapa da análise, dentro do método de melhoria Seis Sigma, com um conjunto validado de Xs que explique o desempenho atual de Y. Para chegar a estas raízes $(\mathrm{X})$, precisa-se de dois tipos de análise. Um deles é tomar os dados que foram coletados na etapa de Mensuração e analisá-los. Esta tarefa é chamada análise de dados. O segundo tipo é o exame do processo. Este é chamado análise do processo. De maneira geral, a equipe do projeto utilizará uma combinação destes dois tipos de análise para chegar às raízes do problema.

Para análise dos dados coletados é de extrema importância a utilização de representações gráficas tais como histograma, gráfico de pizza, gráfico pareto, o que torna os dados mais visíveis e, em muitos casos fornecem mais informações do que os dados brutos.

Para análise do processo, é necessário detalhar o mapeamento do processo que foi elaborado na fase da Definição. Esta atividade é chamada de mapeamento de subprocessos. Feito o mapeamento, a equipe precisa determinar se os passos de um subprocesso agregam valor ou não. 
Novamente, dentro do método Seis Sigma, vemos a importância da análise da documentação a qual permite validar as medições realizadas na fase anterior, verificando se os dados obtidos estão coerentes com os requisitos do projeto do processo feito pela Engenharia. Tempos de ciclo, métodos de trabalho etc, podem estar dissonantes com o que foi projetado.

Nesta fase também, é possível e recomendada a utilização da modelagem do processo, minimizando o tempo gasto para elaboração do mapeamento detalhado do processo, pois este já estaria no modelo em redes de Petri, auxiliando nas análises dos X's no Y, ou seja, utilizando a simulação é possível variar as entradas que o time considera importante e observar qual o resultado dessa variação no processo (Y).

\subsubsection{Fase Melhorar ("Improve")}

O propósito da fase Melhorar é o de gerar, selecionar e implementar soluções. Falta de criatividade, falhas ao desenhar as soluções, implementação não planejada e resistência da organização são fatores que podem eliminar os benefícios de um projeto Seis Sigma.

A fase Melhorar é baseada em como se remover as causas dos erros e/ou defeitos do processo. A equipe de projeto Seis Sigma consolida as variáveis essenciais e quantifica seus efeitos sobre as características críticas para a qualidade (CTQs). São também identificados os limites máximos aceitáveis para essas variáveis essenciais, bem como a validação de um sistema de medição de desvios para as variáveis. A equipe modifica então o processo para que este possa apresentar um desempenho quanto à variabilidade dentro dos limites aceitáveis. 
Porter (2000) define esta fase como sendo uma etapa que envolve a geração de soluções de melhoria e resolução de problemas para que sejam alcançados os requisitos financeiros e outros objetivos de desempenho.

O último passo na fase de Melhoria é o desenvolvimento de uma aplicação-piloto para determinar se as soluções vão conduzir à melhoria do desempenho sigma. Desta forma, não se assume o comprometimento total requerido pelas mudanças até que se tenha certeza de que elas conduzem à melhoria. Uma aplicação piloto é simplesmente tomar as soluções propostas e implementá-las em pequena escala para avaliar seu impacto sobre as metas almejadas.

Os custos com o Piloto podem ser minimizados realizando a validação das soluções através da simulação do modelo do processo, realizando um Piloto mais simples que apenas corrobore com as observações da simulação, representando menos custo com mão-de-obra e com disponibilização da linha para realização dos testes.

\subsubsection{Fase Controlar ("Control")}

A última das fases do processo DMAIC é a fase Controlar. Por ser a última, não significa a menos importante, pelo contrário, segundo Pande et al. (2001) afirma que esta fase é o começo da melhoria e da integração sustentadas do sistema Seis Sigma. Ele defende a exploração tanto dos desafios de curto quanto dos de longo prazos para sustentar a melhoria e unificar todos os conceitos e métodos das fases anteriores em uma metodologia de gestão transfuncional continuada.

Os principais objetivos da fase "Controlar" são os seguintes:

- Validar as melhorias e ajustar o processo adequadamente para atingir os ganhos; 
- Assegurar que o processo permanece sob controle depois que as soluções tiverem sido implementadas. Os ganhos devem ser mantidos;

- Detectar rapidamente sinais de falta de controle e determinar as causas especiais associadas, de forma que ações possam ser tomadas para corrigir o problema, antes que defeitos ou erros sejam feitos.

Por meio de ferramentas de simulação é possível ao time verificar os pontos de conflitos e conseqüentemente potenciais de falhas no processo, estabelecendo controles adequados que evitem tais falhas e mantendo o desempenho do processo. Ao final dessa fase a atualização de toda a documentação do projeto é ponto chave para a manutenção das melhorias implementadas e do histórico das mesmas, inclusive com as ações que foram testadas e descartadas por algum motivo, evitando que outros profissionais, por desconhecimento, proponham implementar as mesmas ações outrora rejeitadas. Entendemos como documentação, também, o modelo do processo, o qual vimos ser ferramenta de grande valor dentro da sistemática de melhoria contínua.

\subsection{Redes de Petri (PN)}

\subsubsection{Introdução}

Redes de Petri (RdPs) é um termo genérico que se refere a uma família de técnicas para especificação formal de sistemas que possibilita uma representação matemática e possui mecanismos de análise que permitem a verificação de propriedades e a verificação da corretude do sistema especificado (MURATA, 1989). 
A teoria inicial das RdPs foi apresentada pela primeira vez na tese de doutorado de Carl Adam Petri, em 1962, e intitulada Kommunikation mit automaten (Comunicação com autômatos). Trata-se de um modelo do tipo estado-evento, onde cada evento possui précondições que habilitam a sua ocorrência, e pós-condições resultantes deste, as quais são por sua vez pré-condições de outros eventos seqüentes.

Um passo importante no projeto de sistemas consiste na separação e identificação dos elementos passivos dos elementos ativos. Nas RdPs, existem dois conjuntos disjuntos de elementos: lugares e transições.

Entidades do mundo real interpretadas como elementos passivos são representadas como lugares (por exemplo, condições, recursos etc). Entidades do mundo real interpretadas como elementos ativos são representadas como transições (por exemplo: eventos, ações, transmissão de mensagens etc.).

A realização de uma ação está associada a algumas pré-condições, ou seja, existe uma relação entre os lugares e as transições que possibilita a realização de uma ação. Da mesma forma, após a realização de uma ação, alguns lugares terão suas informações alteradas (póscondições).

O comportamento de uma transição depende exclusivamente da sua localidade, que é definida como a totalidade dos objetos de entrada e saída (pré e pós-condições, lugares de entrada e saída etc.), juntamente com a própria transição.

As vantagens da utilização das RdPs na modelagem de sistemas são conhecidas (GIRAULT; VALK, 2003):

- RdPs fornecem um formalismo de modelagem que permite uma representação gráfica e é fundamentado matematicamente. 
- Existe uma grande variedade de algorítmos para o projeto e análise de RdPs além de ferramentas de software desenvolvidas para auxiliar neste processo.

- RdPs provêm mecanismos para abstração e refinamento que são integrados o modelo básico.

- Existe um grande número de ferramentas, tanto comerciais quanto acadêmicas, para o projeto, simulação e análise de sistemas baseados em RdPs.

- RdPs têm sido utilizadas em muitas áreas distintas e em consequiência existe um grande número de especialistas no campo da modelagem.

- Existem várias extensões ao modelo básico de RdP.

Diferentes variantes do modelo de RdPs clássico têm sido desenvolvidas. Isto possibilita as RdPs suprir as necessidades existentes em diferentes áreas de aplicação, além de prover facilidades de comunicação e transferência de métodos e ferramentas de uma área para outra. Atualmente, além do modelo básico, existem extensões tais como redes temporizadas (RAMCHANDANI, 1974), estocásticas, alto-nível (JENSEN, 1992) e orientadas a objetos.

\subsubsection{Elementos Básicos}

Uma RdP é composta dos seguintes elementos (DESROCHES; AL-JAAR, 1990):

Lugares: representam os componentes passivos do sistema. Sua função é armazenar marcas. Tais marcas podem ser acrescentadas e removidas pelo disparo das transições. O lugar cuja marcação influencia o disparo de uma transição é chamado pré-condição daquela transição. $\mathrm{O}$ lugar que tem sua marcação afetada pelo disparo de uma transição é chamado pós-condição daquela transição. Em sistemas de produção, lugares podem representar recursos tais como 
máquinas, ou partes em um buffer. A existência de uma ou mais marcas em um lugar pode representar a disponibilidade de um recurso em particular.

Transições: representam componentes ativos do sistema. Uma transição estará habilitada quando todas as suas pré-condições forem atendidas. Uma transição estará desabilitada caso ao menos uma de suas pré-condições não seja atendida. Uma vez habilitada, uma transição pode ser disparada. O disparo da transição remove um determinado número de marcas dos lugares que são pré-condições e gera novas marcas nos lugares que são pós-condições. Em sistemas de produção as transições podem representar, por exemplo, atividades do sistema modelado.

Arcos: guiam o fluxo das marcas através da rede. Arcos conectam lugares a transições e transições a lugares (não são permitidos arcos entre elementos da mesma classe). É permitido a existência de mais de um arco entre os mesmos elementos (arcos multivalorados). O lugar de partida de um arco com destino a uma transição é uma pré-condição da transição. O lugar de chegada de um arco com origem em uma transição é uma pós-condição da transição.

Marcas: as marcas (também denominadas de fichas ou tokens) são os componentes dinâmicos do modelo. Seu fluxo através da rede determina o comportamento do sistema modelado. O número de marcas presentes em uma rede, bem como a sua localização, determinam o estado atual do sistema.

Na Figura 2.9 temos a representação gráfica de uma RdP. Os lugares são representados por círculos e as transições por traços ou barras. Estes dois elementos são os vértices do grafo associado as RdPs. Os vértices são interligados por arcos dirigidos. Adicionalmente, pode haver inscrições tais como nomes, marcas, expressões, guardas etc. 
Para cada representação gráfica de uma RdP existe uma representação algébrica equivalente. Ela contém o conjunto de lugares, transições, arcos, e informações adicionais como inscrições.

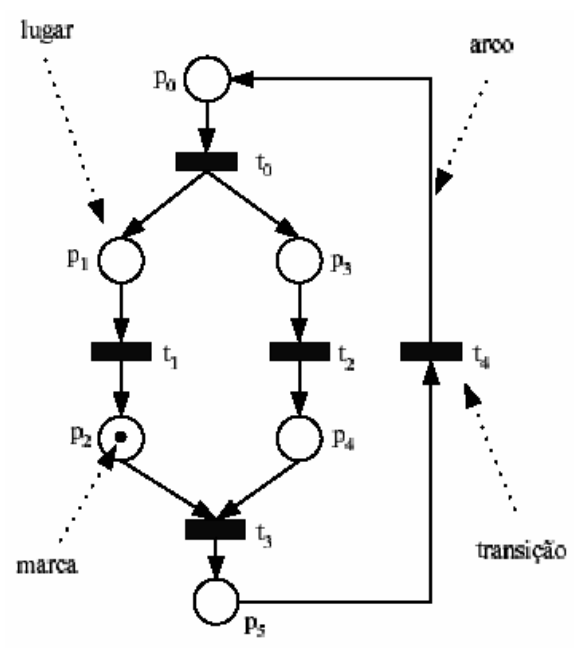

Figura 2.9 - Exemplo de Rede de Petri.

\subsubsection{Estrutura de uma RdP}

As RdPs podem ser enfocadas por meio de três fundamentações diferentes. A primeira utiliza a teoria de bags (PETERSON, 1981) para representar a rede. A segunda utiliza notação matricial (REISIG, 1985). A terceira define RdPs através de relação e pesos associados a estas relações (REISIG, 1985). Tais fundamentações são referentes às RdPs Lugar/Transição, por ser o modelo mais difundido. A seguir é mostrada a terceira fundamentação a qual é mais coerente com esta dissertação:

$>$ Estrutura das RdPs em Relações. Uma RdP é uma quádrupla $N=(P, T, R, W)$ onde

- $P=\left\{p_{0}, p_{1}, \ldots, p_{n}\right\}$ um conjunto finito não vazio de lugares.

- $T=\left\{t_{0}, t_{1}, \ldots, t_{m}\right\}$ um conjunto finito de transições, onde $P \cap T=\emptyset$. 
- $R \subseteq(P \times T) \cup(T \times P)$ arcos que conectam lugares às transições e transições aos lugares.

- $\quad W: R \rightarrow I N$ vetor de pesos dos arcos.

\subsubsection{RdP Marcada}

As marcas são informações atribuídas aos lugares. O número e distribuição das marcas nos lugares correspondem à marcação (estado) da rede em um dado momento. Nesta seção serão apresentados os conceitos de marcação, assim como a definição de uma RdP marcada.

- Marcação: Seja $P$ o conjunto de lugares de uma RdP. Define-se formalmente marcação como uma função que mapeia o conjunto de lugares $P$ a inteiros não negativos. $M: P \rightarrow I N$.

A marcação de uma rede também pode ser definida na forma vetorial:

- Vetor Marcação: Seja $P$ o conjunto de lugares de uma RdP. A marcação pode ser definida formalmente como um vetor $M=\left(M\left(p_{1}\right), M\left(p_{2}\right), \ldots, M\left(p_{n}\right)\right)$, onde $n=(P)$, para todo $p_{i} \in P$, tal que $M\left(p_{i}\right) \in \mathbb{I N}$.

Uma RdP com uma marcação associada é denominada uma RdP marcada. Uma RdP marcada pode ser definida por uma tupla formada pela estrutura da rede $(N)$ e uma marcação inicial $\left(M_{0}\right)$ associada à rede.

- Rede Marcada: Define-se numa RdP marcada pela tupla $R M=\left(N, M_{0}\right)$, onde $N$ é a estrutura da rede e $M_{0}$ é a marcação inicial. 
Normalmente, a presença das marcas em um lugar pode ser interpretada como a presença de um recurso de um determinado tipo. Graficamente estas marcas são normalmente representadas por inscrições no interior dos lugares.

O disparo de uma transição na RdP corresponde à ocorrência de um evento que modifica o estado do sistema. A evolução da marcação de acordo com a regra de disparo das transições simula o comportamento dinâmico do sistema.

\subsubsection{Funcionamento das RdPs}

Sensibilização de uma Transição: Uma transição $t$ é sensibilizada por uma marcação $M$, se e somente se:

$$
\forall p_{i} \in P, M\left(p_{i}\right) \geq \operatorname{Pr} e ́\left(p_{i,} t_{j}\right)
$$

Disparo de uma Transição: Numa rede de Petri $t_{i} \in T$ só pode disparar se estiver sensibilizada. Disparando uma transição sensibilizada $t_{i}$, uma nova marcação $M^{\prime}$ é obtida tal que:

$$
M^{\prime}(p)=M_{0}(p)-\operatorname{Pr} e ́\left(p, t_{j}\right)+\operatorname{Pós}\left(t_{j}, p\right), \forall p \in P
$$

$>$ Seqüência de Disparo: Uma seqüência de transições $s$ que deve disparar para atingir uma marca $M$ 'partindo de $M$ é denominada seqüência de disparo. Se:

$$
M_{0} \stackrel{t_{1}}{\rightarrow} M_{1} \text { e } \quad M_{1} \stackrel{t_{2}}{\rightarrow} M_{2}
$$

diz-se que a sequiência $s=t_{1} t_{2}$ é disparável a partir de $M_{0}$ com a seguinte notação:

$$
M_{0} \stackrel{t_{1} t_{2}}{\rightarrow} M_{2}
$$




\subsubsection{Propriedades das RdPs}

O estudo das propriedades de uma RdP permite uma análise detalhada do sistema modelado. As propriedades de uma RdP costumam ser divididas em propriedades comportamentais, que dependem do estado (ou marcação inicial) e da estrutura da RdP, e propriedades estruturais, que dependem apenas da estrutura da rede.

Dentre as principais propriedades comportamentais das RdPs, podem ser citadas a alcançabilidade, limitação, segurança, vivacidade e reversibilidade.

- A alcançabilidade de uma marcação de uma RdP refere-se a possibilidade de um sistema atingir determinado estado. Uma marcação $M_{i}$ é alcançável a partir de $M_{0}$ se existir uma seqüência de disparos de transições que leve uma rede com marcação $M_{0}$ a outra rede com marcação $M_{i}$.

- Uma RdP é limitada se e somente se o número de marcas de cada lugar da rede não supera um dado inteiro $k . \mathrm{M}\left(\mathrm{p}_{\mathrm{i}}\right) \leq k$ para qualquer marcação alcançável. Um caso particular das redes limitadas ocorre quando o número de marcas em cada lugar é um, no qual a rede é dita segura. Em um ambiente de manufatura, a limitação de uma rede indica a ausência de overflow (caso o lugar represente áreas de armazenamento como em buffers) ou a limitação de recursos (caso os lugares modelem a disponibilidade de recursos).

- Uma RdP é viva se e somente se para cada marcação $M_{i}$ existe uma seqüência de disparo de transições a partir de $M_{i}$ que habilitam as transições $t_{i} \in T$. A vivacidade de uma RdP indica a ausência de bloqueios. Contudo, a ausência de bloqueio não implica vivacidade. 
- Um bloqueio (ou deadlock) em uma RdP ocorre quando se atinge uma marcação a partir da qual o disparo de uma ou mais transições não é mais possível.

- Uma rede é considerada conservativa se todas as suas transições adicionam nos lugares de saída exatamente a mesma quantidade de marcas que removem dos seus lugares de entrada. Em uma rede conservativa, o número de marcas permanece constante e não é alterado pelo disparo das transições. Portanto, a quantidade de marcas é um invariante. Uma rede é subconservativa se todas as transições adicionam nos lugares de saída no máximo o mesmo número de marcas que removem dos seus lugares de entrada. O número de marcas, portanto, não pode aumentar.

\subsubsection{Método de Análise e Validação de uma RdP}

Uma grande vantagem na utilização de RdPs na modelagem de sistemas é a sua capacidade de formalização para a análise e verificação das propriedades do sistema modelado. A análise destas propriedades é implementada através de três modelos: geração do grafo de alcançabilidade, análise da equação de estados e técnicas de redução. A validação das propriedades pode ser realizada através da simulação.

- Geração da árvore ou grafo de alcançabilidade - envolve a listagem de todas as marcações alcançáveis a partir da marcação inicial $M_{0}$. Cada nó da árvore representa uma marcação alcançável e cada arco representa o disparo de uma transição.

- Análise através da Equação de Estado - utiliza a matriz de incidência, que representa as conexões entre lugares e transições, para representar a estrutura da rede e caracterizar o comportamento dinâmico do sistema. 
- Técnicas de Redução - consistem em transformações que reduzem a dimensão do grafo de alcançabilidade, mas que asseguram parcialmente a conservação das propriedades a serem analisadas.

- Simulação - utilizada quando o sistema é relativamente complexo e sua análise através de métodos analíticos se mostra inviável. Neste contexto, a simulação é utilizada para a validação virtual do sistema, ou seja, para que se tenha uma maior confiança de que o sistema modelado apresenta as propriedades desejadas.

Na sequiência serão detalhados os métodos de análise baseados na árvore de cobertura, equação de estado e em técnicas de redução.

\subsubsection{1. Árvore de Cobertura}

Árvore de cobertura é um método de análise que se baseia na construção de uma árvore que possibilite a representação de todas as possíveis marcações de uma rede. A árvore de cobertura é utilizada para representar de forma abrangente a evolução das marcas.

Para uma dada RdP com uma marcação inicial, é possível obtermos diversas marcações para um grande número de transições potencialmente habilitadas. Essas marcações podem ser representadas por uma árvore, onde os nós são as marcações e os arcos as transições disparadas. Algumas propriedades, tais como limitação, segurança, transições mortas e alcançabilidade de marcações, podem ser analisadas através da árvore de cobertura.

Árvore de cobertura: Seja $N=\left(P, T, R, W, M_{0}\right)$ uma RdP marcada. Define-se árvore de cobertura pelo par $A C=(S, A)$, onde $S$ representa as marcações e $A$ os arcos rotulados por $t_{j} \in T$ 
Para uma RdP limitada, árvore de cobertura é denominada árvore de alcançabilidade, dado que esta contém todas as possíveis marcações da rede. Uma outra possível representação finita das marcações acessíveis pode ser obtida do grafo de cobertura.

Grafo de cobertura: Seja $N=\left(P, T, R, W, M_{0}\right)$ uma RdP marcada. Define-se grafo de cobertura pelo par GC $=(S, A)$, onde $S$ representa o conjunto de todos os nós na árvore de cobertura e $A$ os arcos rotulados por $t_{j} \in T$ representando todos os possíveis disparos de transição tal que $M_{i}\left[t_{k}>M_{j}\right.$, onde $M_{i}, M_{j} \in S$.

Se uma rede é limitada, o grafo de cobertura também é denominado de grafo de alcançabilidade. Este método de análise permite a análise das propriedades de limitação, segurança, conservação e problemas de cobertura de marcações. Todavia, não possibilita a resolução de vivacidade, alcançabilidade e reversibilidade em redes não-limitadas. Este problema está relacionado à introdução do símbolo $\omega$ que é uma informação da qual não se sabe o seu real valor (JENSEN, 1992).

\subsubsection{Matriz de Incidência e Equação de Estado}

O comportamento dinâmico de muitos sistemas pode ser descrito por equações diferenciais ou equações algébricas. A vantagem das técnicas algébricas sobre as técnicas baseadas na análise de propriedades pode ser efetuada pela resolução de equações lineares simples. As equações desenvolvidas governam o comportamento concorrente dos sistemas modelado por RdPs. Todavia, a solução destas equações é limitada, em parte devido à natureza não determinística dos modelos de RdP e por causa da restrição que soluções devem ser encontradas como inteiros não-negativos (MURATA, 1989). 
Matriz de Incidência - A matriz de incidência $A$ de uma RdP é uma matriz $n \times m$ de inteiros, definida como:

$$
A=\left[a_{i j}\right]
$$

$\mathrm{e}$

$$
a_{i j}=a_{i j}^{+}-a_{i j}^{-}
$$

onde $a_{i j}^{+}=\omega(i, j)$ é o peso do arco da transição $i$ para seu lugar de saída $j$ e $a_{i j}^{-}=\omega(j, i)$ é o peso do arco do lugar de entrada $j$ para a transição $i$.

Equação de Estado: Seja $m_{k}$ a marcação de uma RdP após sua $k$-ésima execução, $\operatorname{com} k \geq 0$. A próxima marcação $m_{k+1}$ é determinada pela Equação de Estado definida por:

$$
m_{k+1}=m_{k}+A u_{k}
$$

Onde $A$ é a matriz de incidência e $u_{k}$ é um vetor de dimensão $(m \times 1)$ de inteiros não negativos, chamado vetor de disparo, no qual cada entrada representa o número de vezes que a respectiva transição disparou durante a $k$-ésima execução da rede.

\subsubsection{Redução}

A análise de sistemas de grandes dimensões normalmente é uma operação custosa. Reduções são transformações aplicadas ao modelo de um sistema com o objetivo de simplificá-lo, e ainda preservando as propriedades do sistema a ser analisado. De modo oposto, existem técnicas para transformar um modelo abstrato em um modelo mais refinado que podem ser utilizadas para processos de síntese. 
Existem várias técnicas de transformação para RdPs. Aqui serão citadas as mais simples, que podem ser utilizadas para a análise de vivacidade, segurança e limitação por preservarem tais propriedades.

- Fusão serial de lugares, como mostrado na Figura 2.10 (a)

- Fusão serial de transições, como mostrado na Figura 2.10 (b)

- Fusão paralela de lugares, como mostrado na Figura 2.10 (c)

- Fusão paralela de transições, como mostrado na Figura 2.10 (d)

- Eliminação de lugares auto-laço, como mostrado na Figura 2.10 (e)

- Eliminação de transições auto-laço, como mostrado na Figura 2.10 (f)

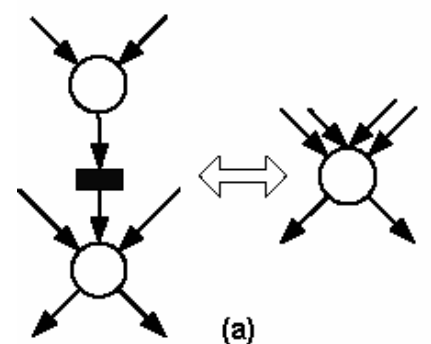

(a)

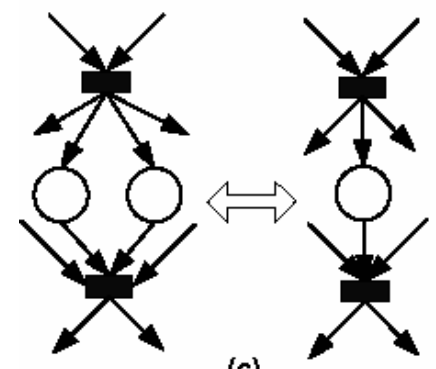

(c)

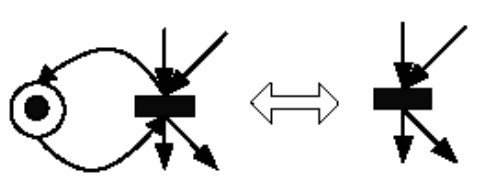

(e)

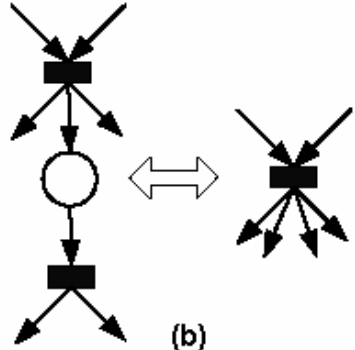

(b)

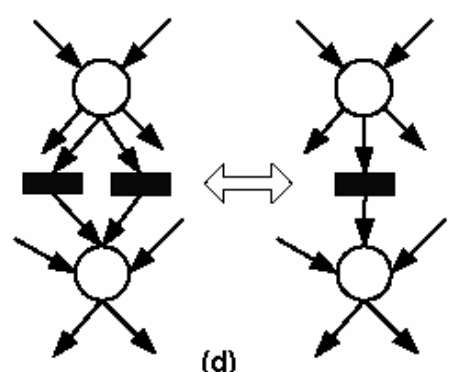

(d)

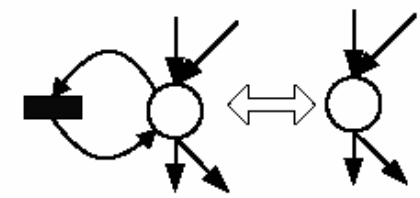

(f)

Figura 2.10 - Seis transformações preservando Vivacidade, Segurança e Limitação.

Segundo Murata (1989), a maior fraqueza das RdPs é o problema da complexidade, ou seja, modelos de RdP tendem a ser muito grandes para a análise até mesmo de sistemas de 
tamanho reduzido. Portanto, é muito importante desenvolver métodos de transformação que permitam reduções hierárquicas ou graduais e preservem as propriedades do sistema a serem analisadas.

\subsubsection{Classes de RdPs}

Existem várias classificações para RdPs na literatura. A escolha da classe de RdP adequada para a modelagem de um sistema é crucial para a obtenção de um modelo que seja conciso, simples e que modele adequadamente o sistema apresentado. Conforme descrito em Reisig (1985), as RdPs se classificam em:

- RdPs elementares.

- RdPs lugar/transição.

- RdPs ordinárias.

$>$ Máquinas de estado (State Machine).

$>$ Grafo marcado (Marked Graph).

$>$ Redes escolha livre (Free-choise).

- RdPs de alto nível.

- RdPs Predicado-Evento.

- RdPs Coloridas.

A primeira classe de RdPs são as redes elementares, onde lugares representam valores booleanos, ou seja, um lugar apresenta no máximo uma marca não estruturada.

A segunda classe são as redes lugar/transição, onde lugares representam valores inteiros, ou seja, um lugar apresenta um certo número de marcas não estruturadas. Um caso 
particular das RdPs lugar/transição são as redes ordinárias, nas quais o peso dos arcos é unitário.

A terceira classe são as redes de alto nível, onde cada lugar já não corresponde a uma variável Booleana (presença ou ausência de uma marca), mas pode corresponder a qualquer tipo de variável.

Adicionalmente algumas extensões podem ser consideradas tais como redes temporizadas, redes com arcos inibidores e redes com prioridades. Tais extensões afetam tanto a concisão quanto o poder de modelagem dos modelos adotados.

Duas características de um modelo de RdP que as torna tão úteis são os níveis de abstração e as diferentes interpretações. Estas características especificam um espaço de formalismos apropriados para diferentes propósitos.

\subsubsection{RdPs Ordinárias}

Uma RdP ordinária é um grafo bipartido no qual lugares de capacidade ilimitada e transições alternam-se conectados por arcos orientados de peso unitário, formando a estrutura da rede.

RdPs ordinárias podem ser colocadas em várias classes. Cada classe tem um certo poder de modelagem e propriedades próprias (DESROCHES; AL-JAAR, 1990). Aqui serão descritas as seguintes sub-classes: grafo marcado, máquina de estado e as redes escolha-livre.

Um grafo marcado é uma RdP (ordinária) na qual cada lugar tem exatamente uma transição de entrada e uma transição de saída.

Uma máquina de estado é uma RdP (ordinária) na qual cada transição tem exatamente um lugar de entrada e uma transição de saída. 
Uma rede escolha-livre é uma RdP (ordinária) tal que um arco com origem em um lugar é o único arco de saída (sem escolha) ou, é a única entrada para uma transição.

Uma RdP pura é uma rede que não contém auto-laços (termo encontrado na literatura como self-loops), isto é, nenhum lugar é ao mesmo tempo entrada e saída de uma transição.

Uma RdP marcada é uma rede que contém marcas em adição aos elementos descritos anteriormente. As marcações estão associadas aos lugares e seu fluxo através da rede é regulado pelas transições. Marcações são representadas graficamente por pontos.

A execução de uma RdP ordinária modifica a marcação da rede. A execução é realizada através do disparo de transições habilitadas. Uma transição está habilitada quando cada um dos seus lugares de entrada está marcado com pelo menos uma marca. O disparo da transição remove uma marca de cada lugar de entrada e coloca uma marca em cada lugar de saída.

No caso de transições que apresentam arcos de entrada com multiplicidade $k>1$, a transição $t_{i}$ irá disparar quando cada lugar de entrada tiver pelo menos um número de marcas igual a multiplicidade do arco que o conecta a $t_{i}$.

\subsubsection{Extensões de RdPs}

As extensões das RdPs fazem referência a modelos que incorporam regras adicionais de funcionalidade para aumentar seu poder de funcionalidade. São consideradas três subclasses (DESROCHES e AL-JAAR, 1995).

- Modelos equivalentes às máquinas de Turing - correspondem às RdPs com arcos inibidores (que inibem o disparo de uma transição caso o lugar que é pré-condição da transição esteja marcado) e redes com prioridade. 
- Modelos para sistemas híbridos - correspondem às RdPs híbridas.

- Modelos que evoluem em função do tempo ou de eventos eternos - correspondem às RdPs sincronizadas, RdPs temporizadas e RdPs estocásticas.

\subsection{RdPs com Arco Inibidor}

Uma das principais limitações das RdPs é a impossibilidade da realização do teste de zero marcas em um lugar com capacidade ilimitada. A extensão mais simples que possibilita a realização do teste de zero marcas é a rede com arco inibidor. Esta extensão inclui um arco diferenciado dos demais, denominado arco inibidor, que inibe o disparo de uma transição caso o lugar que é pré-condição à transição esteja marcado (PETERSON, 1981). Graficamente, o arco inibidor é um arco de um lugar para uma transição (pré-condição), terminando com um pequeno círculo.

A regra de disparo das transições que têm arcos inibidores como entrada é alterada. Tais transições só estarão aptas a serem disparadas caso os lugares de entrada, relacionados às transições pelos arcos inibidores, não contenham marcas (JENSEN, 1992).

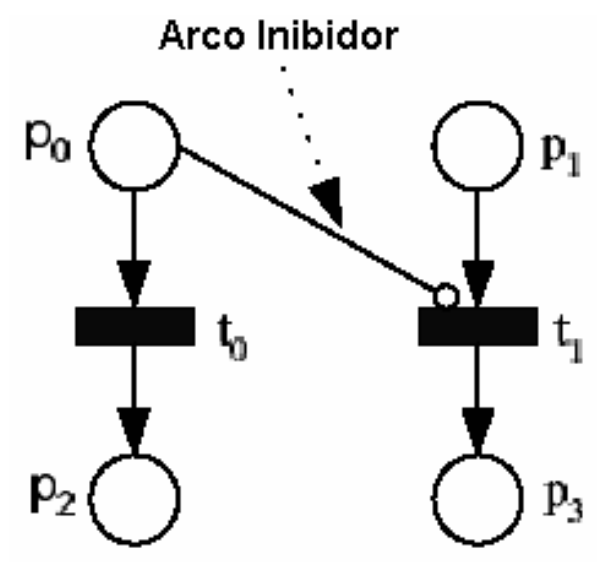

Figura 2.11 - Rede com arco inibidor. 
A Figura 2.11 mostra uma rede com arco inibidor, possibilitando o teste se zero marcas mo lugar $p_{0}$,ou seja, a transição $t_{1}$ só estará habilitada quando não houver marcas $p_{0}$.

\subsection{Extensões Temporizadas}

RdPs é um formalismo que possibilita a expressão do comportamento dinâmico de sistemas que tenham atividades concorrentes, assíncronas e não determinísticas. O conceito de tempo não está explícito na definição original de RdPs. Isto motivou Ramchandani (1974) a desenvolver as RdPs temporizadas (TPN - Timed Petri Net). A introdução da especificação de tempo é crucial quando são considerados problemas que envolvem a análise de desempenho, escalonamento, controle de tempo real. Para tanto, foram definidas várias extensões temporizadas para as RdPs.

Os tempos de um modelo podem ser associados aos lugares, às marcas e transições. Existe também uma abordagem que associa o tempo às transições pelo uso de intervalos.

Existem três maneiras de associar um valor ao tempo que o evento leva para ocorrer: determinística, estocástica e por intervalo. Se o tempo é determinístico, tem-se uma RdP determinística. Os primeiros trabalhos sobre TPN utilizavam atrasos de tempo determinísticos. Nas RdPs estocásticas, a duração de um evento é determinada por uma função de distribuição de probabilidade. A distribuição de probabilidade normalmente adotada é a distribuição exponencial, todavia, é possível utilizar outras funções de distribuição de probabilidade. Nas RdPs com intervalo, as durações definidas na rede estão entre um valor máximo e um valor mínimo, e o valor utilizado para disparar ou habilitar uma transição é tomado neste intervalo. 
As redes estocástica, ou SPNs (Stochastic Petri Net), permitem aplicar modelos de RdP temporizados em sistema não-determinísticos, devido, por exemplo, a tempos randômicos de atraso e falhas. Formalmente, pode-se dizer que uma SPN de tempo contínuo é temporizada nas transições e possui um conjunto de atrasos de tempo exponencialmente distribuídos, com taxa de disparo $\lambda_{i}>0$.

As SPNs vivas e limitadas são isomorfas às cadeias de Markov homogêneas. A principal vantagem da SPN é que ela simplifica a geração da Cadeia de Markov e provê uma representação mais compacta e lógica do sistema. Isto abre uma nova possibilidade de análise de desempenho de sistemas de produção: a modelagem do sistema é realizada com RdPs. Então, com base na marcação inicial, a árvore de cobertura pode ser gerada e uma cadeia de Markov equivalente pode ser obtida e analisada.

RdPs estocásticas generalizadas (GSPN - Generalized Stochastic Petri Net) apresentam transições imediatas (que disparam com tempo zero) e estocásticas. As transições temporizadas têm tempo de disparo distribuído exponencialmente e disparam, em média, a $1 / \lambda$ unidades de tempo depois de habilitadas. É comum dizer que estas transições têm taxa de disparo $\lambda$. As transições imediatas disparam em tempo zero.

GSPNs permitem a utilização de arcos inibidores (utilizados para evitar que certas transições disparem quando alguma condição for verdadeira), funções de prioridade e distribuições de probabilidade discreta. A função de prioridade é definida para as marcações que apresentam habilitadas ao mesmo tempo tanto transições estocásticas quanto transições imediatas (normalmente, as transições imediatas têm maior prioridade). As distribuições de probabilidade discretas são utilizadas para resolver conflitos entre duas ou mais transições imediatas. 
RdPs temporizadas são a base para a análise de desempenho. Elas têm sido muito utilizadas para a modelagem e análise de desempenho de sistemas nas mais diversas áreas de aplicação.

\subsection{Redes Hierárquicas}

As redes hierárquicas proporcionam uma descrição estruturada dos sistemas, possibilitando sua especificação em níveis de abstração que pode ser refinada quanto necessário. Nessa classe de rede, os lugares e as transições dos níveis superiores podem ser refinados, ou seja, podem ser subredes da rede global. Esta subredes fornecem uma descrição mais detalhada do lugar ou da transição do nível superior. A interface entre um lugar ou transição de mais alto nível e a subrede correspondente é efetuada através de transições ou lugares denominados "port-transitions" e "port-places", respectivamente (JENSEN et al, 1990).

O primeiro morfismo utilizado nesta abordagem para a obtenção de hierarquia em RdPs é a substituição de lugares. Cada lugar de alto nível designa uma página (denominada sub-página). Um lugar de alto nível é visto como uma caixa preta e a sub-página correspondente representa o detalhamento desse lugar. O lugar de alto nível e a página em que está inserido são, para a sub-página, denominados super-página.

Do ponto de vista teórico, a hierarquia é apenas uma conveniência gráfica que não adiciona nenhum poder computacional. Todavia, o seu uso facilita a modelagem de sistemas de grandes dimensões. A Figura 2.12 (a) apresenta uma RdP na qual temos um lugar de alto nível. A Figura 2.12 (b) apresenta uma página que representa o refinamento do lugar $p_{0}$. 


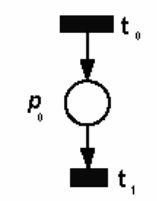

a) super-página

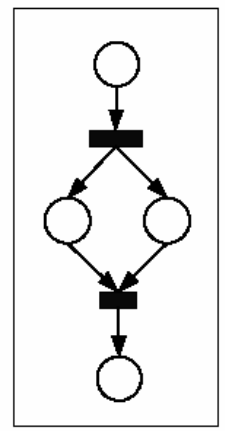

b) sub-página

Figura 2.12 - Exemplo de Hierarquia em Redes de Petri.

Os seguintes passos são necessários para a representação clara da semântica de substituição de lugares, que possibilitam a representação não-hierárquica equivalente da rede (JENSEN, 1992):

- Remove-se o lugar de alto nível.

- Insere-se a sub-página que representa o refinamento do lugar.

- Fundem-se os "port-transitions" da rede de mais alto nível e da sub-página.

As transições também podem ser substituídas por redes que representem o seu refinamento (página), de forma semelhante à substituição de lugares.

A Figura 2.13 mostra algumas das extensões de RdPs mais comuns. A partir do modelo elementar de RdP, pela adição de capacidade aos arcos e transições, chega-se às redes lugar/transição. A partir das redes lugar/transição, pela individualização das marcas (marcas correspondem a tipos de dados estruturados), chega-se às redes com marcas individualizadas tais como as redes PrT e as redes CPN. As RdPs acrescidas de tempo são obtidas através das redes lugar/transição pela introdução de informações explícitas de tempo. A informação de tempo pode ser determinística, levando às redes determinísticas (ex: TPN) ou estocástica, na qual a informação temporal associada ao elemento da rede é uma variável aleatória. 


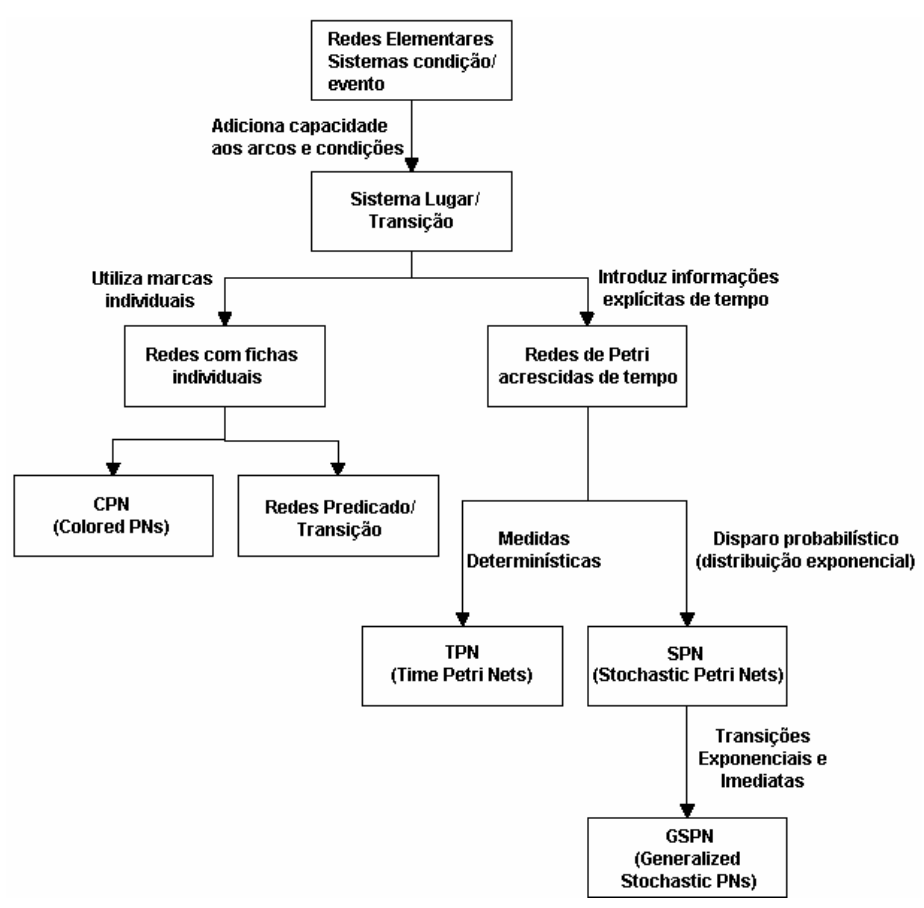

Figura 2.13 - Extensões de RdPs.

Conforme já salientado, existem muitas outras extensões de RdP tais como redes com arco inibidor, redes hierárquicas, redes orientadas a objetos etc.

\subsubsection{Considerações Finais}

RdPs constituem-se em uma poderosa família de técnicas de modelagem de sistemas concorrentes, provendo um grande conjunto de ferramentas de análise. Várias das características das RdPs as tornam particularmente úteis para a modelagem e análise de sistemas de produção.

Os modelos iniciais de RdPs não incluem a noção de tempo e objetivam modelar apenas o comportamento lógico do sistema através da descrição das relações causais existentes entre os eventos. A introdução da especificação de tempo é crucial quando são 
considerados problemas que envolvem a análise de desempenho, escalonamento e controle de tempo real, por exemplo. Para tanto, foram definidas várias extensões temporizadas para as RdPs.

Para sistemas de produção reais, que são usualmente de grandes dimensões, os modelos RdPs gerados utilizando-se RdPs ordinárias, apresentam um grande número de elementos, tornando a sua análise difícil ou mesmo impossível. Alguns tipos de RdPs, tais como as RdPs hierárquicas, permitem uma representação mais compacta do sistema modelado.

\subsection{Modelagem de Sistemas de Produção}

\subsubsection{Modelo de um Sistema}

Um modelo é definido como a representação simplificada de um sistema real com o objetivo de estudo deste sistema. Um modelo pode ser classificado de várias formas:

- Modelo Físico: reproduz as características construtivas do sistema real em uma dada escala geométrica, observando as mesmas características físicas e estruturais do sistema real, como por exemplo, protótipo de aviões, em menor escala, testados em túneis de vento.

- Modelo Matemático: usa notações simbólicas em termos de lógica e equações matemáticas para representar um sistema, como por exemplo, um modelo matemático para a modelagem de sistemas de manufatura. Os modelos matemáticos de simulação, ou simplesmente modelos de simulação, podem ser classificados em: 
Estáticos ou dinâmicos - denominam-se como modelos estáticos os que visam representar o estado de um sistema em um instante ou que em suas formulações não se leva em conta a variável tempo, enquanto os modelos dinâmicos são formulados para representarem as alterações de estado do sistema ao longo da contagem do tempo de simulação;

$>$ Determinístico ou estocástico - são modelos determinísticos os que em suas formulações não fazem uso de variáveis aleatórias, enquanto os estocásticos podem empregar uma ou mais;

$>$ Discretos ou contínuos - são modelos discretos aqueles em que o avanço da contagem de tempo na simulação se dá na forma de incrementos cujos valores podem ser definidos em função da ocorrência dos eventos ou pela determinação de um valor fixo, nesses casos só é possível determinar os valores das variáveis de estado do sistema nos instantes de atualização da contagem de tempo; enquanto para os modelos contínuos o avanço da contagem de tempo na simulação dá-se de forma contínua, o que possibilita determinar os valores das variáveis de estado a qualquer instante.

Pode-se especificar, para um determinado sistema, vários modelos distintos, em função do aspecto que se deseja analisar. Uma das vantagens das RdPs é o fato de o mesmo formalismo poder ser utilizado para especificar, por exemplo, um modelo matemático, modelo dinâmico, um modelo determinístico e ainda um modelo estocástico do sistema.

\subsubsection{Modelagem usando RdPs}

RdPs são muito úteis na modelagem, análise, simulação e controle de sistemas de produção pelos seguintes motivos (DESROCHES; AL-JAAR, 1995): 
- Capacidade de representar de forma natural a sincronização de processos, eventos concorrentes, causalidade, compartilhamento de recursos, conflitos etc.

- Permite uma representação gráfica dos sistemas.

- Conflitos e buffers podem ser modelados de forma simples e eficiente.

- Deadlocks no sistema podem ser identificados.

- Como uma ferramenta formal, um modelo de RdP pode ser descrito matemática mente.

- Várias extensões das RdPs, tais como RdPs temporizadas, RdPs estocásticas e RdPs lugartransição ou elementares, ou ainda redes de alto nível (RdPs Coloridas) possibilitam a análise qualitativa e quantitativa dos sistemas, permitindo a análise da utilização de recursos, efeito de falhas, "throughout", etc.

Um processo comumente adotado para a modelagem de sistemas de produção usando RdPs consiste nos seguintes passos:

- Identificação dos recursos, operações e atividades do sistema.

- Estabelecimento da sequiência de atividades em cada processo.

- Representação das atividades geralmente através de transições.

- Representação de recursos geralmente através de lugares.

- Especificação da marcação inicial.

Na seqüência serão apresentados e formalmente definidos os elementos de modelagem utilizados neste trabalho. 


\subsubsection{Elementos de Modelagem}

Para a modelagem dos sistemas de manufatura, os seguintes elementos precisam ser definidos:

- Produto: o elemento que se está manufaturando ou comprando. Um produto pode ser composto de outros produtos.

- Estrutura do Produto: descreve as relações pai-filho entre os elementos que compõem o produto, além de atributos adicionais tais como o lead time para obtenção/manufatura de cada item que compõe o produto, e a quantidade de elementos necessária para formar o produto final.

A partir das definições de Produto e Estrutura do Produto, o Modelo da Fabricação do Produto pode ser definido. Este modelo permite, por exemplo, o cálculo da necessidade de materiais para a manufatura de um dado produto, tempos mínimos de produção, além do escalonamento das atividades no tempo. Sua limitação resulta no fato desta abordagem não levar em conta restrições de capacidade do sistema de manufatura. Portanto, para que se leve em consideração tais restrições, é necessário que se modele também os recursos produtivos e suas restrições produtivas:

- Recursos: todo e qualquer bloco funcional que possa ser utilizado no processo de manufatura, como por exemplo, máquinas e pessoas. Os recursos apresentam parâmetros cujos valores variam em função da atividade que realizam, tais como tempo de operação, tempo de recuperação em caso de falha, tempo médio entre falhas etc.

- Atividades: Operações realizadas com os recursos. 
O próximo passo consiste em determinar como cada produto será manufaturado, ou seja, definir para um dado produto os recursos utilizados e as operações necessárias para a sua produção. Para tanto, é necessário definir:

- Planta da Produção: representa os recursos alocados à realização de um dado processo de manufatura.

- Roteiro de Produção: seqüência de operações efetuadas pelos recursos para a realização de um dado processo de manufatura.

Os passos básicos adotados no processo de modelagem são os seguinte, conforme

\section{Figura 2.14:}

- Definir o modelo de alto nível para o produto/recurso.

- Definir o modelo intermediário (também denominado modelo hierárquico), usando RdPs, a partir do modelo de alto nível.

- Refinar os lugares do modelo intermediário.

- Gerar o modelo RdP final.

Modelo de Alto

Nivel

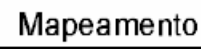

Mapeamento

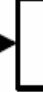

Modelo Intermediário

Figura 2.14 - Etapas do Processo de Modelagem. 


\subsubsection{Aplicações e Benefícios de Um Modelo de Sistemas de Produção}

As aplicações são as mais diversas possíveis, conforme listado a seguir:

- Obter uma maior compreensão do processo produtivo.

- Adquirir e registrar conhecimentos para uso posterior.

- Servir como base para análise de partes do processo produtivo.

- Base para simulação do funcionamento da produção.

- Base para tomada de decisões sobre operações e organização do processo.

É importante ressaltar que diversos elementos podem ser representados num modelo de processo produtivo:

- A funcionalidade e comportamento da empresa em termos de processos, operações básicas e eventos que os iniciam.

- Processo, fluxo e pontos das decisões que têm que ser tomadas.

- Os componentes físicos ou recursos, como máquinas, ferramentas, dispositivos de armazenagem e movimentação etc.

São vários os benefícios dos modelos de sistemas de produção, sendo os mais relevantes:

- Construção de uma cultura, visão e linguagens compartilhadas.

- Formalização do know-how e memória dos conhecimentos de manufatura da empresa.

- Suportar decisões para melhoria e controle dos processos. 


\subsubsection{Manufatura Virtual (MV)}

A Manufatura Virtual (MV) pode ser definida de acordo com Lin (1995) como o uso de modelos computacionais e de simulação dos processos de manufatura para auxiliar no projeto e na produção de um produto manufaturado. Ela pode fornecer também um ambiente de modelagem e simulação tão poderoso quanto à fabricação e montagem de um produto, que podem ser simulados em um computador, reproduzindo suas propriedades principais. Um exemplo do fluxo entre a MV e a execução na prática encontra-se na Figura 2.15.

Envolve desde o ambiente de produção dos processos de chão de fábrica (local onde se fabricam os produtos) até as transações de negócios da empresa, ou seja, deve considerar os processos de produção, planejamento do processo, programação, planejamento de montagem, logísticas das linhas da empresa e os processos de suporte relacionados tais como contabilidade, compras e gerenciamento (LAWRENCE ASSOCIATES INC, 1994).

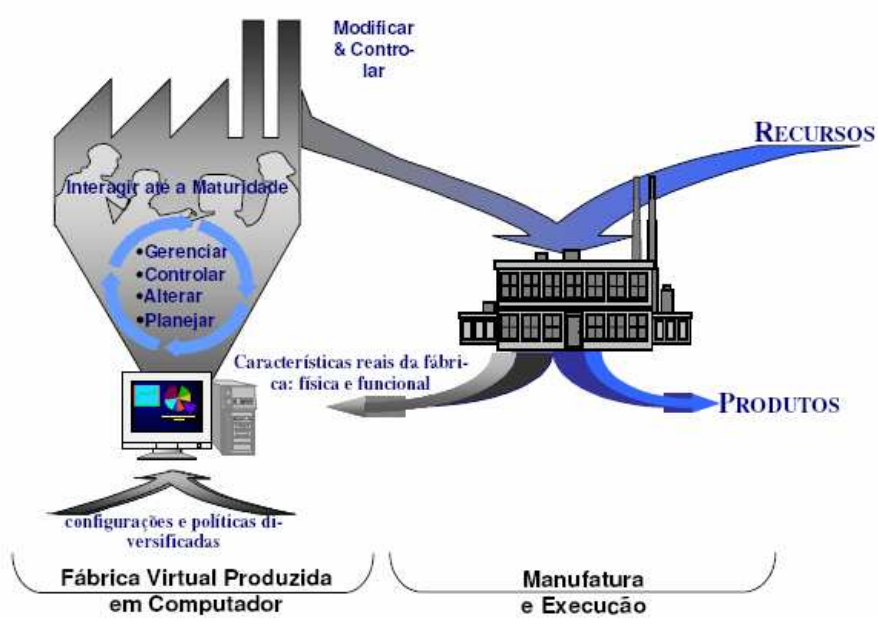

Figura 2.15 - Conceituação de uma fábrica virtual (PORTO; PALMA, 2000).

A Manufatura Virtual pode permitir a avaliação de projetos completos ou parciais pela "manufatura no computador" em um ambiente melhorado de desenvolvimento integrado do 
produto e do processo reduzindo, dessa forma, o número de processos pela fabricação em um computador antes da fabricação física. O ambiente da MV é ilustrado na Figura 2.16.

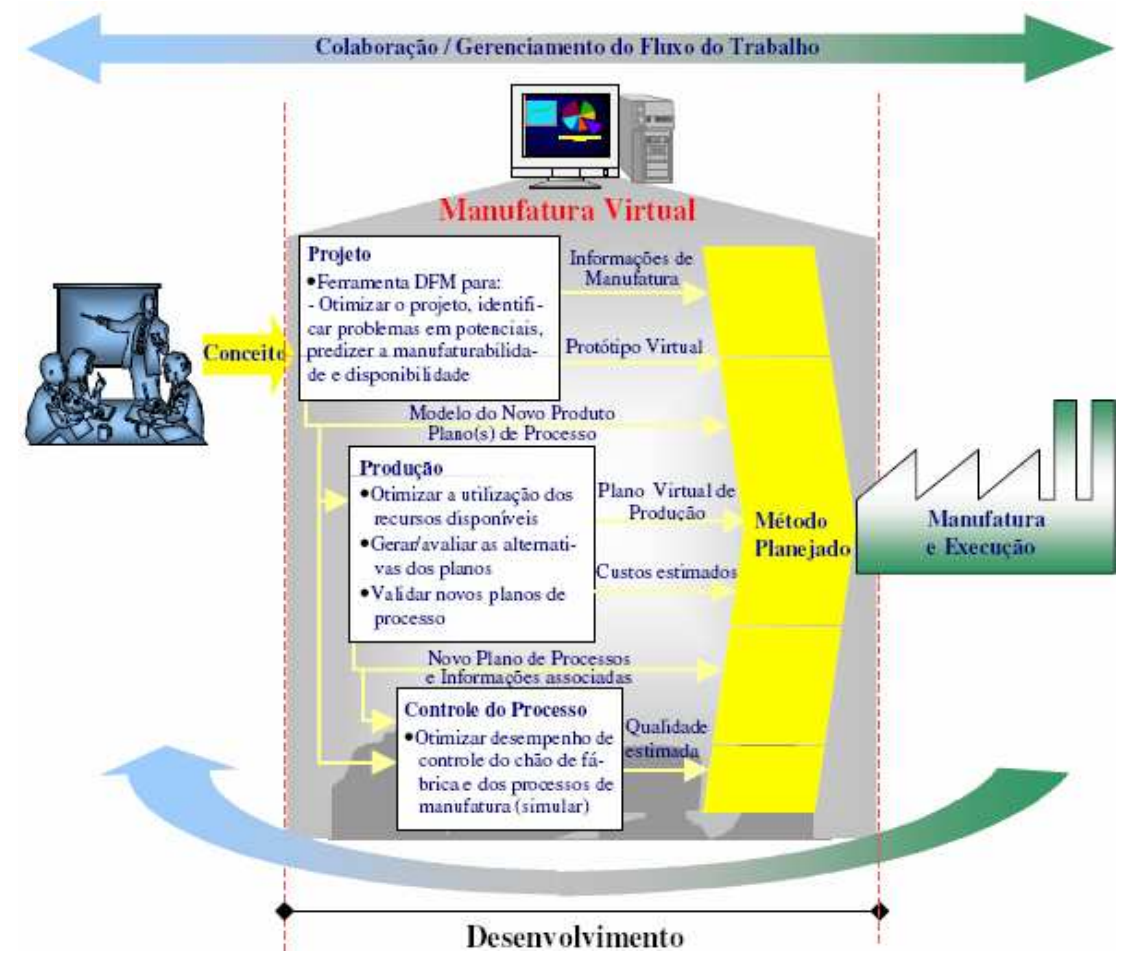

Figura 2.16 - Ambiente da Manufatura Virtual (PORTO; PALMA, 2000).

No ambiente de Manufatura Virtual o processo da concepção do produto até o seu lançamento no mercado pode ser proposto sinteticamente por essa ferramenta através das tecnologias computacionais avançadas, principalmente da utilização de simulação e interfaces de realidade virtual, que proporciona a interação e criação de um ambiente sintético e facilita a visualização dos resultados.

Simulações realizadas durante todo o ciclo de vida dos produtos irão fornecer dados precisos que excluem o desenvolvimento de um projeto que seja difícil ou impossível de ser produzido. Assim, a Manufatura Virtual pode fornecer suporte ao processo de desenvolvimento integrado do produto e do processo desde que forneça um "caminho" para que as informações e o conhecimento da manufatura sejam transportados para as fases iniciais 
do ciclo de vida do produto (LIN, 1995). Melhorando a efetividade do processo de desenvolvimento e a habilidade de ir diretamente à produção sem inícios falsos, o ciclo de desenvolvimento pode ser significativamente reduzido.

A Manufatura Virtual além de identificar e solucionar problemas da manufatura enquanto o produto está sendo projetado, reduz o time to market e melhora a qualidade do produto.

Esta também pode ser definida como um "ambiente de manufatura integrado e sintético executado para melhorar todos os níveis de decisão de controle" (LAWRENCE ASSOCIATES INC, 1994) onde:

- Ambiente: é o suporte para a construção e o uso da simulação distribuída da manufatura fornecendo uma coleção de ferramentas de análise, ferramentas de simulação, ferramentas de implementação, ferramentas de controle, modelos (produtos, processos e recursos), equipamentos, metodologias e princípios organizacionais (cultura).

- Sintético: é uma mesclagem do real com objetos, atividades e processos simulados;

- Executado: construir e executar simulações da manufatura específica usando o ambiente;

- Melhorar: aumentar o valor, precisão e validade;

- Níveis: do conceito do produto à sua disponibilização, do chão de fábrica à alta administração, do equipamento de fábrica ao empreendimento, da transformação do material à transformação da informação;

- Decisão: compreender o impacto da mudança (visualizar, organizar, identificar alternativas);

- Controle: prever os efeitos reais. 


\subsubsection{Estratégias para a Utilização da Manufatura Virtual}

As empresas têm investido em melhorar o ambiente de engenharia simultânea, com a finalidade de acelerar o tempo de desenvolvimento do produto e processo, além de prever e controlar melhor os custos de manufatura desde o início do projeto.

Relacionando essas necessidades das empresas com os paradigmas da Manufatura Virtual, a estratégia é adicionar:

- Centralizado no Projeto: simulação de alternativas de manufatura e a criação de protótipos soft, pela "Manufatura no Computador"; otimização do projeto do produto e processo para DFA (Design for Assembly), DFM (Design for Manufacture); avaliação de diferentes cenários para tomadas de decisão de projeto.

- Centralizado na Produção: diversas alternativas de processos para otimizar a fábrica; validação de novos processos; efetivamente balancear opções de projeto com equipamentos de produção (por exemplo, a adição de uma nova máquina poderá ser uma opção muito mais custosa que uma outra opção de projeto com o equipamento existente).

- Centralizado no Controle: otimização durante o ciclo real de produção.

Busca-se a integração de dados e sistemas, padronização de ferramentas e programas. Não há um único produto que domine o mercado de software de simulação, e como os pacotes variam consideravelmente em muitos aspectos - custo, funcionalidade, flexibilidade, facilidade de uso, plataforma - a seleção das ferramentas deverá ser direcionada para aquelas que permitam:

- Melhorar a tecnologia para obter recursos; 
- Permitir associatividade gerenciável;

- Reduzir recriação de geometria, onde os projetos de produtos, máquinas,

- Ferramentas e outras entidades são baseadas em modelagem de sólidos;

- Eliminar desenhos em papel (o que implica não apenas no uso de ferramentas de CAD/CAM, mas também o controle de versões e a manutenção da documentação);

- Permitir trabalho em paralelo/simultâneo;

- Prover integração entre ferramentas de software de ERP (Enterprise Resource Planning);

- Acesso de fornecedores usando a WEB;

- Uso de modelos em fase de desenvolvimento (trabalho em processo);

- Fluxo de trabalho integrado com sistema de gerenciamento de projeto.

\subsubsection{Benefícios com a Aplicação da MV}

Com relação ao desenvolvimento de produto, a Manufatura Virtual realizará o processo de desenvolvimento integrado do produto e do processo, desde que as informações da manufatura sejam passadas às fases iniciais do desenvolvimento (LIN et al, 1995). Em outras palavras, ela proporcionará a introdução de um nível novo, muito mais preciso e verificável se as informações de manufatura estiverem disponíveis nas fases iniciais do processo de desenvolvimento, permitindo o desenvolvimento integrado do produto e do processo.

Ela permite a expansão do "espaço de soluções" disponíveis na fase de projeto porque torna possível a verificação rápida de projetos que incorporam potencialmente os princípios da solução (refere-se a uma abordagem básica para resolver um problema de projeto). 
O objetivo é expandir o espaço, capacitando os projetistas para a avaliação mais efetiva dos custos de diversos projetos via simulação de alternativas e a criação de protótipos "soft" pela manufatura no computador.

Dessa forma, melhorias na transição da etapa de projeto do produto para a sua produção são esperadas com o uso da MV devido à disponibilidade maior das informações sobre os custos de manufatura e sobre a capacidade do processo que guiam o engenheiro do produto e que podem influenciar as decisões chave de projeto e de gerenciamento, tão bem quanto a habilidade de fazer mais interações de projeto antes de construir o produto fisicamente.

A Manufatura Virtual poderá proporcionar também a inclusão do cliente e de seus requisitos no processo de desenvolvimento integrado e, assim, uma melhor resposta às perguntas do tipo "what if ("o que aconteceria se") dos clientes sobre mudanças nos prazos de entrega e orçamentos (LAWRENCE ASSOCIATES INC, 1994). Além disso, acelerará a integração funcional dentro das companhias promovendo o compartilhamento de informações e melhorando o relacionamento de trabalho interfuncional dentro do processo de desenvolvimento integrado.

Em resumo, o papel da Manufatura Virtual no projeto será tornar todas as informações necessárias ao desenvolvimento do produto, incluindo processo de manufatura, fabricação, montagem e informações de suporte associadas, integradas com o processo de desenvolvimento, o que significa que sua implantação poderá proporcionar não apenas uma maneira das informações das questões importantes para o desenvolvimento estarem disponíveis ao engenheiro de projeto mas também fornece um mecanismo de ligação viável e verificável dos custos do produto final ou componentes com certas características e 
tolerâncias específicas do projeto antes de ir para a produção (LAWRENCE ASSOCIATES INC, 1994).

O fluxo de informações gerado através da MV pode influenciar os parâmetros de projeto. Os parâmetros de projeto, por sua vez, podem influenciar os requisitos da capacidade do processo e, em um cenário de Manufatura Virtual, essa informação poderia ser entregue muito mais rapidamente e com maior precisão (ou seja, menor incerteza) e muito mais completa do que hoje é possível.

Outros benefícios estarão relacionados à melhora da qualidade, flexibilidade da fábrica, menor ciclo de produção, melhor relacionamento e responsabilidade com os clientes.

O uso de ferramentas computacionais aplicados à manufatura virtual no início do processo de desenvolvimento do produto é a chave para se obter o retorno de investimento desta tecnologia.

As empresas que utilizarem a Manufatura Virtual serão capazes de alcançar importantes benefícios tais como diminuir drasticamente o time to market, reduzir os custos de prototipagem e de engenharia de pré-produção e além de tudo estarão aptas a experimentar mais variações antes de efetuar a manufatura real do produto.

Existem diversas técnicas e ferramentas aplicadas à Manufatura Virtual. A seguir é descrito a simulação.

\subsubsection{Simulação}

Com um modelo "virtual" é possível testar soluções, prever imprevistos, desempenho e obter respostas sobre o sistema sem a necessidade de operá-lo na prática. A simulação compreende 
a modelagem de um processo ou sistema de tal maneira que o modelo imita a resposta do sistema real a eventos que ocorrem ao longo do tempo.

A simulação pode ser definida como o processo de construção de um modelo que representa o sistema real, e da condução de experimentos com este modelo com o propósito de entender o comportamento do sistema e/ou avaliar várias estratégias para a operação do sistema. A modelagem em simulação, portanto, pode ser considerada uma metodologia experimental e aplicada que busca:

- Descrever o comportamento do sistema;

- Construir teorias ou hipóteses que explicam o comportamento observado, e

- Usar o modelo para predizer comportamento futuro, ou seja, os efeitos produzidos por mudanças no sistema ou em seu modo de operação.

Com os avanços na área de informática, modernos equipamentos e novas linguagens de programação e de simulação têm permitido empregar a técnica de simulação nas diversas áreas do conhecimento humano, fatos que têm propiciado:

- Projetar e analisar sistemas industriais;

- Avaliar desempenho de armas e estratégias militares;

- Determinar freqüência de pedidos de compra para recomposição de estoques;

- Projetar e administrar sistemas de transportes como: portos e aeroportos;

- Configurar e aliar desempenho de hardware e software em sistemas de computação;

- Analisar sistemas de atendimento em hospitais, supermercados e bancos.

Atualmente o mundo está rodeado por informações. De acordo com Porto e Palma (2000) a utilização e manipulações das informações têm proporcionado muitos avanços, mas 
muitos desses poderiam ser maximizados por meio da inclusão da tecnologia de simulação existente.

A seguir, são mostradas algumas das vantagens que a aplicação da simulação contribui para a manufatura (PORTO; PALMA, 2000):

- Novas políticas, procedimentos operacionais, regras de projetos, fluxo de informação, procedimentos organizacionais podem ser explorados sem perturbar a continuidade das operações do sistema real;

- Hipóteses de "como" e "por que" certos fenômenos ocorrem podem ser testadas para verificar a viabilidade;

- Tempo pode ser comprimido ou expandido permitindo o aumento ou a redução da velocidade do fenômeno da investigação.

- Estudo da simulação pode ajudar o entendimento de como o sistema opera em vez de como os indivíduos pensam que o sistema opera.

As desvantagens são em relação ao custo versus benefício, sendo que às vezes, as dificuldades e os gastos para implementação da simulação superam os resultados obtidos. Hoje, o que era considerado tendência vem se concretizando, e as relações das desvantagens estão sendo superadas pelas novas tecnologias e a ampliação dos conhecimentos dos seres humanos nas áreas de simulação.

Existem no mercado centenas de softwares e sistemas de simulação que variam consideravelmente em muitos aspectos - custo, funcionalidade, flexibilidade, facilidade de uso, plataforma. Nas aplicações de simulação na MV busca-se a integração de dados e sistemas, padronização de ferramentas e programas. 
O uso de ferramentas de simulação de manufatura, no início do processo de desenvolvimento do produto, é o principal objetivo para se obter o retorno de investimento dessa tecnologia.

\subsection{Importância da Simulação}

É quase certo que, em futuro próximo todas as organizações de produção estarão sujeitas a exigências muito mais intensas, não apenas para adotar mudanças cada vez mais importantes e freqüentes, mas ainda para prever e propô-las. Tanto as mudanças provocadas externamente por imposição do mercado, como aquelas derivadas de propostas espontâneas para geração de produtos e serviços novos, exigirão estudos para sua viabilização. Estas inovações sucessivamente demandarão maior intensidade de mudanças, promovidas pela característica exponencial da globalização, e por esta razão, seus impactos sobre as funções básicas da organização terão idêntica característica, exigindo por sua vez, ferramentas de análise mais aprimoradas. E, quando se trata de projetar atividades em áreas ou com tecnologia ainda não dominadas, a simulação torna-se indispensável.

As mudanças exigidas para manter a competitividade são necessidades de um mercado mais personalizado, porém sem sacrifício de outros requisitos considerados garantidos pelos consumidores, como qualidade e respeito ao ambiente.

Neste cenário, a simulação terá papel muito mais significativo que hoje, por ser uma ferramenta ideal para testar propostas de alterações em produtos, métodos e processos, permitindo avaliar em ambiente virtual, quais as alternativas mais promissoras, além de gerar hipóteses e testar suas viabilidades. 
Com maior difusão de sua aplicação, a técnica vai tornar-se mais amigável e flexível, e assim despontar como uma tecnologia indispensável para a sobrevivência das organizações, dentro de médio ou mesmo curto prazo.

Dentro da provável forma futura da organização, com reduzida estrutura hierárquica e intenso intercâmbio com fornecedores e clientes, a vantagem competitiva ficará concentrada no corpo diretivo, porque as operações serão mais flexíveis e conduzidas diretamente pelos operários do conhecimento.

Dentro da perspectiva de melhoria continua, a simulação pode sanar as seguintes dificuldades encontradas, atualmente, pelas empresas com relação a utilização de ferramentas de apoio à qualidade:

- Complexidade do sistema sob estudo - o cenário atual dos negócios tornou-se altamente complexo com a contínua mudança com que as organizações devem lidar. Mesmo a metodologia Seis Sigma pode falhar quando se torna impossível analisar estatisticamente o sistema ou fornecer alternativas estatísticas ao sistema existente. Isto tem levado equipes de projeto a fornecer alternativas ad hoc como soluções.

- Sensibilidade ou robustez requerida - os métodos atuais de análise fornecem uma solução ao problema, mas por outro lado uma pequena mudança na entrada ou na decisão do negócio requer, muitas vezes, que a equipe de projeto "reinvente a roda" iniciando um novo projeto para resolver "novo problema".

- Verificação da solução analítica - não existe modelo pedagógico para reforçar ou garantir a eficácia da solução chegada. A maioria das metodologias de qualidade inclui a execução e medição da solução fornecida para determinar se o nível requerido de qualidade (ou nível Sigma) foi alcançado e então controlar o sistema para permanecer nesse nível. Se o projeto não se encontrar conforme as expectativas, necessitará ser reiniciado ou revisto. Isto é 
altamente custoso à organização que deve mudar os processos ou a força de trabalho ou mesmo fazer as decisões de negócio baseadas na análise do projeto. O custo está incorrido também quando a experimentação real (projeto das experiências) é feita no chão-defábrica.

- Inabilidade ao analisar um sistema estocástico - quando o resultado de uma atividade puder ser descrito completamente nos termos da entrada, a atividade é determinística. Quando os efeitos da atividade variam aleatoriamente além dos vários resultados possíveis, não obstante a complexidade do sistema, a atividade é estocástica. Muitos sistemas usados atualmente na indústria são estocásticos e não podem ser facilmente modelados ou estudados nas metodologias atuais da qualidade. As soluções fornecidas a tais sistemas são ad hoc e nunca satisfatórias. Modelo estatístico é necessário para estudar tais sistemas.

- Inabilidade para visualizar o sistema - ao estudar um sistema em relação aos gargalos, a redução do lead-time e mudanças do processo podem se tornar de difícil visualização. $\mathrm{O}$ time então foca num modelo estático que evidencie os gargalos e verificam alguns números tais como tempo de manipulação médio (tempo médio) ou o desvio padrão os quais podem ser enganadores. Mesmo as mudanças de sistema precisam ser visualizadas.

Além disso, o emprego de técnicas de simulação na análise do processo estudado tem as seguintes vantagens:

- Disponibilidade de dados - a simulação requer uma grande quantidade de dados. No passado, os dados geralmente não estavam disponíveis e tinham que ser coletados, o que era uma atividade árdua e despendia muito tempo. Agora, o uso de softwares de planejamento de recursos da empresa (ERP - Enterprise Resource Planning) e programas de gerenciamento do relacionamento com o cliente fornecem um grande volume de dados. Esses dados podem ser usados como a entrada para a simulação. 
- Custo de modelagem - no passado, as companhias desenvolviam seu próprio software de simulação para suplementar sua análise. Esse software era caro de se obter. Atualmente, muitos softwares de simulação encontram-se disponíveis no mercado, sendo mais baratos, mais fáceis de se usar e podendo ser aplicados em cenários diferentes do negócio. Os pacotes de software fornecem também representações gráficas do modelo como é o caso do WITNESS o qual é um dos softwares de modelagem e simulação utilizados na indústria automobilística objeto do nosso estudo de caso.

- Conhecimento de probabilidade e estatística - a simulação requer o uso de probabilidade e estatística e isto era um problema no passado, pois os que utilizavam o sistema ficavam relutantes em lidar com probabilidade e estatística. Os pacotes de software de simulação atuais contêm analisadores e muitas outras ferramentas da qualidade, portanto, não exigindo profundo conhecimento estatístico.

- Executando a simulação - Graças à velocidade dos atuais processadores, a simulação pode ser executada rapidamente e até mesmo vagarosamente para ajudar a equipe de projeto.

\subsection{Softwares Utilizados em Simulações}

A seguir são descritos os principais softwares de simulação para eventos discretos disponíveis no mercado e utilizados pela indústria, particularmente a indústria automotiva: 
Tabela 2.6 - Softwares de Simulação para Eventos Discretos.

\begin{tabular}{|c|c|}
\hline RobCAD (Tecnomatix - Israel) & $\begin{array}{l}\text { ROBCAD é um conjunto de ferram entas de } \\
\text { Engenharia de Produção Auxiliada por } \\
\text { Computador (CAPE) para desenvolvim ento, } \\
\text { simulação, otimização e program ação de } \\
\text { sistemas de manufatura automatizadas e } \\
\text { manuais. Provê melhor qualidade, reduz tempo } \\
\text { total do diclo de m anufatura, previne erros em } \\
\text { projetos e assegura que os sistem as de } \\
\text { mamufatura virtual que você tem no monitor } \\
\text { do computador é o que você irá obter no chão } \\
\text { de fábrica. }\end{array}$ \\
\hline AutoMod (AutoSimulations - E.U.A.) & $\begin{array}{l}\text { AutoMod é uma ferram enta de simulação } 3 \mathrm{D} \\
\text { que permite modelar questões de manuseio } \\
\text { complex o de material e manufatura. Provê } \\
\text { animações em escal a real } 3 \mathrm{D} \text { enquanto o } \\
\text { modelo está sendo ex ecutado. Através do } \\
\text { modelo de simulação, pode-se avaliar e testar } \\
\text { alternativas de projeto antes de sua } \\
\text { implem entação, evitando investim entos } \\
\text { desnecessários nas empresas. }\end{array}$ \\
\hline ProModel (ProModel Corp. - E.U.A.) & $\begin{array}{l}\text { Permite melhorar os processos de manufatura. } \\
\text { Principais caracteristicas incluem anim ação } \\
\text { total, projeto e layout de fábrica. }\end{array}$ \\
\hline Arena (Systems Modeling Corp) & $\begin{array}{l}\text { Integra as funções necessárias para uma } \\
\text { simulação (anim ação, análise de dados de } \\
\text { entrada e saida, e verifícação do m odelo) em } \\
\text { um ambiente compreensivo. }\end{array}$ \\
\hline Witness (Lawer Group Ltd -Inglaterra) & $\begin{array}{l}\dot{E} \text { um pacote de simulação visual interativo } \\
\text { que permite rodar, testar e alterar os modelos } \\
\text { de simulação sem reex ecutá-1o ou reinicia-lo. }\end{array}$ \\
\hline
\end{tabular}

\subsubsection{3. Áreas de Aplicação da Simulação}

Existem inúmeras áreas de aplicação da simulação. A seguir, estão listadas algumas das mais importantes:

- Simulação das operações de uma companhia aérea para testar alterações em seus procedimentos operacionais; 
- Simulação da passagem do tráfego em um cruzamento muito grande, onde novos sinais estão para ser instalados;

- Simulação de operações de manutenção para determinar o tamanho ótimo de equipes de reparo;

- Simulação do fluxo de partículas não carregadas através de um campo radioativo para determinar a intensidade de radiação que penetra o campo;

- Simulação de uma siderúrgica para avaliar alterações nos seus procedimentos operacionais;

- Simulação da economia de um setor de um país para prever o efeito de mudanças econômicas;

- Simulação de batalhas militares visando avaliar o desempenho de armas estratégicas;

- Simulação de sistemas de distribuição e controle de estoque, para melhorar o funcionamento destes sistemas;

- Simulação de uma empresa como um todo para avaliar o impacto de grandes mudanças ou como treinamento para seus executivos (Business Games);

- Simulação de sistemas de comunicações para determinar o que é necessário para fornecer um determinado nível de serviço;

- Simulação de uma barragem em um determinado rio para avaliar os problemas advindos com a sua construção;

- Simulação de uma linha de produção em determinada indústria, para avaliar efeitos de mudanças previstas no processo produtivo. 


\subsection{Aplicações dentro da Indústria Automotiva de Simulacão a Eventos Discretos}

A simulação da manufatura pode ser usada dentro da indústria automotiva como uma técnica de análise para prever o efeito de modificações em um sistema existente ou como uma técnica de apoio ao projeto, para avaliar o desempenho de um novo sistema sob uma ampla variedade de circunstâncias. O comportamento de um sistema, durante sua evolução ao longo do tempo, pode ser estudado por meio do desenvolvimento de um modelo, o qual toma a forma de um conjunto de considerações relacionadas à operação do sistema. Uma vez desenvolvido e validado, o modelo pode ser usado para investigar uma grande variedade de perguntas do tipo "e se" sobre o sistema real.

Áreas de notáveis aplicações da simulação no campo da manufatura automotiva incluem a simulação do arranjo físico de fábrica, do fluxo de processo, dos sistemas de manuseio de material, do planejamento de capacidade, da utilização de mão-de-obra, do investimento em novos equipamentos, e da programação de produção. Outras aplicações estão relacionadas a logística, configuração de ferramentas e treinamento.

Tradicionalmente, a simulação tem sido pouco aplicada ao planejamento, projeto e análise de longo prazo de linhas de montagem de automóveis, porém sua utilização tem sido crescente como uma proeminente ferramenta de suporte à decisão, onde empresas do setor automobilístico podem fazer uso da simulação de eventos discretos para modelar sistemas de manufatura e em questões relativas ao layout de fábrica, fluxo de processo, sistemas de manuseio de material, planejamento de capacidade, utilização de mão-de-obra, investimento em novos equipamentos, programação da produção e logística. 
Durante o projeto a simulação é, muitas vezes, usada nas primeiras etapas para ajudar a compreender a forma de funcionamento do sistema. Pode também ser usada para validar e verificar a solução final, assegurando que o projeto da linha, quando implementado, irá alcançar os objetivos identificados.

Assim, um modelo de simulação pode ser utilizado para: assegurar que um sistema de manufatura validado se mantenha consistente com os seus requisitos ao longo de prolongados períodos de tempo; dar suporte às mudanças para a realização de melhorias contínuas; auxiliar na solução do planejamento e programação do sistema; avaliar a utilização dos recursos humanos necessários; auxiliar o treinamento e educação do pessoal envolvido na operação do novo sistema. Alguns parâmetros de projeto podem ser facilmente analisados através da simulação, tais como:

- O número de estações paralelas e seus tempos de ciclo.

- Modos de operação "off-line" e "in-line".

- Confiabilidade de máquinas e outros equipamentos.

- Velocidade dos transportadores.

- Tempo de reparo dos pallets rejeitados.

- Arranjo de estações paralelas otimizando o uso do espaço.

Uma das capacidades mais exigidas pelo mercado automotivo é a agilidade de uma organização em responder às modificações de necessidades deste mercado. Para isso, a organização deve desenvolver estruturas de decisão que permitam o rápido planejamento e replanejamento da produção. Neste aspecto, o estudo apresentado mostra-se muito útil para ser incorporado a essas estruturas de decisão. 


\subsection{Manufatura Virtual, Processo de Melhoria Contínua e Seis Sigma}

Como vimos neste capítulo, os processos modernos de modelagem, design e controle da manufatura estão intimamente relacionados com os processos da Manufatura Virtual, onde a simulação ocupa um papel de destaque. Por outro lado, a demanda cada vez mais crescente por processos de melhoria contínua, capazes de aliviar a pressão sobre a fase de design e do planejamento da produção aponta para ciclos de melhoria que sigam os modelos da manufatura virtual.

Portanto, não é possível ter processos baseados em Seis Sigma que perseguem a melhoria contínua, mas que não levam em conta a preservação da documentação, ou onde a fase inicial do DMAIC não contemple uma fase de familiarização do processo (antes e depois da definição da equipe) onde a simulação tem um papel de destaque.

\subsubsection{Melhoria Contínua na Indústria Automotiva}

Retomando, portanto, a discussão sobre a manufatura moderna, que se caracteriza pela costumização maciça (Pine II, 1994) que impõe o desafio de contínua melhoria de qualidade com outro desafio de atendimento fiel aos requisitos e mesmo a requisitos emergentes e diversificados por parte do cliente final. $\mathrm{Na}$ indústria automotiva isto se reflete especialmente nos acessórios, adaptações de câmbio, eletrônica embarcada e, em alguns casos, em adaptações mais profundas para veículos especiais (corpo de bombeiros, ambulâncias, etc.).

Uma estratégia de produção bastante difundida se insere no escopo da prototipagem rápida, que implica em reduzir o tempo de colocação do produto no mercado, mas inserindo 
um processo de melhoria contínua como fator de melhoria de qualidade e como um trunfo para enfrentar a concorrência. Neste caso se busca não apenas uma melhoria direta, que vá ao encontro da expectativa do cliente final, mas também melhorias no próprio processo de fabricação, em fatores como eficiência, redução de despedícios, utilização racional de recursos, redução de falhas, redução do tempo de recuperação de falhas, redução de riscos.

Nota-se, portanto, que se trata de um processo que integra o design do processo com sua manutenção e revisão, reduzindo o tempo do ciclo de melhoria, mas aumentando por outro lado o número de repetições deste mesmo ciclo por meio de uma comunicação robusta e sistêmica. Evidentemente, se trata de uma versão industrial aplicada das técnicas de design dirigidas para a manufatura. Portanto, o controle do ciclo de melhoria é uma questão vital para atingir um nível de eficiência aceitável, e para o sucesso comercial.

É bastante curioso que o principal instrumento deste "controle" do ciclo não apareça com força e em toda sua plenitude: a documentação do processo, incluindo aí desde o modelo original, o controle de todas as versões originadas dele, seus rationales e sua avaliação de eficiência, qualidade, uso de recursos, quantidade de falhas etc. De fato esta documentação seria o fator agregador e integrador entre as equipes de design e de produção.

A seguir será apresentadoa proposta de como ter um ciclo controlado dentro do método Seis Sigma, baseado na documentação, e em processos de gestão deste ciclo reduzido de projeto. A sistematização deste ciclo é feita utilizando as técnicas de modelagem e simulação baseada em redes de Petri, por escolha do autor (outras representações podem ser utilizadas, de acordo com a cultura da empresa). Naturalmente este mesmo processo pode funcionar com outras técnicas como, por exemplo, as Redes de Fila, usadas mundialmente pela empresa do nosso estudo de caso. Assim, apesar de fazer uso de uma técnica específica de modelagem e simulação, a proposta não depende da escolha do formalismo e pode ser perfeitamente aplicada com qualquer outro formalismo igualmente disciplinador e 
consistente. A contribuição maior deste trabalho está, no entanto, ligada à própria proposta do ciclo controlado, associado ao processo de melhoria contínua, onde este processo característico de chão de fábrica está em plena consonância com as tendências modernas, especialmente da manufatura virtual. 


\section{Proposta de Utilização de Ferramentas de Modelagem e Simulação em Projetos de Manufatura e no Ciclo de Melhoria Contínua}

O método proposto é iniciado analisando criticamente o fluxograma da metodologia de simulação apresentada por Andrade (1989) e que pode ser visto na Figura 3.1. Esse fluxograma foi desenvolvido de uma forma macro e básica, contendo os passos para a validação e simulação de qualquer modelo que se deseja propor.

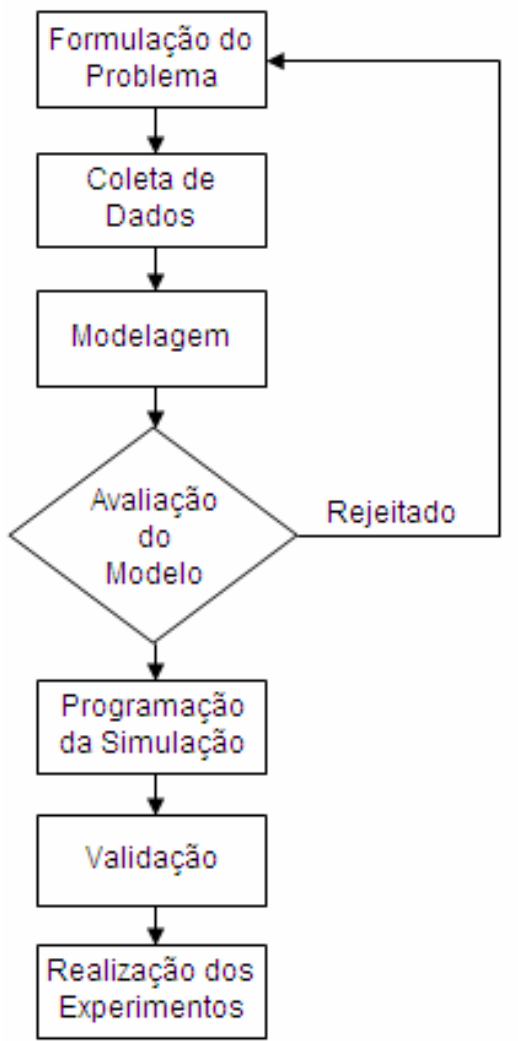

Figura 3.1 - Fluxograma da metodologia de simulação. Fonte: Andrade (1989) 
A Figura 3.2 mostra um fluxograma desenvolvido pelo autor e adaptado do fluxograma de Andrade (1989). Esta adaptação se aplica somente a fase de design do processo. No contexto da validação do modelo por meio da simulação, foi integrada à etapa de "Avaliação do Modelo" todas as etapas subseqüentes a mesma no fluxograma proposto por Andrade (1989), ou seja, a programação da simulação, sua validação e a realização de experimentos, chamando esta etapa de "Avaliação do Modelo e Simulação". Além disso, se o modelo for rejeitado, deve-se reavaliar os dados (benchmarking, requisitos, documentação e experiência), reavaliar o modelo e também o DFMEA (Design Failure Mode and Effect Analysis) desenvolvido durante a validação. O DFMEA é acrescentado no fluxograma da Figura 3.2 como ferramenta de suporte à análise dos modos de falhas e seus efeitos para validação do modelo e também é acrescentado à etapa de documentação de todo o processo modelado o que deve ser feito logo após a validação.

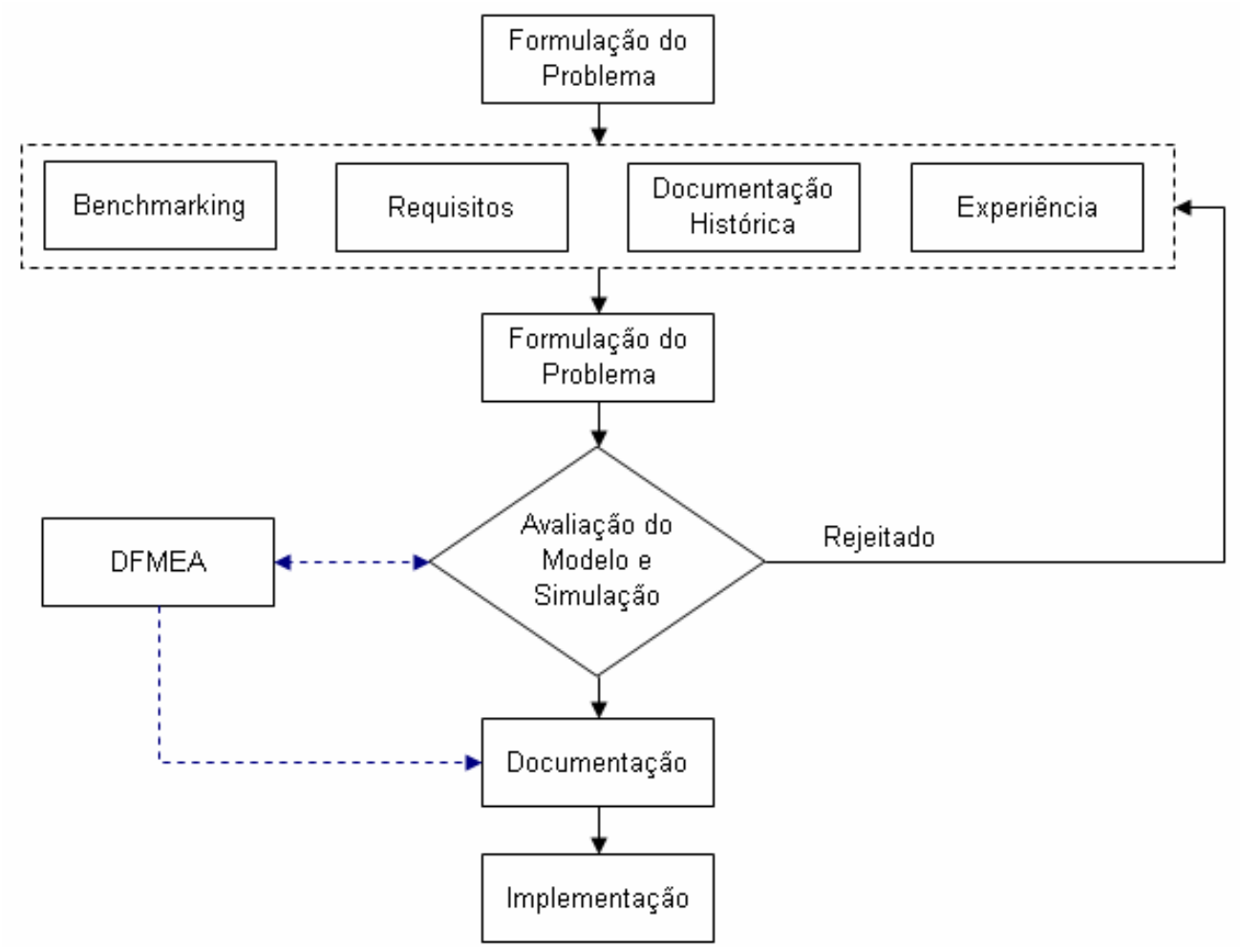

Figura 3.2 - Proposta de fluxograma da metodologia de simulação. Fonte: Autor 
Pelo fluxograma proposto na Figura 3.2, após a formulação do problema, os dados a serem considerados serão os dados de benchmarking, os requisitos do projeto, a documentação histórica e a experiência dos especialistas. A seguir é mostrada a importância de cada um desses fatores que fornecem informações para o correto desenvolvimento do modelo.

a) Benchmarking: é um processo sistemático e contínuo de avaliação dos produtos, serviços e processos de trabalho de organizações que são reconhecidas como representantes das melhores práticas, com a finalidade de introduzir melhorias na organização. É um processo gerencial permanente, que requer atualização constante da coleta e análise cuidadosa daquilo que há de melhor externamente em práticas e desempenho para as funções de tomada de decisões e de comunicações em todos os níveis da empresa. Um processo que obriga ao teste constante das ações internas em relação aos padrões externos das práticas da indústria. Se aplica integralmente para o desenvolvimento do modelo e simulação, visto que "copiar" modelos de empresas que possuem a "melhor prática" significa reduzir tempo e trabalho. Por definição as "cópias" nunca serão iguais. Haverá sempre ajustes, adaptação e aprimoramentos, o que garante a melhoria da idéia original. No caso das automobilísticas, por existir diversas plantas ao redor do mundo, uma técnica muito utilizada é o próprio benchmarking interno. Tem como vantagens a facilidade para se obter parcerias, custos mais baixos e a valorização pessoal interna. A grande desvantagem é que as práticas estarão sempre impregnadas com os mesmos paradigmas.

b) Requisitos: Antes de dar início ao modelo, todos os requisitos dos projetos devem ser levantados, sejam eles funcionais (o que o processo precisa fazer) ou não-funcionais (as qualidades que o processo precisa possuir), estudando todas as características que o sistema deverá ter para atender às necessidades e expectativas do cliente. Tal estudo deve 
produzir um documento de requisitos e determinar o ciclo de manutenção dessa documentação.

c) Documentação histórica: Conforme mencionado anteriormente, a documentação do processo deveria incluir o modelo original do processo, o controle de todas as versões originadas dele, seus rationales e sua avaliação de eficiência, qualidade, uso de recursos, quantidade de falhas. Essa documentação é de suma importância para o desenvolvimento de um modelo que, se não isento de falhas, ao menos é um modelo robusto baseado no histórico da Empresa e elaborado de forma a não repetir as mesmas falhas de outrora. Infelizmente, muitas empresas ainda falham na atualização das documentações dos seus processos e conseqüentemente na geração de um conhecimento mais profundo dos seus processos.

d) Experiência: A experiência dos especialistas de processo no desenvolvimento de novos processos ou mesmo na modificação e adequação dos mesmos é um fator relevante e agregador quando tal experiência é praticada de forma sistêmica, ou seja, empregada nos itens a), b) e c) citados anteriormente. Empregar informações dos especialistas sem utizar dados, informações e documentação, pode levar a falhas graves no projeto.

A simulação é utilizada na validação desse modelo, obtendo dados para a melhoria no sentido de se aproximar mais do atendimento aos requisitos, mas é evidente que a mesma deve ser usada também para melhor conhecimento do próprio sistema, sendo uma poderosa ferramenta no processo de melhoria contínua.

Sob o ponto de vista de melhoria contínua num processo já implementado, é proposto neste trabalho o fluxograma da Figura 3.3: 


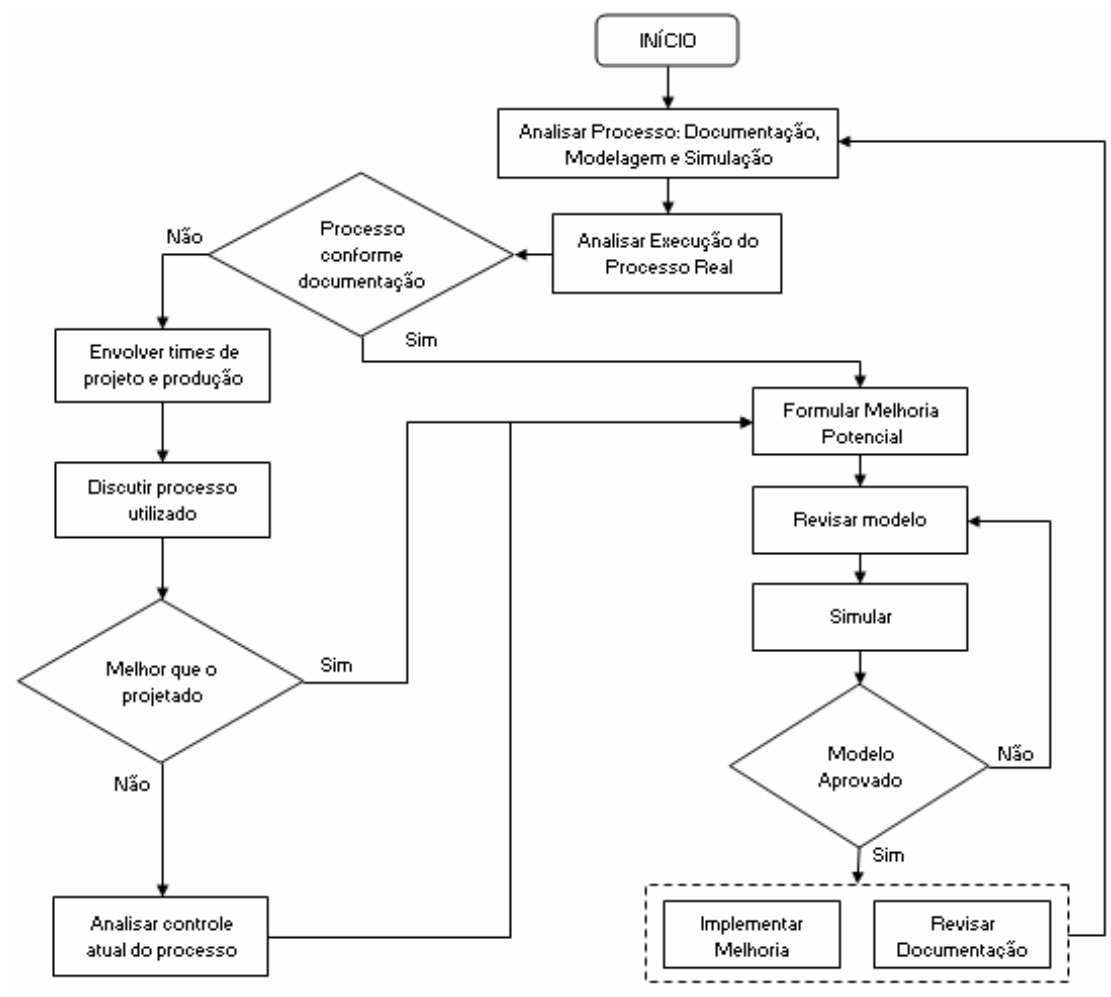

Figura 3.3 - Proposta de Melhoria Continua por meio da utilização de Modelagem e Simulação com foco na atualização das documentações. Fonte: Autor.

O fluxograma da Figura 3.3 mostra um ciclo de melhoria contínua por meio da utilização de técnicas de modelagem e simulação, focando também na atualização da documentação do processo. Deve-se ter documentado, em sua totalidade, o processo de fabricação, seus subprocessos, incluindo tempos e fluxos de produção, tempo de espera, estocagem, manuseio de material, movimentação e retrabalho, despacho para o processo seguinte etc. Parte-se do pressuposto de que o processo esteja completamente e corretamente modelado e com isto, os engenheiros podem simulá-lo de forma a adquirir um conhecimento mais profundo das suas propriedades se antecipando a falhas potenciais ou propondo melhorias que adequem o processo a um novo contexto vigente. A ferramenta de modelagem e simulação mais do que representar um recurso que permita análise dos processos sem impacto nos volumes produtivos, fornece aos engenheiros a possibilidade do aprendizado e 
melhoria contínua, bem como aumento do foco nos processos e resultados, ambos valores de comportamento enxuto (lean behavior) apreciados pelo mercado.

O passo seguinte, "Analisar Execução do Processo Real”, ratifica a importância de se caminhar pelo chão-de-fábrica analisando como os processos estão sendo realizados na prática tendo-se como referência a documentação de projeto. É evidente que pode haver discrepâncias entre o que foi projetado e o que está sendo executado, mas tais divergências devem estar justificadas nas revisões das documentações e do próprio modelo ou, se for simplesmente uma falha de disciplina por parte da operação, que haja um plano concreto de correção. Então, a pergunta que deve ser respondida após a análise de como o processo está sendo executado é: “Processo conforme Documentação?”. Neste ponto o fluxograma dividese basicamente em duas partes conforme descrito a seguir:

\section{Processo não está conforme documentação:}

Neste caso, deve-se:

a) “Envolver times de projeto e produção" e "Discutir processo utilizado".

Os times de manufatura e projeto devem trabalhar juntos no entendimento e correção dessa questão. Neste ponto não está em discussão se a falha é de disciplina da operação ou se o próprio projeto, por algum motivo, não mais é exequível (devido, por exemplo, a obsolescência de equipamentos, mudança dos requisitos frente aos novos desafios do mercado etc), mas sim a importância de haver um alinhamento claro entre projeto e manufatura e conseqüente aprendizado dessa integração. A discussão entre esses dois times é importante sob todos os aspectos, permitindo decisões rápidas, acertivas e o mais fundamental: documentação revisada gerando conhecimento, conforme será visto nos próximos passos. Os times devem questionar a eficácia do processo sob análise e concluir se a documentação deve 
ser revisada ou o processo ou até mesmo os dois, pois na prática é possível que os times decidam por um processo que seja diferente tanto do projetado quanto daquele que está sendo executado. Caso o processo em questão não seja melhor que o projetado deve-se "Analisar controle atual do processo" visto que evidentemente há uma falha de controle que permite discrepâncias entre o que deveria ser o processo e o que realmente é. Em qualquer dessas circunstâncias, notar que o passo seguinte é "Formular Melhoria Potencial".

\section{b) "Formular Melhoria Potencial".}

A formulação da melhoria potencial segue enfoques diferentes para cada análise a seguir:

Adequar processo ao que foi projetado: se for necessário adequar o processo ao que foi projetado, precisa-se questionar, basicamente, o controle desse processo. O time poderá analisar e concluir se há problemas de disciplina, inadequação dos dispositivos zero defeito, degradação dos equipamentos, manutenção inadequada, falta de operações com recursos críticos redundantes, documentação mal elaborada etc. Por isto, deve-se ir além do fato de readequar o processo ao seu projeto, pois este também precisa ser melhorado em termos de controle.

Adequar documentação de projeto ao processo implementado: Além de checar os controles é fundamental a análise dos FMEA's ou de outras ferramentas de suporte a análise dos modos de falha elaborados na fase de projeto. Um projeto pode parecer bem planejado e realizável quando apresentado no papel, porém não funcionar como deveria no plano real. Erros no cálculo da demanda, displicência quanto às características de componentes em um equipamento ou inadequação do sistema de produção utilizado pela empresa ao produto, são exemplos freqüentes de falhas de projeto. 
Modificar documentação de projeto e o processo real: Neste caso, podem-se considerar as recomendações dos dois itens mencionados anteriormente.

c) "Revisar modelo".

Revisar o modelo, neste caso em redes de Petri, com as melhorias levantadas pelo time. Nesta fase deve-se estar atento ao correto desenvolvimento do modelo utilizando-se das técnicas já mencionadas no Capítulo 2.

d) "Simular".

Simular o processo modelado permitindo inferências sobre esse modelo. Caso o modelo seja reprovado, deve-se novamente revisar o modelo; caso aprovado, deve-se implementar as melhorias e garantir a adequada documentação do novo processo.

e) "Revisar Documentação" e "Implementar".

A revisão da documentação e implementação das melhorias podem ser executadas paralelamente. Esta é a etapa final do ciclo onde a documentação deve assumir papel de destaque. A revisão documental e seu controle são, sem dúvida, um dos alicerces do sistema de qualidade, pois, com ele, o cumprimento dos requisitos estabelecidos é evidenciado, a informação atualizada de como desenvolver cada atividade é de conhecimento dos funcionários e, além disso, os processos de trabalho da empresa contam com um ambiente propício para sua melhoria contínua. As empresas, na sua grande maioria, atualizam as documentações de processo como a folha de processo, instruções de trabalho, lições de ponto único etc, mas tais documentações são apenas no nível de chão-de-fábrica e perde-se o histórico e lições aprendidas (lessons learning) para a formação base do conhecimento de novos engenheiros. É ponto fundamental a existência de um único "pacote" de documentação por estação ou célula de trabalho onde toda a documentação do projeto inicial estará junto com suas revisões, planos de ação e motivo da revisão. Aliás, dentro da mentalidade Seis 
Sigma, a documentação das razões, ou seja, porque se escolheu um dado problema como o foco do processo Seis Sigma, se foi ocasionado por "falhas" ou pela antecipação destas, ou por requisitos emergentes vindos da pós-venda do produto, é uma informação de grande ajuda para os Black Belts. Além disso, permite que outras equipes possam analisar o produto/sistema. A proposta nesta dissertação é que a modelagem baseada em redes de Petri ou qualquer outra técnica de modelagem, seja parte integrante da documentação do processo, visto que alguns programas atuais, como por exemplo o WITNESS (baseado na Teoria de Filas), fornecem uma documentação completa dos processos nele modelados, conforme pode ser visto na Figura 3.4.

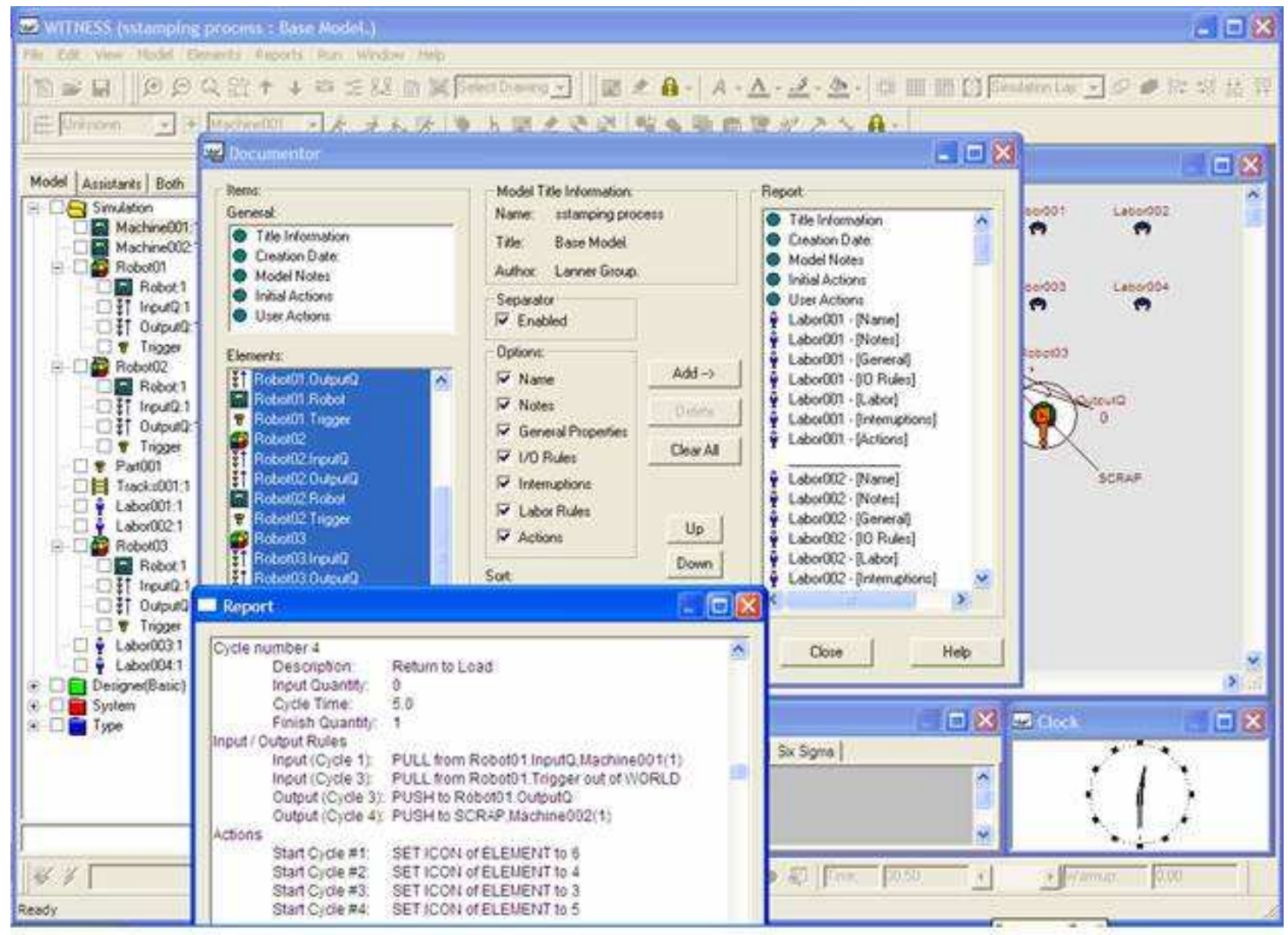

Figura 3.4 - Geração da documentação do processo por meio do programa WITNESS. 


\section{$2^{\circ}$. Processo conforme documentação:}

Mesmo no caso do processo estar conforme a documentação, deve-se dar seqüência ao ciclo de melhoria contínua ("Formular Melhoria Potencial") buscando-se soluções que ajudem a empresa a atingir suas metas e objetivos. A análise profunda do processo nas etapas anteriores irá identificar a causa de um mau desempenho para que, nesta etapa, sejam formuladas e desenvolvidas alternativas, viabilizando econômica e tecnicamente as decisões. A partir deste ponto, o fluxograma segue a mesma lógica da $1^{a}$ Etapa, itens c), d), e). Tem-se desta forma um processo robusto de melhoria contínua dos processos.

Nota-se, no fluxograma da Figura 3.3, a proposta da simulação utilizada para validar os modelos, obter dados para a melhoria - no sentido de se aproximar mais do atendimento aos requisitos - mas principalmente, para melhor conhecimento do sistema. A proposta desse fluxograma que mostra a integração entre um processo de melhoria contínua, neste caso o Seis Sigma, e técnicas de modelagem e simulação, é demonstrar que no processo de melhoria contínua a "falha" não é o único motivador de mudanças, sendo interessante sua antecipação e solução antes de provocar paradas de produção e acidentes. Neste ponto a simulação poderia entrar como um fator consistente e didático de conhecimento do processo e até de se antecipar problemas, tendo a vantagem de estar diretamente ligado à modelagem e design do processo ou a versão corrente deste.

A seguir, na Figura 3.5, tem-se uma adaptação do fluxograma da Figura 3.3 sob o enfoque do Seis Sigma. 


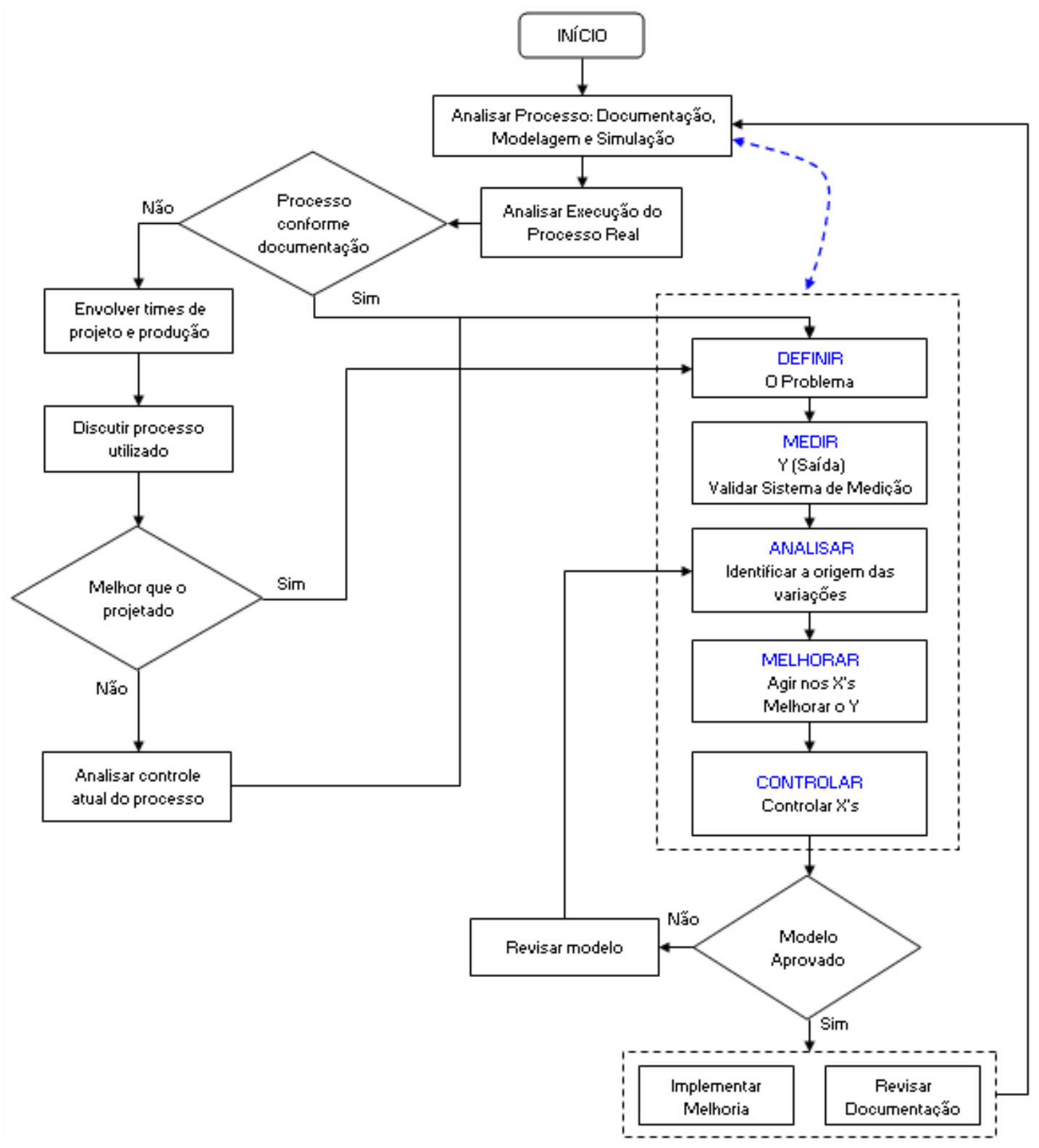

Figura 3.5 - Fluxograma do DMAIC atrelado ao ciclo de melhoria proposto. Fonte: Autor

O fluxograma da Figura 3.5 se divide, claramente, em quatro partes distintas, a saber:

\section{1) Análise constante do processo por meio da sua documentação, modelagem e} simulação (descrição conforme a do fluxograma da Figura 3.3):

A Figura 3.6 ilustra o modelo de uma linha de montagem em Redes de Petri e seu auxílio no conhecimento do processo e como base documental. 


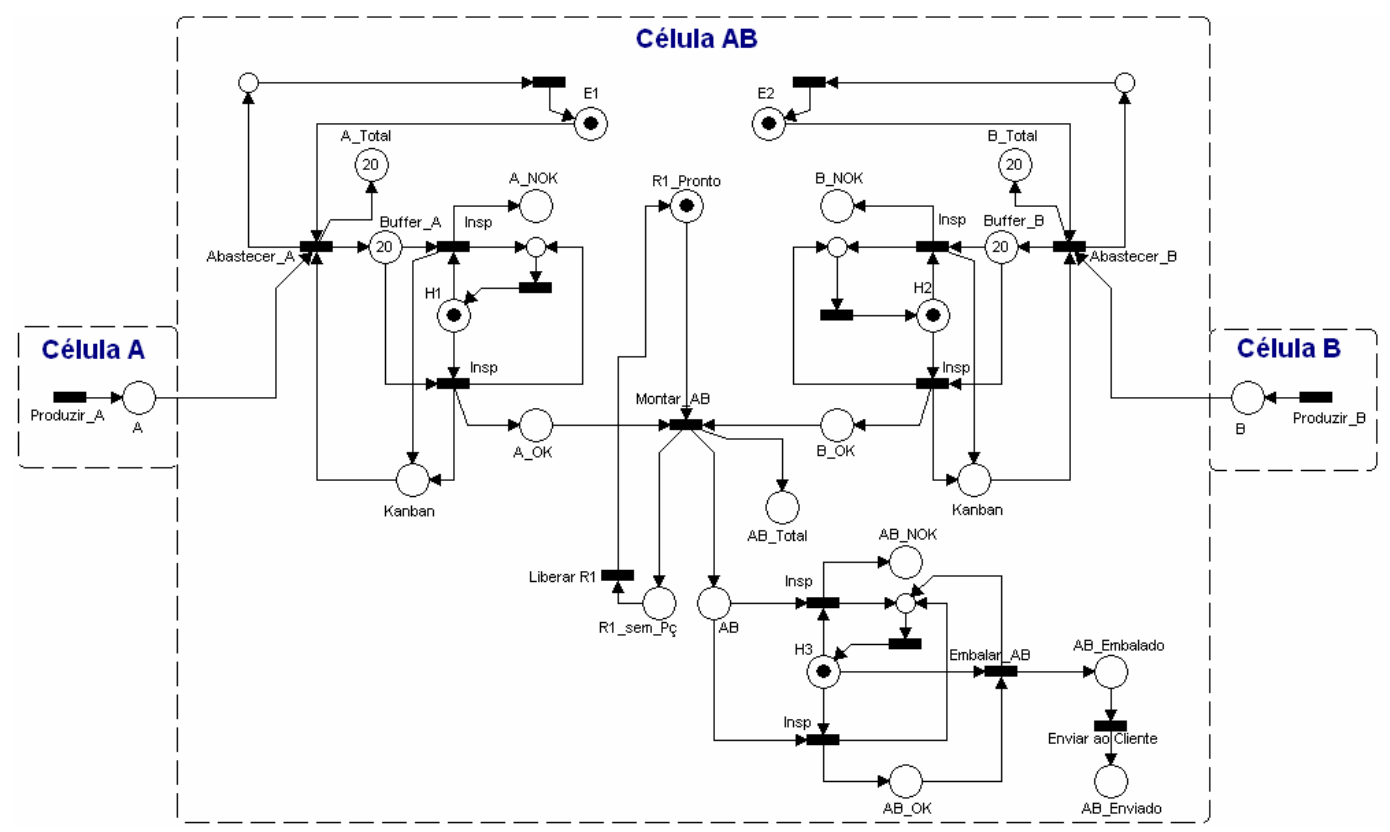

Figura 3.6 - Exemplo A - Projeto de uma linha de montagem modelada e simulada em Redes de Petri. Fonte: Autor.

Este modelo feito em Redes de Petri por meio do software de modelagem e simulação HPSim, mostra uma linha de produção que monta um produto $A B$ a partir das suas peças $A$ e B. O buffer de peças Buffer_A e Buffer_B é controlado por um sistema Kanban de chamada de peças obedecendo um máximo de 20 peças e mínimo de 5 peças. O reabastecimento de peças é feito pelas empilhadeiras $E 1$ e E2. Os operadores $H 1, H 2$ e $H 3$, são responsáveis pelas inspeções de qualidade das peças $A, B$ e $A B$, respectivamente, que ocorrem na célula $A B$ e, além disso, $H 1$ e $H 2$ disponibilizam peças aprovadas $A$ e $B$ para a montagem pelo robô R1_Pronto. Já o operador $H 3$ também tem o papel de embalar o produto final AB (AB_Embalado). $\mathrm{O}$ modelo possui os lugares $A \_T o t a l, B \_T o t a l$ e $A B \_T o t a l$ que indicam o total de peças $\mathrm{A}, \mathrm{B}$ e $\mathrm{AB}$ disponibilizadas para inspeção ao longo da produção, auxiliando no cálculo do nível de qualidade. Neste exemplo, consideraremos a Célula $\mathrm{AB}$ como o gargalo do processo produtivo, tendo o maior ciclo (tempo por peça) da linha de produção. Hipoteticamente, diremos que os processos das Células A e B, os quais não estão detalhados no modelo, rodam a 50\% da sua capacidade para manterem o mesmo ritmo da Célula $\mathrm{AB}$. 
Alguns programas de modelagem e simulação como o WITNESS, permitem a parametrização de todo o modelo construido, como por exemplo: a velocidade de operação do robô $R 1$ e dos operadores $\mathrm{H} 1, \mathrm{H} 2$ e H3 na execução de cada atividade, distância percorrida pelas empilhadeiras para reabastecimento e velocidade das mesmas, porcentagem de rejeição das peças, inventário máximo e mínimo, tempo médio de ciclo, tempo de produção, tempo de parada, takt time etc. Essas e outras informações disponíveis no modelo já formam, por si só, uma documentação robusta do design do processo que permitindo sua análise constante pelo time de engenharia e produção.

\section{2) Adequação do processo ao projeto ou vice-versa ou adequação de ambos:}

Retomando, portanto, ao exemplo da linha de produção do produto $\mathrm{AB}$ e supondo que os engenheiros de processo dessa empresa tenham verificado um aumento significativo dos custos de produção e por meio dos indicadores de qualidade, uma alta taxa de peças A e B não-conformes. Analisando o processo real verificaram o cenário da Figura 3.7, a seguir:

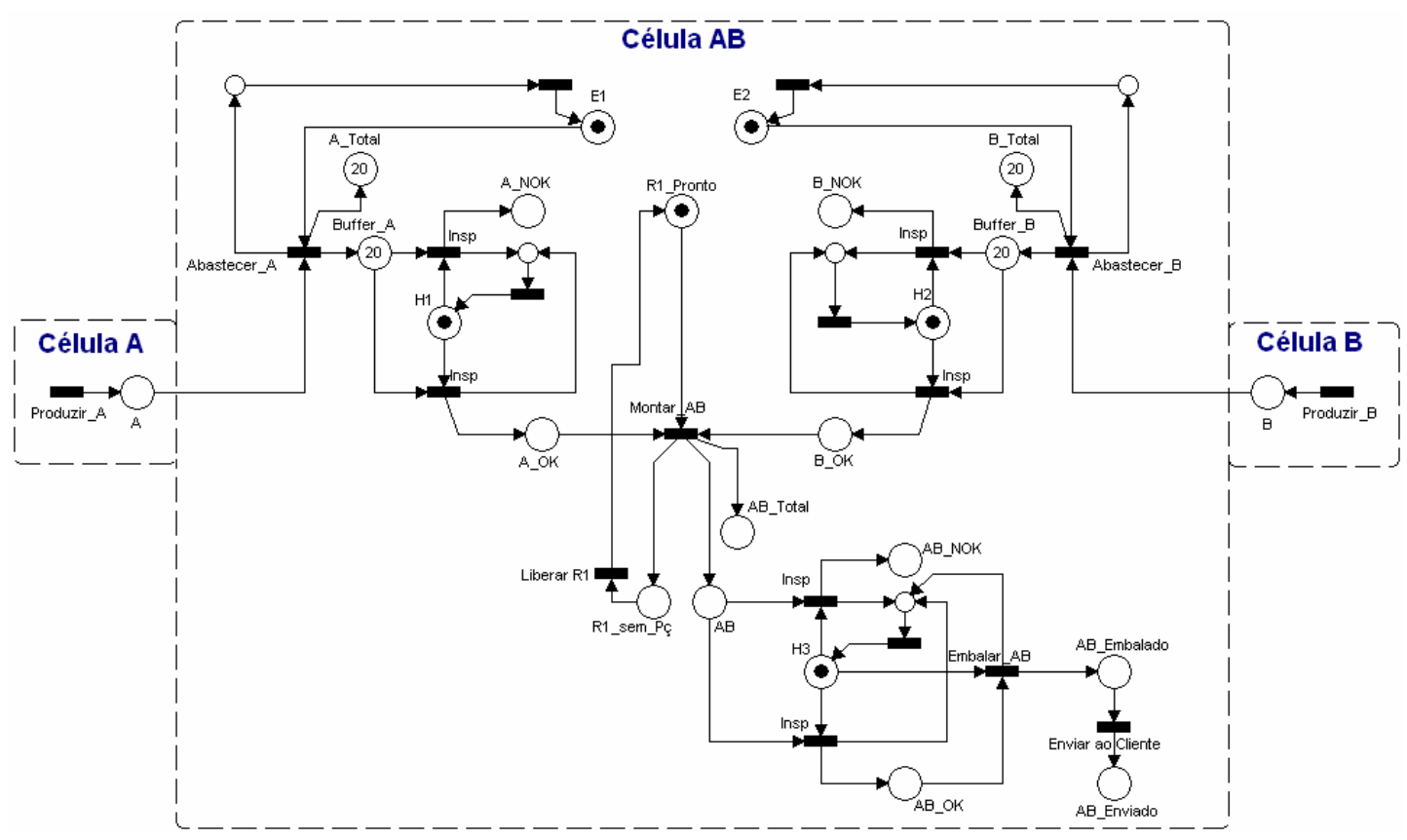

Figura 3.7 - Exemplo B - Processo real divergente do processo projetado. Fonte: Autor. 
O cenário do processo real demonstra uma produção empurrada e não puxada, visto que tanto a Célula $\mathrm{A}$ quanto a Célula $\mathrm{B}$ continuam produzindo peças e enviando à Célula $\mathrm{AB}$, mesmo estando o Buffer_A e o Buffer_B no máximo permitido. Obviamente, a Célula A e a Célula B, possuem um buffer intermediário que no modelo são os lugares $A$ e $B$ e que possuem um limite de peças calculado para que o sistema Kanban funcione sem falta de peças na Célula $\mathrm{AB}$, mas também sem excesso de peças neste buffer intermediário. Notem, porém, que o sistema Kanban não está em funcionamento e, portanto, não há controle na entrega de peças, nem do seu inventário. Além disso, os engenheiros detectaram que as Células A e B estão rodando a $80 \%$ da sua capacidade, gerando tempo ocioso da mão-de-obra naquelas estações de trabalho. Alto inventário implica em maiores despesas operacionais, bem como impacto na qualidade das peças visto que a fábrica é estruturada para esse estoque. Estas conclusões podem ser facilmente tiradas com um simples cross-check entre o modelo projetado, suas documentações e o processo real.

\section{3) Aplicação da metodologia DMAIC:}

Inicia com a formulação do problema cujo processo é contínuo por meio do estudo e análise constante do processo. Novas informações surgem e trazem novas restrições, alteram objetivos e fornecem novas alternativas de investigação. Essas informações devem ser utilizadas para atualizar continuamente a formulação e definição do problema e fica claro, nesta etapa, o suporte que a modelagem e simulação oferecem ao ciclo de melhoria contínua visto que as etapas da metodologia DMAIC podem ser alimentadas com informações das simulações do modelo ou fornecerem informações que ao serem modeladas podem ser testadas e analisadas por meio da simulação.

Supondo que o processo exemplificado anteriormente tenha sido implementado conforme o seu projeto e que, apesar disso, o volume de produção bem como os lucros 
atrelados ao mesmo estejam aquém dos novos objetivos impostos pela empresa frente às demandas do mercado e que em vista desse contexto o time tenha decidido abrir um projeto Seis Sigma, o primeiro passo será definir o problema, atendo-se ao que é crítico para o cliente (CTC - Critical to Costumer), que neste exemplo é "entrega dentro do prazo" e "baixo custo”. Neste momento, o time de melhoria já deve conhecer todo o processo, seus requisitos, documentações históricas etc o que, junto com o modelo, podem ajudar a visualizar e responder questões, tais como:

- O processo é capaz de atender a nova demanda?

- Quais as entradas mínimas do processo que atendem aos novos requisitos?

- Porquê a inspeção de qualidade é feita na Célula Gargalo?

- A célula que produz não deve assegurar a qualidade antes de enviar ao cliente interno, no caso a Célula $\mathrm{AB}$ ?

- Se a qualidade for assegurada nas células A e B a detecção não é mais efetiva e, portanto, melhora-se o nível de peças rejeitadas?

- O processo da Célula $A B$ pode ser automatizado se a inspeção de qualidade nesta estação de trabalho for eliminada?

- São necessárias duas empilhadeiras para o reabastecimento da Célula AB?

- O Kanban pode ser revisto de forma a se eliminar uma das empilhadeiras?

- Quais as principais saídas do processo e correlações com as entradas?

- Onde o projeto inicial falhou?

- Porquê o FMEA, ou outras ferramentas de análise de falhas, não detectou essas falhas?

- Onde são aplicáveis sistemas de controle Zero Defeito?

Evidentemente, o time chegará à conclusão de que muitas melhorias podem ser implementadas. 
A Figura 3.8 a seguir, é uma proposta de modelo melhorada, onde as duas empilhadeiras foram substituídas por um veículo guiado automaticamente - AVG (Automated Guided Vehicle) - que consegue realizar a transferência e reabastecimento de peças automaticamente. Os operadores $\mathrm{H} 1$ e $\mathrm{H} 2$ foram retirados visto que a inspeção das peças passou a ser feita nas Células A e B e o abastecimento para o robô R1 é feito automaticamente. Implementado controle no trabalho do operador H3 priorizando Embalar $A B$ para envio ao Cliente. O processo tornou-se mais enxuto e eficaz otimizando o ciclo da Célula AB, elevando a capacidade das Células A e B e aumentando o volume de produção.

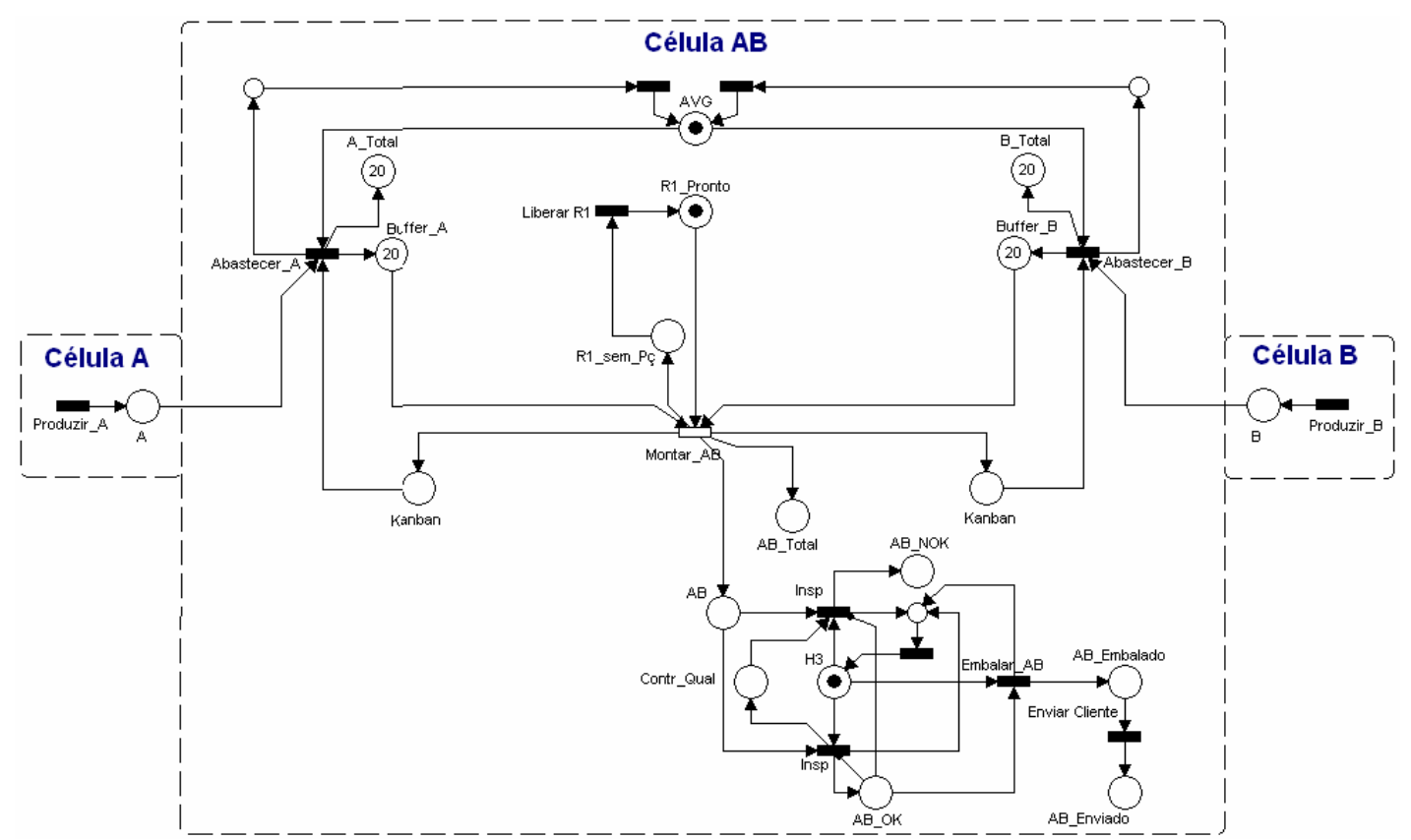

Figura 3.8 - Exemplo C - Modelo do processo melhorado durante um Projeto Seis Sigma. Fonte: Autor.

4) Implementar Melhoria e Revisar Documentação: A descrição desta etapa é idêntica a do fluxograma da Figura 3.3.

No capítulo seguinte será mostrado os resultados práticos obtidos da aplicação desse método na área de estampagem de uma indústria automotiva. 


\section{Estudo de Caso}

O estudo de caso descreve a aplicação de um projeto Seis Sigma na área da Estamparia de uma empresa multinacional da área automotiva. O projeto foi desenvolvido na forma tradicionalmente realizada na empresa em questão e após sua finalização foi aplicada a técnica da engenharia reversa e utilizados conceitos de modelagem e simulação para análise das vantagens desta aplicação.

\subsection{Desenvolvendo o Projeto Seis Sigma}

\subsubsection{Etapa 1 - Definindo o Problema}

O projeto foi conduzido por um Black Belt que atua como engenheiro do A\&ME (Advanced and Manufacturing Engineering) o qual definiu os seguintes membros para participarem do desenvolvimento desse projeto:

01 Master Black Belt (Mestre Faixa Preta)

01 Champion (Campeão)

01 Process Owner (Dono do Processo)

03 Engenheiros do A\&ME

01 Supervisor do A\&ME

03 Engenheiros de Produção

02 Coordenadores de Produção

02 Líderes de Linha

02 Engenheiros de Manutenção 
Importante ressaltar que o autor dessa dissertação atuou neste projeto Seis Sigma como Process Owner (Dono do Processo), por ser o Superintendente de Produção da Estamparia, suportando o time nas informações e implementações requeridas, porém mantendo a imparcialidade diante do desenvolvimento desse projeto Seis Sigma de forma a não alterar a condução do time na aplicação da metodologia tradicional utilizada na empresa.

O projeto foi aberto no final de Maio/2007 com o objetivo de minimizar o tempo de Troca do Ferramental da Linha 4, o qual pela análise dos indicadores correspondia a 71\% do tempo de Die Set (tempo desde a parada da linha para troca de ferramentas até a aprovação da próxima peça).

O tempo de Die Set é composto pelo tempo de três fatores, conforme pode ser visto na

\section{Figura 4.1:}

1. Troca do Ferramental (Die Change): é o tempo de troca das matrizes e dispositivos de transferência das peças entre prensas. Esse tempo depende do:

a) Cumprimento adequado das nas folhas de QPS (Quality Process System) que são instruções que descrevem o passo a passo de cada funcionário para realização padronizada de determinada atividade.

b) Velocidade dos equipamentos e de execução opearcional de cada uma das atividades.

2. Quebra: é o tempo correspondente a todas as paradas para manutenção corretiva dos equipamentos durante a execução da troca.

3. Qualidade: é o tempo relativo a aprovação de qualidade da peça. 


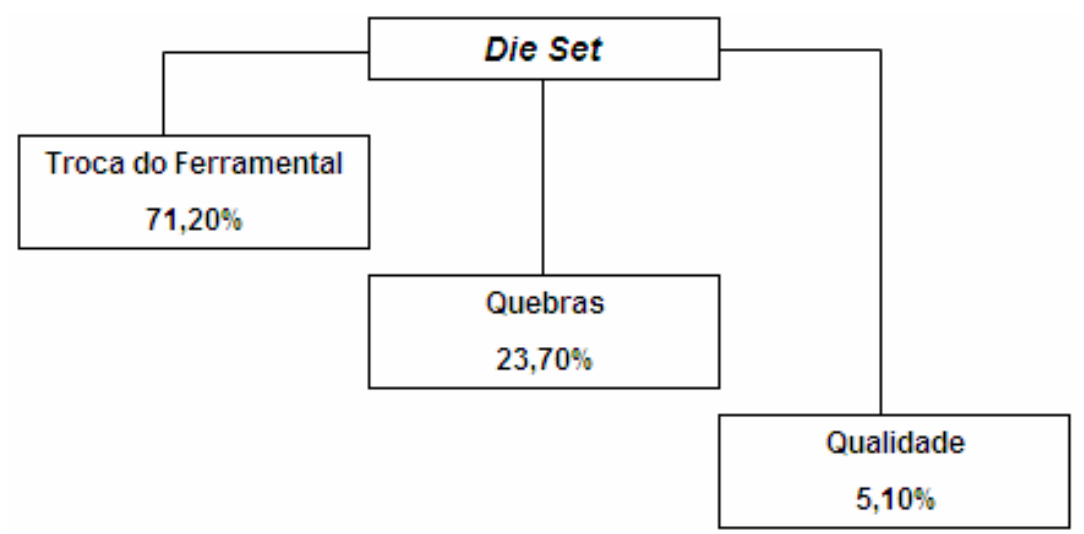

Figura 4.1 - Estratificação do tempo de Die Set. Fonte: Autor.

O objetivo do projeto foi a redução do tempo médio de Troca do Ferramental de 29 minutos para 25 minutos. A Figura 4.1 mostra, ainda, a estratificação do tempo de Die Set e a contribuição percentual de cada um dos seus fatores.

A Figura 4.2 mostra o mapeamento macro do processo de Die Set que foi utilizado para o entendimento inicial do processo pela equipe. Notem que o Die Set engloba todo o tempo de troca do ferramental incluindo as paradas de manutenção e qualidade.

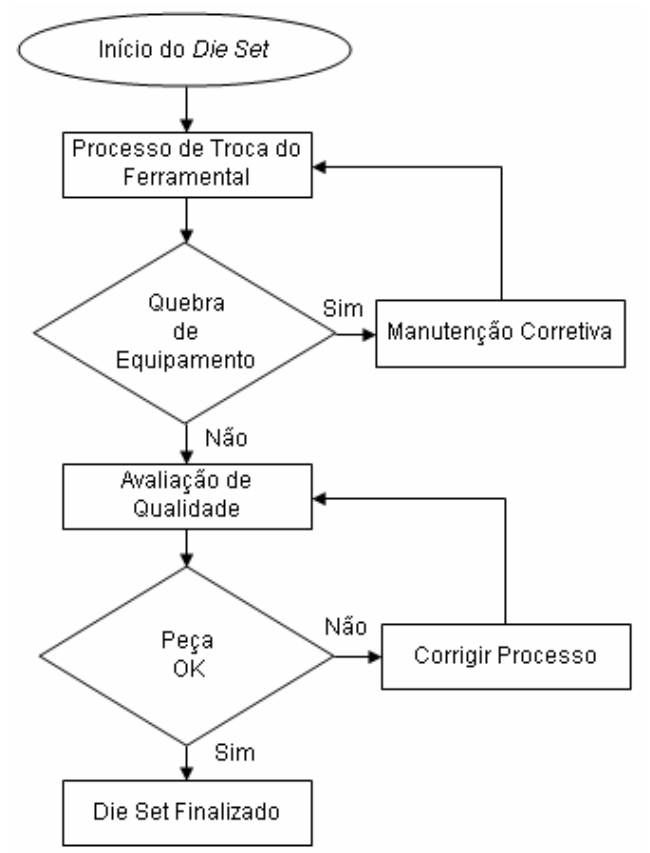

Figura 4.2 - Mapeamento Macro do Processo de Die Set. Fonte: Autor. 
A linha 4 da Estamparia objeto desse estudo de caso é composta por 02 mesas de abastecimento e separação das chapas metálicas, 01 oleadora de chapas, 01 mesa centralizadora - centraliza a chapa para que o robô a deposite adequadamente na ferramenta de repuxo da prensa $1-, 05$ prensas, 04 carros de transferência de ferramentas (die cars), 05 mesas de preparação do ferramental, 08 robôs e 01 esteira final de linha. $\mathrm{O}$ sistema de troca da linha (Die Set) ocorre com a substituição das aranhas - dispositivos montados nos robôs para movimentação da chapa metálica e das peças entre prensas - e das ferramentas. A substituição das aranhas é realizada manualmente pelos operadores e a troca das ferramentas é feita por meio dos die cars que são carros elétricos usados na transferência das ferramentas e acionados, também, pelos operadores. O layout da linha 4 encontra-se na Figura 4.3.

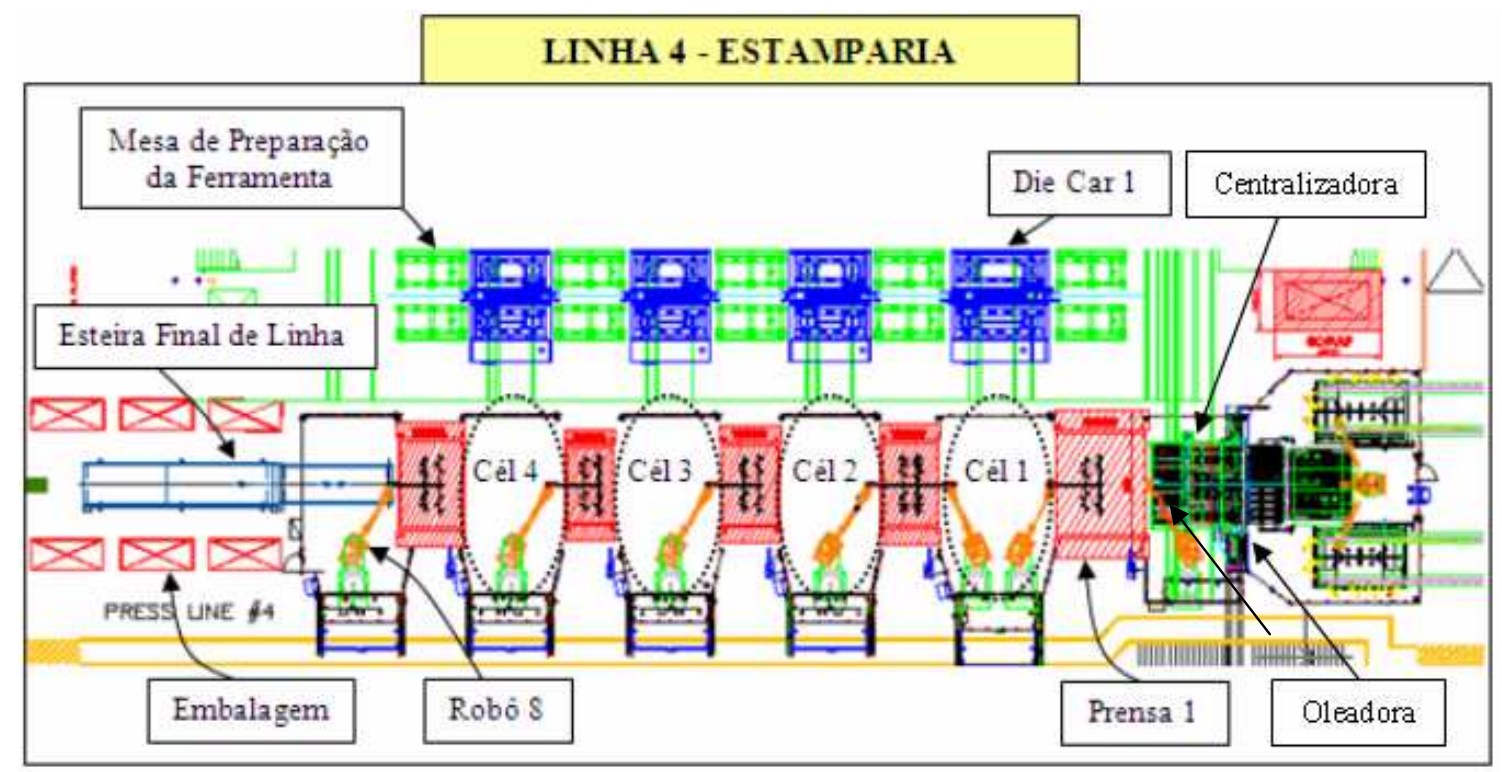

Figura 4.3 - Layout da Linha 4. Fonte: Autor. 


\subsubsection{Análise Crítica da Etapa 1}

A dissertação proposta defende a importância de não se banalizar o método Seis Sigma por meio de projetos abertos à revelia para cumprir, meramente, objetivos quantitativos que são colocados, anualmente, para os Black Belts. Na etapa Definir do Seis Sigma, é notável a importância para o Black Belt, de se ter o modelo do processo suportando a visualização dos gargalos e das etapas críticas para o Cliente, fornecendo-lhe uma ferramenta que valide a abertura dos seus projetos. Seria de grande valor, por exemplo, um modelo baseado em redes de Petri hierárquicas, pois permite "explodir" a etapa do processo que seja mais conveniente para análise, ou simplesmente visualizar de forma macro o processo em questão, tendo-se uma melhor percepção de onde deve ser aberto um projeto Seis Sigma.

Outro ponto importante seria a verificação da documentação do processo de Troca do Ferramental, dando-se especial atenção à seqüência do processo, aos tempos de ciclos e às velocidades individuais de cada equipamento. O indicador pelo qual o Black Belt se baseou para definir o projeto a ser aberto, é meramente um dado de saída de um processo cuja documentação deveria estar facilmente disponível para análise e constatação do cumprimento ou não das especificações ou requisitos pelo grupo do chão-de-fábrica. Essa análise é indispensável para evitar que nas etapas posteriores, o time venha a definir ações que já estão conforme as apresentadas nas documentações deste processo e que simplesmente não estão sendo seguidas.

Ao se discutir sobre a documentação do processo com a equipe que desenvolveu esse projeto Seis Sigma, foi constatado a inexistência de uma pasta única de documentação do

processo da linha 4, havendo apenas informações com alguns engenheiros o que leva a depender do conhecimento dos mesmos e também da permanência deles na empresa. Além 
disso, não existia nenhuma documentação que embasasse o objetivo de tempo de Troca do Ferramental de 30 minutos com o qual a estamparia vinha trabalhando, sendo verdadeiramente, um prognóstico com base no histórico das outras linhas que, porém, possuem sistemas e equipamentos diferentes. O fato é que trabalhar com um valor que de antemão não se sabe ser possível é complicado. Dessa forma, foi solicitado ao time retroceder nas análises e procurar informações técnicas de todos os equipamentos envolvidos na operação. O resultado será visto nas demais etapas.

\subsubsection{Etapa 2 - Medindo o Processo}

Nesta fase, o time Seis Sigma elaborou uma folha de coleta de dados de forma a medir o tempo de cada etapa da Troca do Ferramental, padronizando a tomada dos tempos. A folha de coleta de dados é apresentada na Tabela 4.1 seguir.

\section{Tabela 4.1 - Folha de Coleta de Dados. Fonte: Autor.}

\begin{tabular}{|l|l|}
\hline EVENTOS & TEMPO \\
\hline 1- START (Cota de colocação, ajuste e apertar o botão) & \\
\hline 2- Abertura do Portão & \\
\hline 3- Início da Troca de Aranha & \\
\hline 4- Término da Troca de Aranha & \\
\hline 5- Subida do Prensa Chapa e Martelo (ponto morto superior após Desclampeamento) & \\
\hline 6- Entrada do Die Cart & \\
\hline 7- Cota de colocação da ferramenta nova + apertar o botão & \\
8- Saída do Die Cart & \\
\hline 9- Subida do Prensa Chapa e Martelo (ponto morto superior após Clampeamento) & \\
\hline 10- Fechamento do Portão &
\end{tabular}

Foram acompanhadas trinta Trocas do Ferramental e registrados os tempos de cada etapa por meio da Folha de Coleta de Dados, desconsiderando-se os tempos de atraso devido 
a falhas ou quebras de equipamentos. A Figura 4.4 demonstra o tempo médio de Troca do Ferramental por célula. Observa-se que a célula gargalo é a Célula 1 com um tempo médio de 28,74 minutos que também pode ser visto no estudo de capacidade do tempo de troca da célula 1 na Figura 4.5.

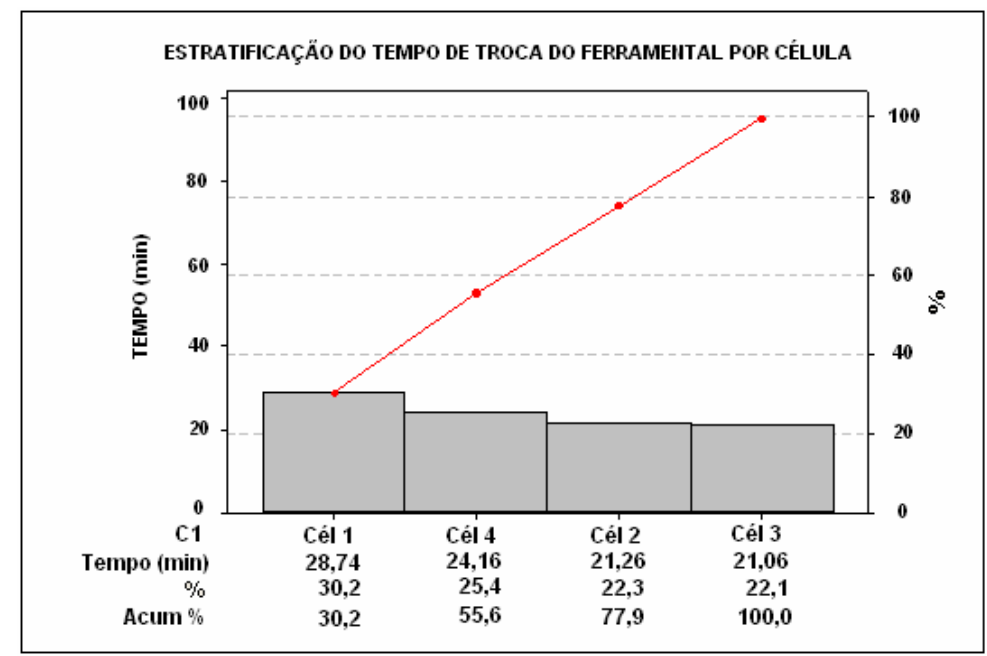

Figura 4.4 - Tempo Médio de Troca do Ferramental por Célula. Fonte: Autor.

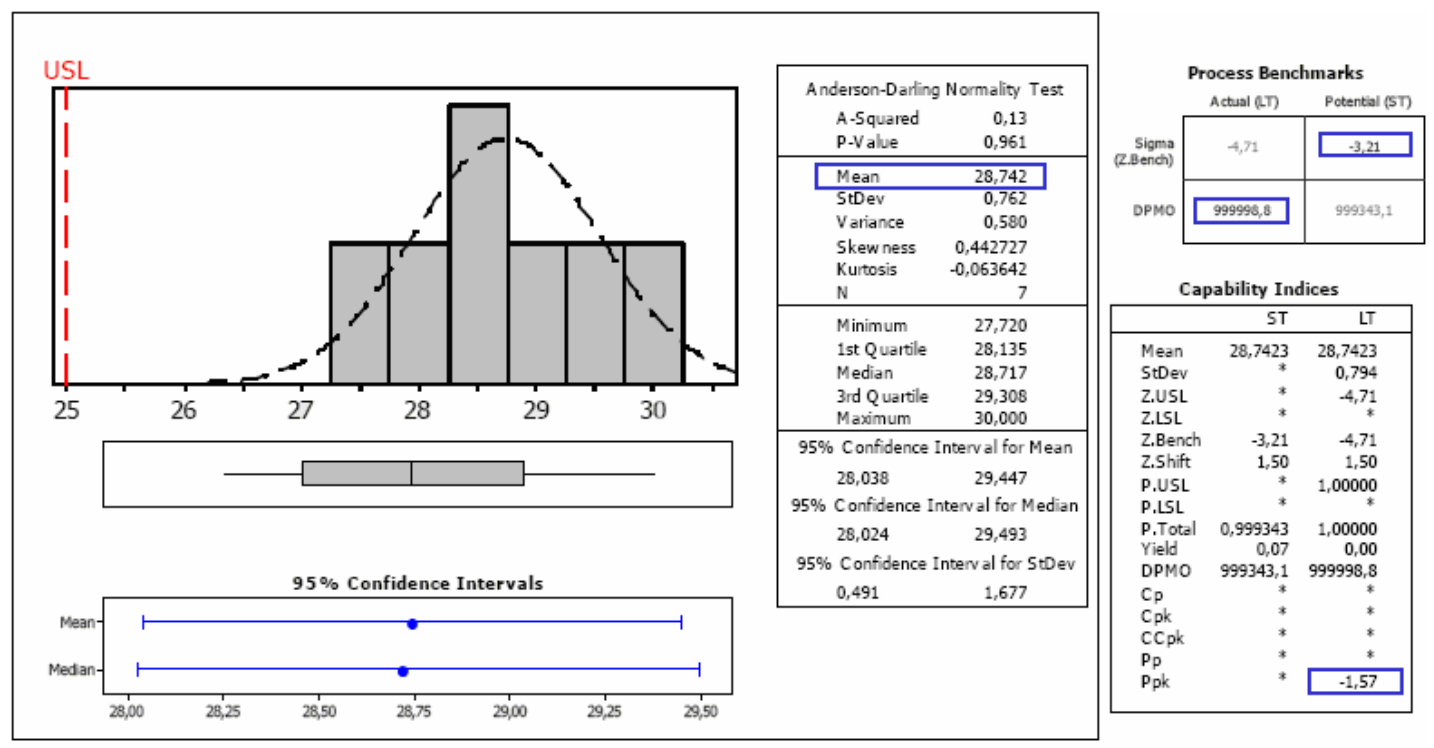

Figura 4.5 - Análise estatística do tempo de troca do ferramental. Fonte: Autor. 
$\mathrm{Na}$ etapa seguinte todos os membros da equipe percorreram o processo observando como a Troca do Ferramental era realizado no chão-de-fábrica e elaboraram um mapa mais detalhado do processo da célula 1 para entenderem o motivo da mesma ser o gargalo, conforme pode ser visto na

Figura 4.6. 


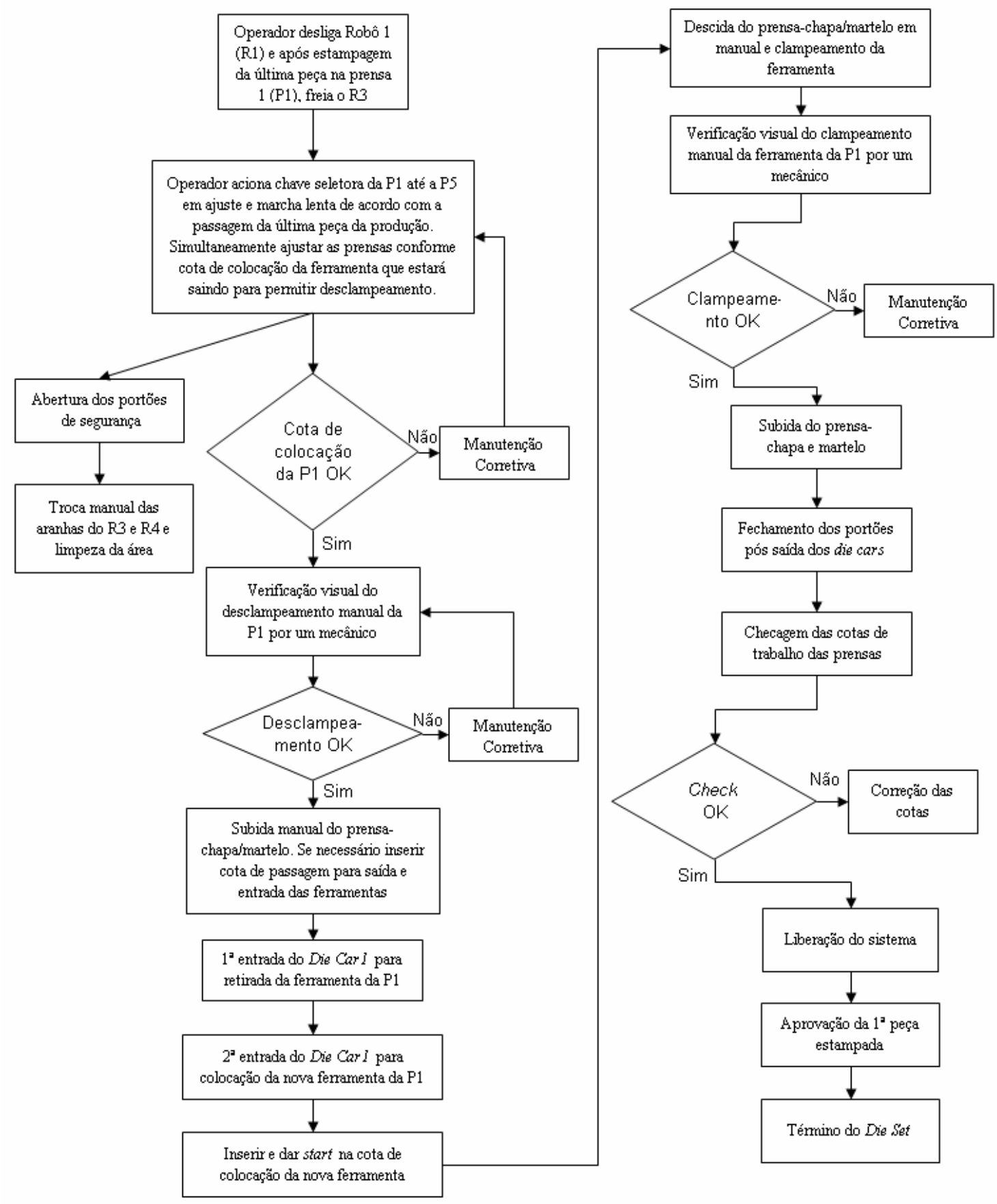

Figura 4.6 - Mapa detalhado do processo de Troca do Ferramental na Célula 1. Fonte: Autor.

\subsubsection{Análise Crítica da Etapa 2}

A elaboração do mapeamento do processo seria transferida para uma análise crítica do modelo, caso a empresa o tivesse e conforme mostrado na proposta apresentada no Capítulo 3 
desse trabalho. Por não haver modelagem do processo da Estamparia, modelá-lo demandaria um elevado tempo pela inexistência de um time conhecedor desse tipo de ferramenta e pela própria complexidade do processo. Para validar a proposta nesta etapa, foi modelado em redes de Petri, o processo de troca dos estampos com os Die Cars, usando o software HPSim. Foi escolhida esta etapa por ser a de maior tempo na Troca do Ferramental, conforme será visto na fase Analisar que está no próximo tópico.

A simulação do modelo demonstrou, para a Troca do Ferramental, que o gargalo estava realmente na Célula 1. O modelo pode ser visto na Figura 4.7.

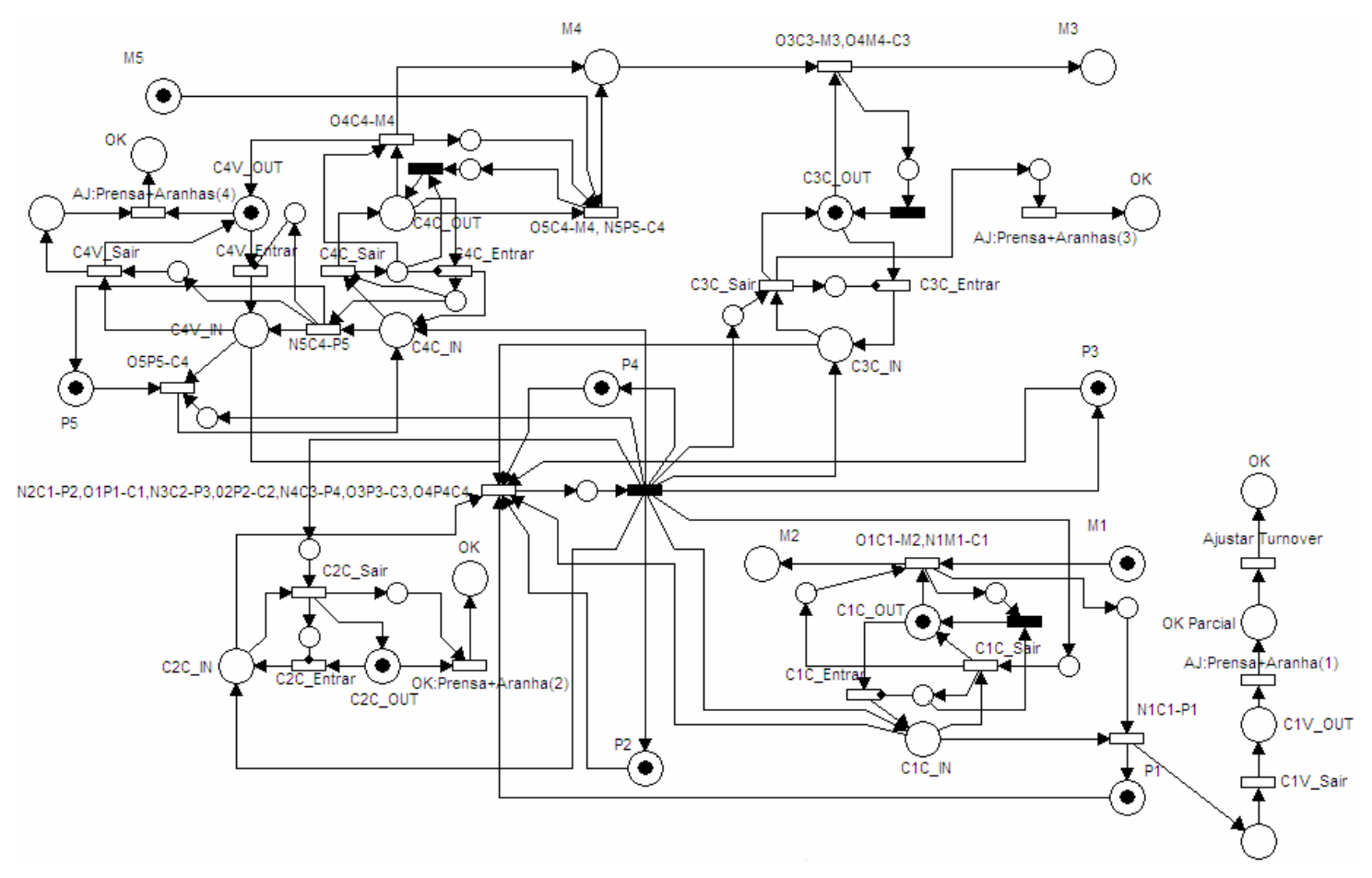

Figura 4.7 - Modelo em Redes de Petri do processo de troca de estampos com os Die Cars. Fonte: Autor.

\subsubsection{Etapa 3 - Analisando o Processo}

O sistema de movimentação dos Dies Cars (responsáveis pela troca dos estampos) demandou na média, "13,125" minutos. Esta etapa, portanto, corresponde a de maior tempo dentro da 
Troca do Ferramental e devido a sua relevância foi escolhida para validar a proposta da dissertação. A linha de tempo de cada uma dessas etapas encontra-se na Figura 4.8.

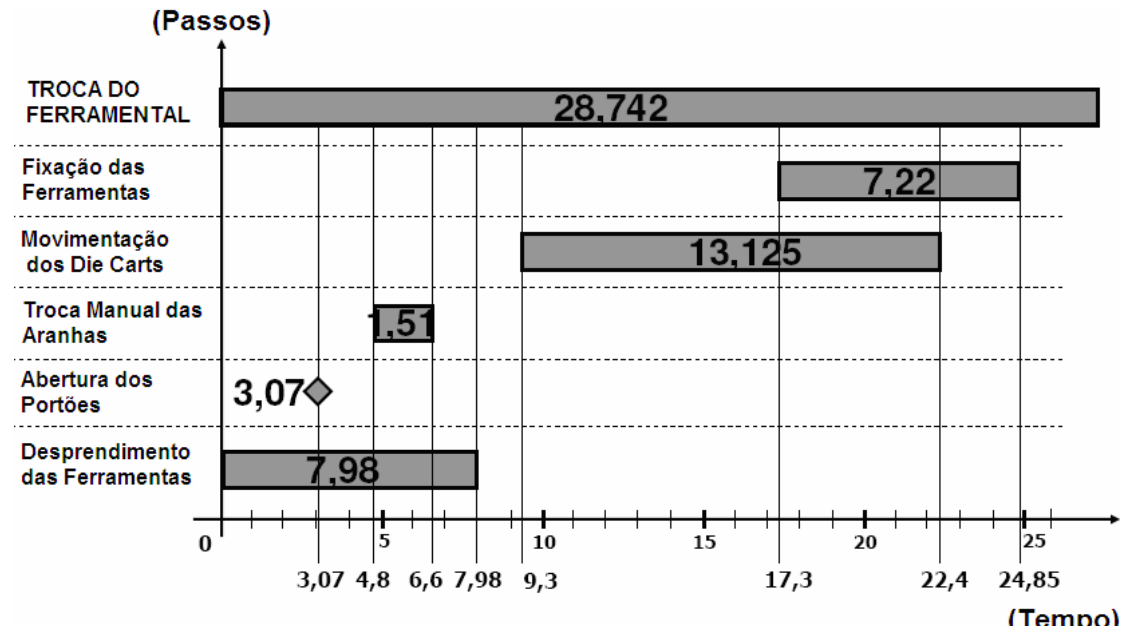

Figura 4.8 - Linha do Tempo de cada Etapa. Fonte: Autor.

De posse da estratificação dos tempos de cada passo do processo de Troca do Ferramental, o time realizou um brainstorming utilizando a ferramenta espinha-de-peixe e levantando as causas potenciais. O resultado da espinha-de-peixe encontra-se na Figura 4.9.

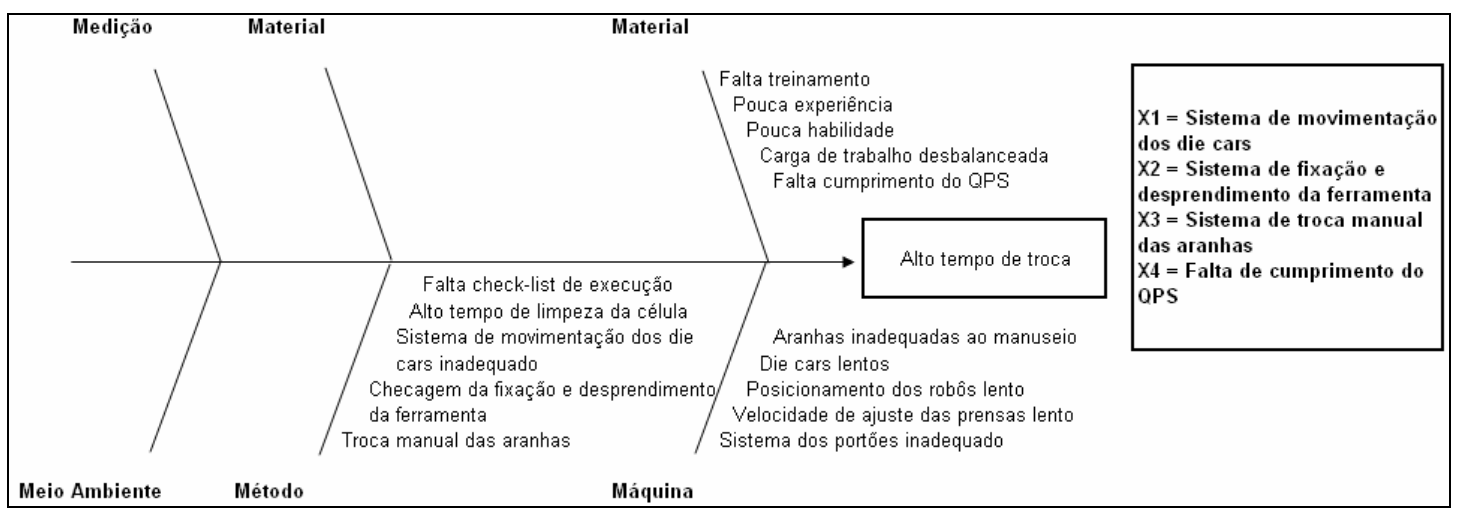

Figura 4.9 - Espinha-de-Peixe: alto tempo de Troca do Ferramental na linha 4. Fonte: Autor.

Do ponto de vista da Movimentação dos Die Cars que é a etapa de maior tempo, o time realizou um mapa específico do processo (Figura 4.10) mostrando o passo-a-passo de movimentação dos die cars na troca dos ferramentais. Importante notar que a célula 1 não seria o gargalo devido a movimentação dos die cars, pois a última ferramenta a ser trocada é a 
da célula 4. Porém, essa sequência de movimentação do die cars é pouco flexível (ver item 4.1.4.1.) a atrasos operacionais ou pequenas falhas de equipamentos que, por serem de baixo tempo, são de difíceis detecção mas afetam diretamente no tempo de Die Set. Além disso, o tempo de Die Set na célula 1 é afetado, principalmente nos ajustes da prensa dupla ação (prensa-chapa e martelo) e aranhas, os quais não estão neste fluxograma mas no modelo em HPSim.

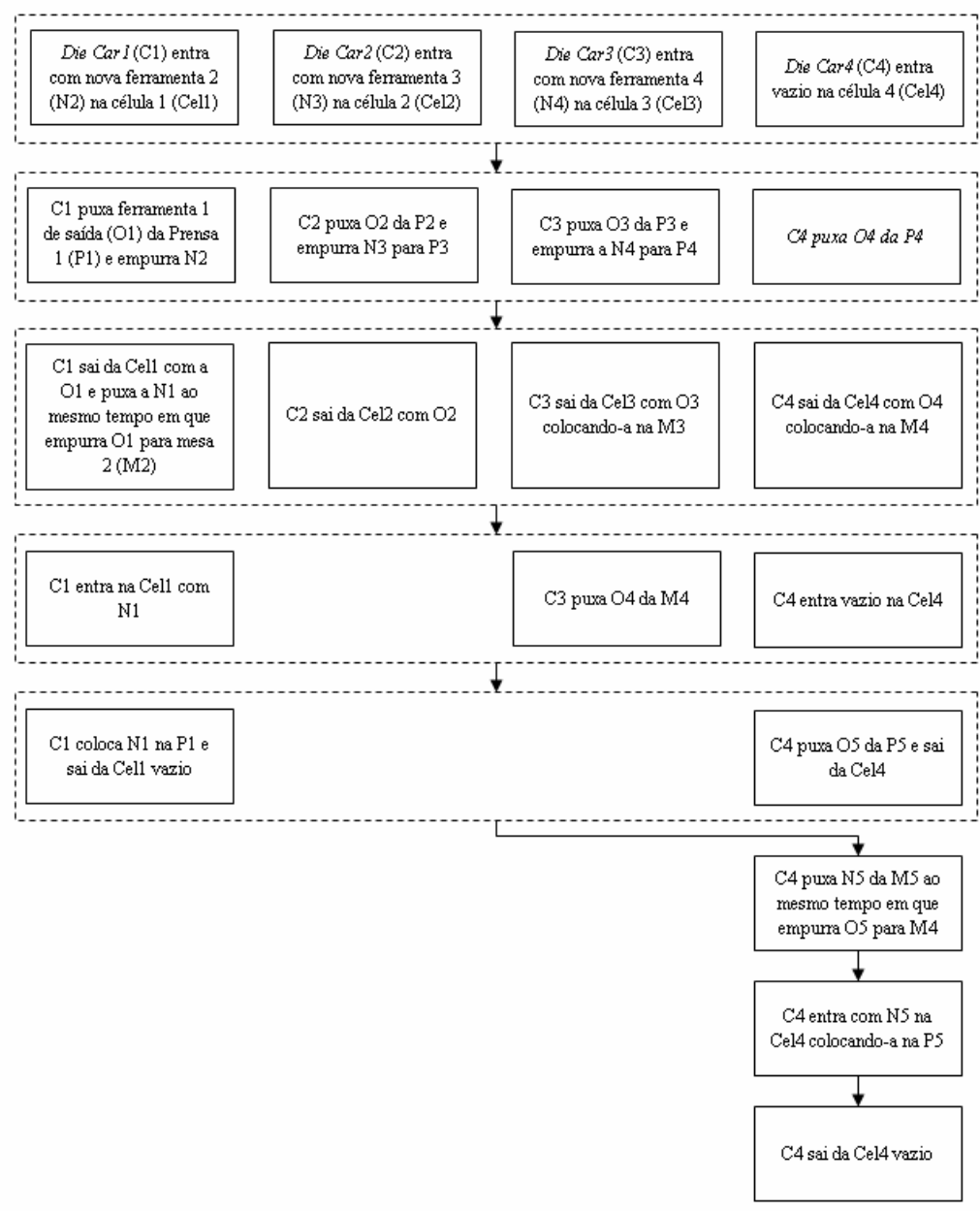

Figura 4.10 - Mapeamento do processo de movimentação dos Die Cars antes da melhoria. Fonte: Autor.

Com base nas análises realizadas durante esta fase do Seis Sigma, o time Seis Sigma definiu as ações de melhorias listadas a seguir, onde em negrito estão as ações relativas aos die cars:

1. Implementar sistema semi-automático de fixação e desprendimento das ferramentas. 
2. Trocar aranhas 3 e 4 simultaneamente.

3. Suporte dos operadores da Linha 3 durante os Die Sets.

\section{Otimizar a movimentação dos Die Cars.}

5. Balancear a carga entre coordenador e line leader.

6. Operadores mais hábeis na célula 01.

7. Cumprir check-list de pré Die Set.

8. Redefinir posicionamento de espera dos Die Cars e ajuste automático do push-pull.

9. Alarme visual para os Die Cars.

10. Mudar o posicionamento de sexto eixo dos robôs 3 e 4

11. Estimular a cobrança positiva durante os Die Sets.

12. Gerenciar reuniões com os coordenadores para não impactar no Die Set.

13. Treinar operadores no novo processo (QPS novo).

14. Implementar sistema de carregamento automático das cotas de trabalho.

\section{Mudar estação inativa da prensa 4 para a prensa 5.}

\subsubsection{Análise Crítica - Etapa 3}

$\mathrm{Na}$ fase Analisar os gráficos gerados dos dados levantados na fase Medir deveriam ser comparados contra um objetivo especificado em projeto, como por exemplo, os tempos de abertura dos portões, fixação dos estampos, movimentação dos die cars e todos os demais que já deveriam ser conhecidos por meio das documentações. O time em nenhum momento analisou essas documentações, concentrando seus esforços em propor melhorias sem base no projeto do processo.

Um acontecimento que ratifica a importância da análise documental foi que durante a análise crítica utilizando o método proposto nessa dissertação, verificamos que a velocidade 
no movimento do Die Cars para frente e para trás, bem como a velocidade dos push-pulls (dispositivos que realizam a transferência dos estampos para dentro ou fora dos Die Cars) para a direita ou esquerda estavam fora da velocidade máxima especificada na documentação (10,05 metros por minuto para o Die Car e 4,57 metros por minuto para o push-pull). Por se tratar de um equipamento de baixa utilização foi decidida junto aos especialistas, a mudança da velocidade para o limite máximo da especificação, resultando num ganho de 1 minuto no tempo total de transferência dos estampos. Os dados do manual desse equipamento podem ser vistos na Figura 4.11 e Figura 4.12.

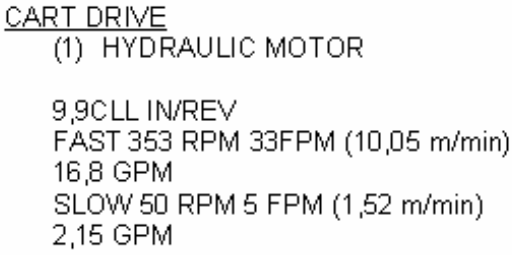

Figura 4.11 - Movimento do Carro Principal, para frente e para trás : Velocidade Alta 10,05 m/min.; Velocidade Baixa 1,52 m/min. Fonte: HIDRAULIC SCHEMATIC da Atlas Technologies K11500.013.

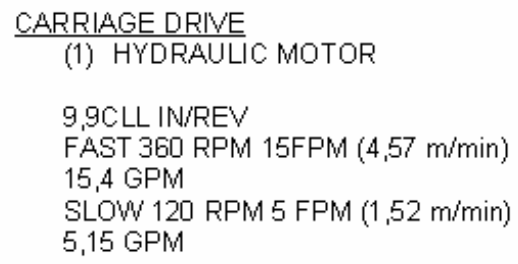

Figura 4.12 - Movimento do Carro do Push Pull ( parafuso de bola ) para direita ou para esquerda: Velocidade 4,57 m/min. Fonte: HIDRAULIC SCHEMATIC da Atlas Technologies K11500.013.

Outro ponto importante é que com a utilização de ferramentas adequadas de modelagem e simulação seria possível a realização de um melhor brainstorming visto que os gargalos, pontos de decisão e conflitos estariam sendo analisados dinamicamente permitindo ao time uma melhor visão do processo. 


\subsubsection{Etapa 4 - Implementando Melhorias}

Esta etapa consistiu, basicamente, em implementar as ações propostas na fase anterior. E umas ações que chamou a atenção do time Seis Sigma e também do time operacional, foi a dificuldade em se propor uma seqüência adequada de movimentação dos estampos pelos Die Cars, conforme estaremos explanando no próximo tópico.

\subsubsection{Análise Crítica da Etapa 4}

Uma das ações que o time Seis Sigma acreditou ser de grande impacto foi a mudança do sequenciamento de entrada dos die cars para troca dos estampos, visto que esta etapa de Troca do Ferramental levava 13.125 minutos para ser concluída. Diversas propostas surgiram, demandando paradas planejadas durante os Die Sets para sua avaliação diretamente no chãode-fábrica e, portanto, custo para realização dessa análise, além do tempo elevado, pois a avaliação somente era liberada se o float de peças estivesse balanceado, exigindo espera do momento mais oportuno para sua realização. As propostas foram elaboradas em Power Point pelo Black Belt que através dos slides procurava explicá-la ao time de produção, porém somente na terceira proposta testada no chão-de-fábrica, os ganhos teóricos se refletiram na prática. Importante frisar que a elaboração dessas propostas em Power Point demandava considerável tempo de uma mão-de-obra tão especializada como a do Black Belt, e isto já justificaria a procura por ferramentas próprias de modelagem e simulação (ver Figura 4.13). 


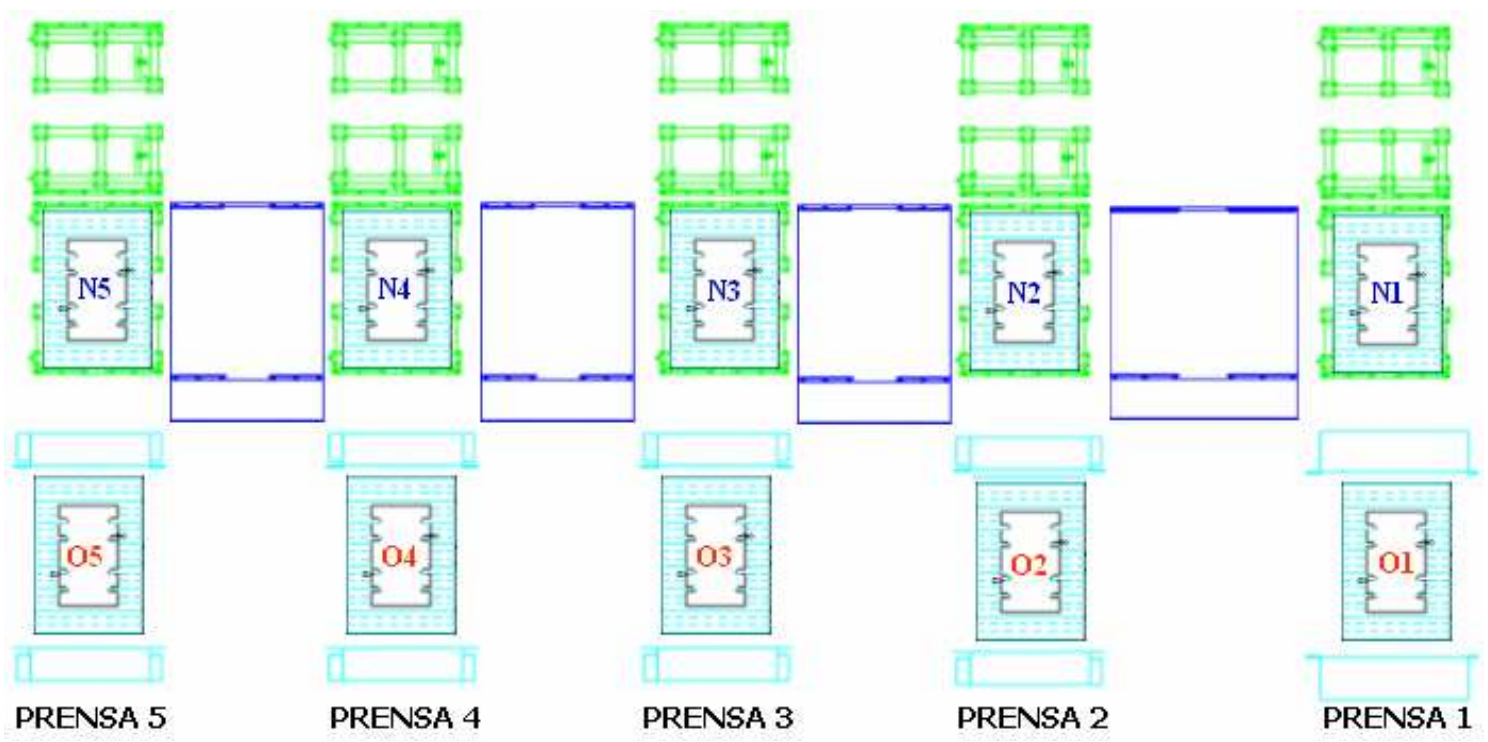

Figura 4.13 - Parte do modelo desenvolvido em Power Point pelo Black Belt.

Com vista na dificuldade de implementação dessa ação, foi realizado neste processo, duas modelagens em redes de Petri por meio do programa HPSim: antes da implementação da melhoria e após esta. Na modelagem foi adicionado tempo nas transições de forma a representar, exatamente, o processo de movimentação dos die cars obtendo o mesmo resultado das avaliações efetuadas no chão-de-fábrica. Apesar de saber que a simulação não elimina a necessidade de execução dos testes pilotos, ela minimiza a necessidade de muitos testes antes da implementação definitiva, acelerando assim os resultados. Além disso, a simulação possibilita eliminar propostas antes que as mesmas entrem no chão-de-fábrica, sejam recusadas e levem a desperdícios, seja de tempo, custo, mão-de-obra etc, ou pior, que levem a perda de credibilidade no método Seis Sigma, ou qualquer outro método de melhoria contínua. O modelo do processo antigo encontra-se na Figura 4.7 anteriormente mostrada e sua simulação permitiu reproduzir o tempo médio de 13 minutos por Troca do Ferramental.

Importante afirmar que o modelo a ser analisado, deveria ser primeiramente o do projeto do processo em estudo, mas como as informações encontravam-se num formato 
independente e confuso e tendo-se apenas uma análise mais detalhada das especificações de equipamentos (especificações que foram levantadas após a aplicação da proposta desta dissertação), porém sem qualquer análise formal do resultado esperado de tais especificações, optou-se por modelar diretamente o processo de movimentação dos die cars - processo mais crítico - conforme o mesmo se encontrava funcionando. A Tabela 4.2 mostra o resultado das simulações executadas (13 minutos sem quebras ou atrasos) e a descrição de cada uma das atividades modeladas no HPSim.

Por meio do estudo do modelo, foi decidido simular quebras aumentando-se o tempo de acionamento das transições, onde se verificou que das vinte e quatro transições (ou tarefas) desse modelo, apenas quatro delas não resultavam em um aumento imediato do tempo total de Die Set, ou seja, apesar de haver uma célula gargalo, quebras na maior parte das demais células, resultavam num aumento direto do tempo de Die Set, mostrando ser um processo pouco flexível. O resultado dessa análise encontra-se na Tabela 4.3. 
Tabela 4.2 - Resultado das simulações do Die Set excluindo quebras (min). Fonte: Autor.

\begin{tabular}{|c|c|c|c|c|c|}
\hline & & TRANSIÇÖES & ATIVIDADE & $\begin{array}{l}\text { Quantidade de } \\
\text { Acionamentos }\end{array}$ & $\begin{array}{c}\text { Tempo } \\
\text { Total }\end{array}$ \\
\hline & & C1C_Entrar & $\begin{array}{l}\text { Die Car } 1 \text { entrar na célula com } \\
\text { ferramental (cheio) }\end{array}$ & 2 & 2 \\
\hline & & C1C_Sair & $\begin{array}{l}\text { Die Car } 1 \text { sair da célula com } \\
\text { ferramental (cheio) }\end{array}$ & 1 & 1 \\
\hline & & C1V_Sair & Die Car 1 sair vazio da célula & 1 & 1 \\
\hline & $-\underset{\frac{1}{4}}{\frac{d}{4}}$ & N1C1-P1 & $\begin{array}{l}\text { Die Car } 1 \text { entra com nova } \\
\text { ferramenta } 1 \text { na Prensa } 1\end{array}$ & 1 & 1 \\
\hline & & O1C1-M2,N1M1-C1 & $\begin{array}{l}\text { Die Car } 1 \text { coloca ferramenta } 1 \text { de } \\
\text { saída na mesa } 2 \text { e puxa nova } \\
\text { ferramenta } 1 \text { da mesa } 1 \text { para si }\end{array}$ & 1 & 1 \\
\hline & & AJl:Prensa+Aranha(1) & $\begin{array}{l}\text { Ajustar Prensa } 1 \text { e aranhas da } \\
\text { célula } 1\end{array}$ & 1 & 3 \\
\hline & & Ajustar Turnover & $\begin{array}{l}\text { Ajustar mesa de transferência e } \\
\text { giro da peça repuxada }\end{array}$ & 1 & 2 \\
\hline & & C2C_Entrar & $\begin{array}{l}\text { Die Car } 2 \text { entrar na célula com } \\
\text { ferramental (cheio) }\end{array}$ & 1 & 1 \\
\hline & $\sim$ & C2C_Sair & $\begin{array}{l}\text { Die Car } 2 \text { sair da célula com } \\
\text { ferramental (cheio) }\end{array}$ & 1 & 1 \\
\hline & & OK:Prensa+Aranha(2) & $\begin{array}{l}\text { Ajustar Prensa } 2 \text { e aranhas da } \\
\text { célula } 2\end{array}$ & 1 & 1 \\
\hline & & C3C_Entrar & $\begin{array}{l}\text { Die Car } 3 \text { entrar na célula com } \\
\text { ferramental (cheio) }\end{array}$ & 1 & 1 \\
\hline 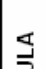 & & C3C_Sair & $\begin{array}{l}\text { Die Car } 3 \text { sair da célula com } \\
\text { ferramental (cheio) }\end{array}$ & 1 & 1 \\
\hline 岂 & $m$ & O3C3-M3,04M4-C3 & $\begin{array}{l}\text { Die Car } 3 \text { coloca ferramenta } 3 \text { de } \\
\text { saída na mesa } 3 \text { e puxa nova } \\
\text { ferramenta } 4 \text { da mesa } 4 \text { para si }\end{array}$ & 1 & 1 \\
\hline & & AJ:Prensa+Aranhas(3) & $\begin{array}{l}\text { Ajustar Prensa } 3 \text { e aranhas da } \\
\text { célula } 3\end{array}$ & 1 & 1 \\
\hline & & C4V_Entrar & Die Car 4 entrar vazio da célula 4 & 2 & 2 \\
\hline & & C4C_Sair & Die Car 4 sair cheio da célula 4 & 2 & 2 \\
\hline & & $\mathrm{O} 4 \mathrm{C} 4-\mathrm{M} 4$ & $\begin{array}{l}\text { Die Car } 4 \text { coloca ferramenta } 4 \text { de } \\
\text { saída na mesa } 4\end{array}$ & 1 & 1 \\
\hline & & O5P5-C4 & $\begin{array}{l}\text { Die Car } 4 \text { puxa ferramenta } 5 \text { de } \\
\text { saída da Prensa } 5 \text { para si }\end{array}$ & 1 & 1 \\
\hline & $\rightarrow$ & O5C4-M4, N5P5-C4 & $\begin{array}{l}\text { Die Car } 4 \text { coloca ferramenta } 5 \text { de } \\
\text { saída na mesa } 4 \text { e puxa nova } \\
\text { ferramenta } 5 \text { para si }\end{array}$ & 1 & 1 \\
\hline & & C4C_Entrar & Die Car 4 entrar cheio na célula 4 & 1 & 1 \\
\hline & & N5C4-P5 & $\begin{array}{l}\text { Die Car } 4 \text { coloca nova ferramenta } \\
5 \text { na Prensa } 5\end{array}$ & 1 & 1 \\
\hline & & C4V_Sair & Die Car 4 sair vazio da célula 4 & 1 & 1 \\
\hline & & AJ:Prensa+Aranhas(4) & $\begin{array}{l}\text { Ajuste das Prensas e aranhas da } \\
\text { célula } 4\end{array}$ & 1 & 1 \\
\hline & TODAS & $\begin{array}{l}\mathrm{N} 2 \mathrm{C} 1-\mathrm{P} 2, \mathrm{O} 1 \mathrm{P} 1-\mathrm{C} 1, \mathrm{~N} 3 \mathrm{C} 2- \\
\mathrm{P} 3,02 \mathrm{P} 2-\mathrm{C} 2, \mathrm{~N} 4 \mathrm{C} 3- \\
\mathrm{P} 4, \mathrm{O} 3 \mathrm{P} 3-\mathrm{C} 3, \mathrm{O} 4 \mathrm{P} 4 \mathrm{C} 4\end{array}$ & $\begin{array}{l}\text { Troca simutânea dos ferramentais } \\
\text { pelos Die Cars }\end{array}$ & 1 & 2 \\
\hline & & $\begin{array}{c}\text { TEMPO TOTAL DA } \\
\text { SIMULAÇÄO SEM QUEBRA } \\
\text { OU ATRASO }\end{array}$ & 13 Minutos & & \\
\hline
\end{tabular}


Tabela 4.3 - Resultado das simulações do Die Set considerando-se quebras ou atrasos. Fonte: Autor.

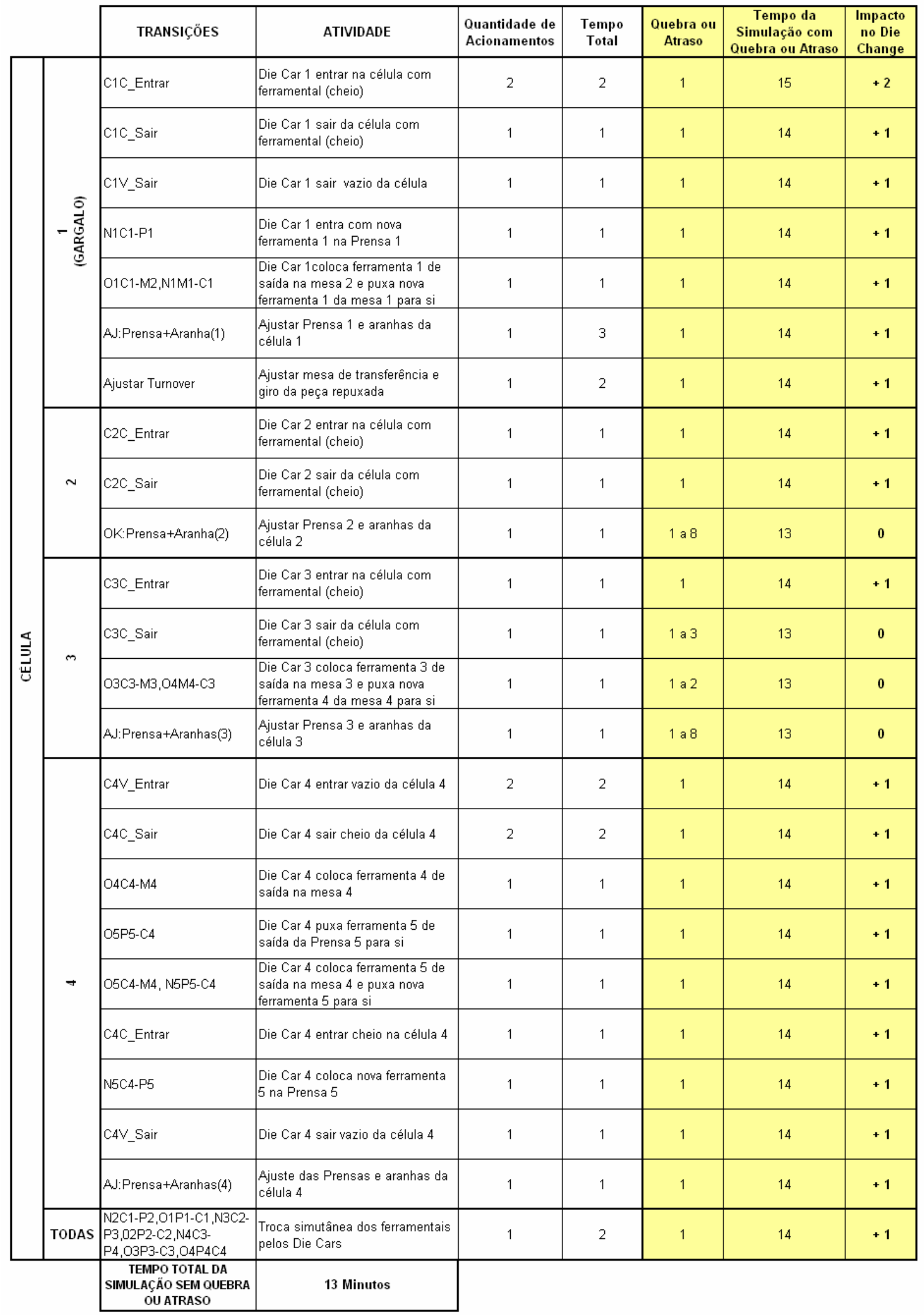


No novo modelo do processo,

Figura 4.14, também foi possível representar o ganho resultante da mudança na sequência de movimentação dos Die Cars o que resultou numa redução de um minuto no tempo de movimentação dos Die Cars conforme pode ser visto na Tabela 4.4.

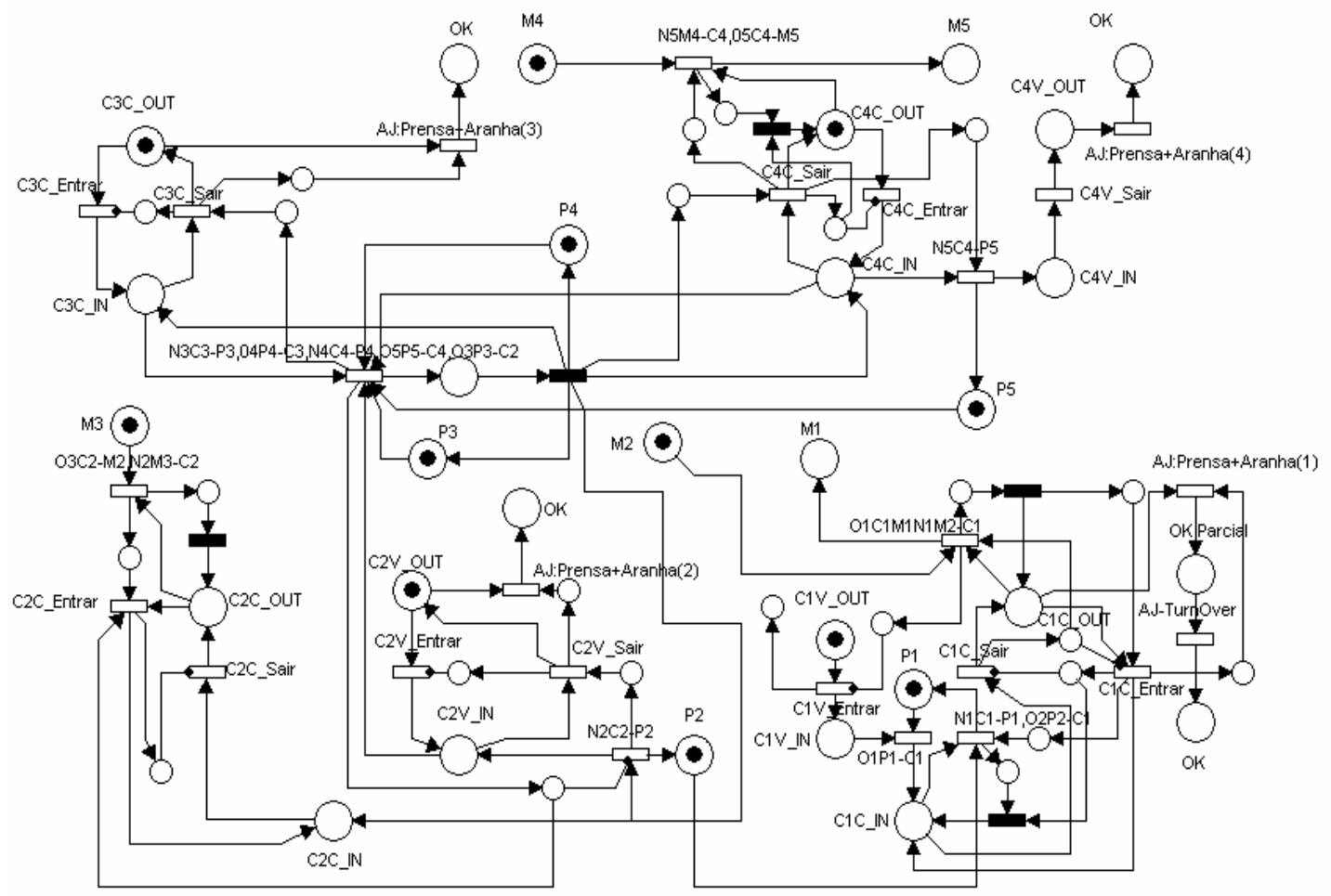

Figura 4.14 - Modelo do processo melhorado de movimentação dos estampos pelos Die Cars. Fonte: Autor. 
Tabela 4.4 - Resultado das simulações do novo processo de Die Set sem quebras. Fonte: Autor.

\begin{tabular}{|c|c|c|c|c|c|}
\hline & & TRANSIÇÖES & ATIVIDADE & $\begin{array}{l}\text { Quantidade de } \\
\text { Acionamentos }\end{array}$ & $\begin{array}{c}\text { Tempo } \\
\text { Total }\end{array}$ \\
\hline & & C1V_Entrar & $\begin{array}{l}\text { Die Car } 1 \text { entrar vazio na } \\
\text { célula } 1\end{array}$ & 1 & 1 \\
\hline & & C1C_Sair & $\begin{array}{l}\text { Die Car } 1 \text { sair da célula } \\
\text { com ferramental (cheio) }\end{array}$ & 2 & 2 \\
\hline & & C1C_Entrar & $\begin{array}{l}\text { Die Car } 1 \text { entrar na célula } \\
\text { com ferramental (cheio) }\end{array}$ & 1 & 1 \\
\hline & $\stackrel{0}{\frac{1}{1}}$ & N1C1-P1,O2P2-C1 & \begin{tabular}{|l|} 
Die Car 1 coloca nova \\
ferramenta 1 na Prensa 1 e \\
retira ferramenta 2 de \\
saída da Prensa 2
\end{tabular} & 1 & 1 \\
\hline & $\underset{\mathbb{d}}{\mathbb{4}}$ & O1P1-C1 & $\begin{array}{l}\text { Die Car } 1 \text { puxa ferramenta } \\
1 \text { de saída da Prensa } 1 \\
\text { para si }\end{array}$ & 1 & 1 \\
\hline & & O1C1M1N1M2-C1 & $\begin{array}{l}\text { Die Car } 1 \text { coloca a } \\
\text { ferramenta } 1 \text { de saída na } \\
\text { mesa } 1 \text { e puxa da mesa } 2 \\
\text { a ferramenta } 1 \text { de entrada }\end{array}$ & 1 & 1 \\
\hline & & AJ:Prensa+Aranha(1) & $\begin{array}{l}\text { Ajustar Prensa } 1 \text { e } \\
\text { aranhas da célula } 1\end{array}$ & 1 & 3 \\
\hline & & AJ-TurnOver & $\begin{array}{l}\text { Ajustar mesa de } \\
\text { transferência e giro da } \\
\text { peça repuxada }\end{array}$ & 1 & 2 \\
\hline & & C2V_Entrar & $\begin{array}{l}\text { Die Car } 2 \text { entrar na vazio } \\
\text { na célula } 2\end{array}$ & 1 & 1 \\
\hline & & C2V_Sair & $\begin{array}{l}\text { Die Car } 2 \text { sair vazio da } \\
\text { célula } 2\end{array}$ & 1 & 1 \\
\hline & & C2C_Entrar & $\begin{array}{l}\text { Die Car } 2 \text { entrar com } \\
\text { ferramental na célula } 2 \\
\text { (cheio) }\end{array}$ & 1 & 1 \\
\hline & $\sim$ & C2C_Sair & $\begin{array}{l}\text { Die Car } 2 \text { sair com } \\
\text { ferramental na célula } 2 \\
\text { (cheio) }\end{array}$ & 1 & 1 \\
\hline 岂 & & $\mathrm{N} 2 \mathrm{C} 2-\mathrm{P} 2$ & $\begin{array}{l}\text { Die Car } 2 \text { coloca nova } \\
\text { ferramenta } 2 \text { na Prensa } 2\end{array}$ & 1 & 1 \\
\hline & & $\mathrm{O} 3 \mathrm{C} 2-\mathrm{M} 2, \mathrm{~N} 2 \mathrm{M} 3-\mathrm{C} 2$ & $\begin{array}{l}\text { Die Car } 2 \text { coloca } \\
\text { ferramenta } 3 \text { de saída na } \\
\text { mesa } 2 \text { e puxa nova } \\
\text { ferramenta } 2 \text { da mesa } 3\end{array}$ & 1 & 1 \\
\hline & & AJl:Prensa+Aranha(2) & $\begin{array}{l}\text { Ajustar Prensa } 2 \text { e } \\
\text { aranhas da célula } 2\end{array}$ & 1 & 1 \\
\hline & & C3C_Entrar & $\begin{array}{l}\text { Die Car } 3 \text { entrar com } \\
\text { ferramental na célula } 3 \\
\text { (cheio) }\end{array}$ & 1 & 1 \\
\hline & $m$ & C3C_Sair & $\begin{array}{l}\text { Die Car } 3 \text { sair com } \\
\text { ferramental da célula } 3 \\
\text { (cheio) }\end{array}$ & 1 & 1 \\
\hline & & Al:Prensa+Aranha(3) & $\begin{array}{l}\text { Ajustar Prensa } 3 \text { e } \\
\text { aranhas da célula } 3\end{array}$ & 1 & 1 \\
\hline & & C4C_Entrar & $\begin{array}{l}\text { Die Car } 4 \text { entrar com } \\
\text { ferramental na célula } 4 \\
\text { (cheio) }\end{array}$ & 2 & 2 \\
\hline & & C4C_Sair & $\begin{array}{l}\text { Die Car } 4 \text { sair com } \\
\text { ferramental da célula } 4 \\
\text { (cheio) }\end{array}$ & 1 & 1 \\
\hline & & C4V_Sair & $\begin{array}{l}\text { Die Car } 4 \text { sair vazio da } \\
\text { célula } 4\end{array}$ & 1 & 1 \\
\hline & $\rightarrow$ & N5M4-C4,05C4-M5 & $\begin{array}{l}\text { Die Car } 4 \text { coloca } \\
\text { ferramenta } 5 \text { de saída na } \\
\text { mesa } 5 \text { e puxa nova } \\
\text { ferramenta } 5 \text { da mesa } 4\end{array}$ & 1 & 1 \\
\hline & & N5C4-P5 & $\begin{array}{l}\text { Die Car } 4 \text { coloca nova } \\
\text { ferramenta } 5 \text { na Prensa } 5\end{array}$ & 1 & 1 \\
\hline & & Ad:Prensa+Aranha(4) & $\begin{array}{l}\text { Ajustar Prensas e aranhas } \\
\text { da célula } 4\end{array}$ & 1 & 1 \\
\hline & $2 / 3 / 4$ & $\begin{array}{l}\text { N3C3-P3,04P4-C3,N4C4- } \\
\text { P4,O5P5-C4,O3P3-C2 }\end{array}$ & $\begin{array}{l}\text { Troca simultânea de } \\
\text { ferramentais }\end{array}$ & 1 & 2 \\
\hline & & \begin{tabular}{|c|} 
TEMPO TOTAL DA \\
SIMULAÇÄO SEM QUEBRA \\
OU ATRASO
\end{tabular} & 12 minutos & & \\
\hline
\end{tabular}


Neste modelo, também foram executadas simulações de paradas de equipamentos para manutenção corretiva ou atrasos por falhas operacionais que demonstraram um processo bem mais robusto e flexível, visto que em $68 \%$ das atividades, quebras de equipamentos ou falhas operacionais de até três minutos não interferiram no tempo de Die Set. O foco maior, então, deve ser dado à célula gargalo pois nesta, qualquer quebra ou atraso reflete diretamente em acréscimo do tempo de Die Set. O resultado dessa simulação encontra-se na Tabela 4.5. Apesar dessas paradas ou atrasos durante a execução dos Die Sets não serem o foco desse projeto Seis Sigma, pela aplicação da modelagem, todos passaram a ter uma visão global do processo e seus subprocessos, em vez de uma visão parcial. Pode-se afirmar que esta visão sistêmica é umas das principais características da modelagem de processos, pois demonstra que cada parte do trabalho deve ser vista e analisada em relação ao todo. 
Tabela 4.5 - Resultado das simulações do novo Die Set considerando-se quebras. Fonte: Autor.

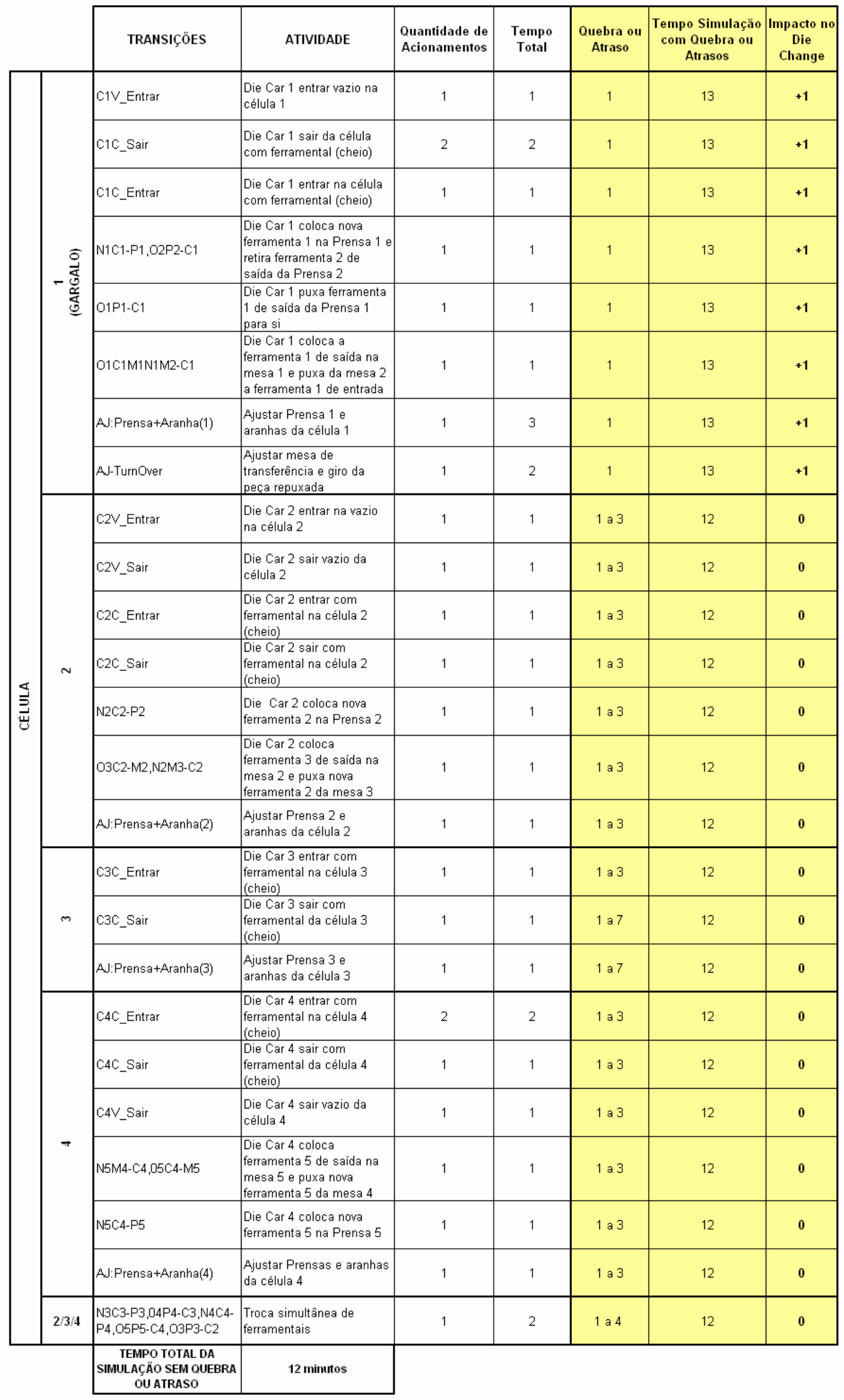




\subsubsection{Etapa 5 - Controlando o Processo}

As ações propostas pelo time Seis Sigma para a fase Controlar foram:

- Revisão das QPS's de Die Set.

- Elaboração e divulgação de uma instrução de trabalho sobre a sequência de movimentação dos Die Cars.

- Elaboração e divulgação de um Auxílio Visual da Troca do Ferramental.

- Implementação de auditorias internas no processo de Troca do Ferramental.

\subsubsection{Análise Crítica da Etapa 5}

$\mathrm{O}$ aspecto mais importante para se manter o controle de melhorias implementadas, é prover uma documentação adequada de todos os passos das melhorias incluindo as ações que não tiveram sucesso. Essa documentação deve migrar para a documentação do projeto e devese ter, na empresa, a cultura de se consultar todas a documentação do projeto antes de se propor melhorias em um determinado processo. Tal cultura somente pode se consolidada se houver um procedimento claro - atuação sistêmica - para toda a organização, conforme proposto no Capítulo 3.

\subsection{Resultados Obtidos}

Considerando-se que o tempo de desenvolvimento do projeto no formato tradicional foi de 4 meses (igual a média da fábrica) e que os testes e modelos no Power Point consumiram 1,5 meses, pode-se afirmar que o tempo de desenvolvimento de um projeto Seis Sigma de um processo já modelado, conforme o processo proposto, reduziria em 30 dias a 
conclusão do projeto. Isto daria 1 projeto Seis Sigma a mais por Black Belt no ano. Sendo a média de redução de custos por projeto Black Belt igual a $\mathrm{R} \$ 100.000,00$ (cem mil reais), este seria o valor anual ganho pela empresa por Black Belt, apenas considerando-se abertura de projetos.

Especificamente com relação aos ganhos do projeto Seis Sigma objeto do estudo de caso, pode ser visto na Figura 4.15 o gráfico de controle individual da movimentação dos die cars durante a realização de 90 Die Sets (relativos a um mês de produção) antes das modificações propostas (tempo médio de 13,125 minutos com amplitude móvel média de 1,5) e na Figura 4.16 o gráfico de controle de 90 Die Sets após as melhorias (tempo médio de 12,049 minutos com um amplitude móvel média de 0,571). Logo, pode ser visto um ganho direto de 1 minuto na média e redução da dispersão desse processo.

A somatória total do tempo de movimentação dos die cars para os 90 Die Sets analisados de antes da melhoria foi igual a 1179 minutos e após, 1084 minutos. Logo, tem-se um ganho mensal de 95 minutos. Sendo o valor da hora de linha parada da estamparia igual a $\mathrm{R} \$ 2.000,00$, tem-se anualmente uma redução de custo da ordem de $\mathrm{R} \$ 40.000,00$. 


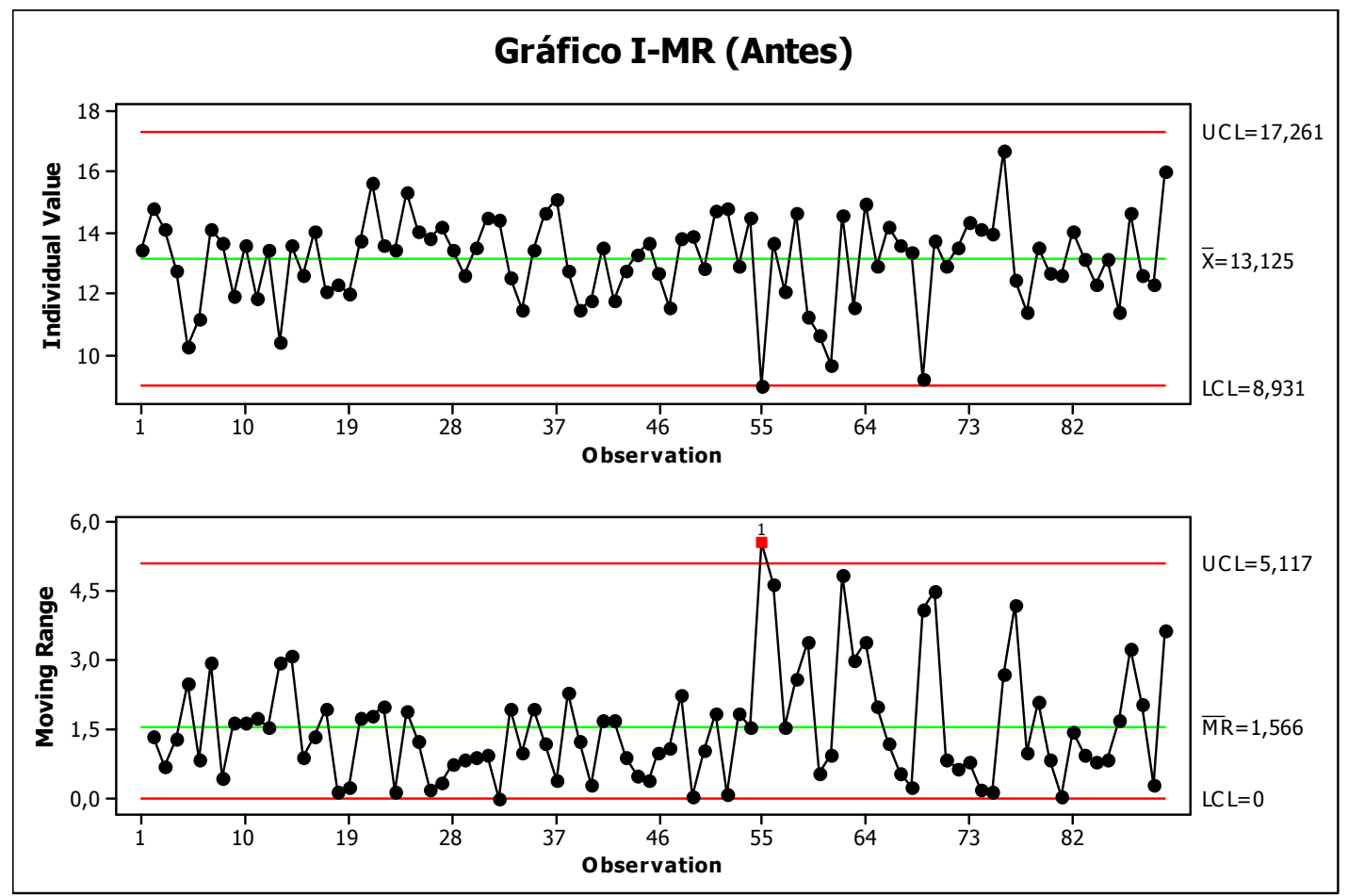

Figura 4.15 - Carta de Controle I-MR do processo de movimentação dos Die Cars na Troca do Ferramental anterior a melhoria. Fonte: Autor.

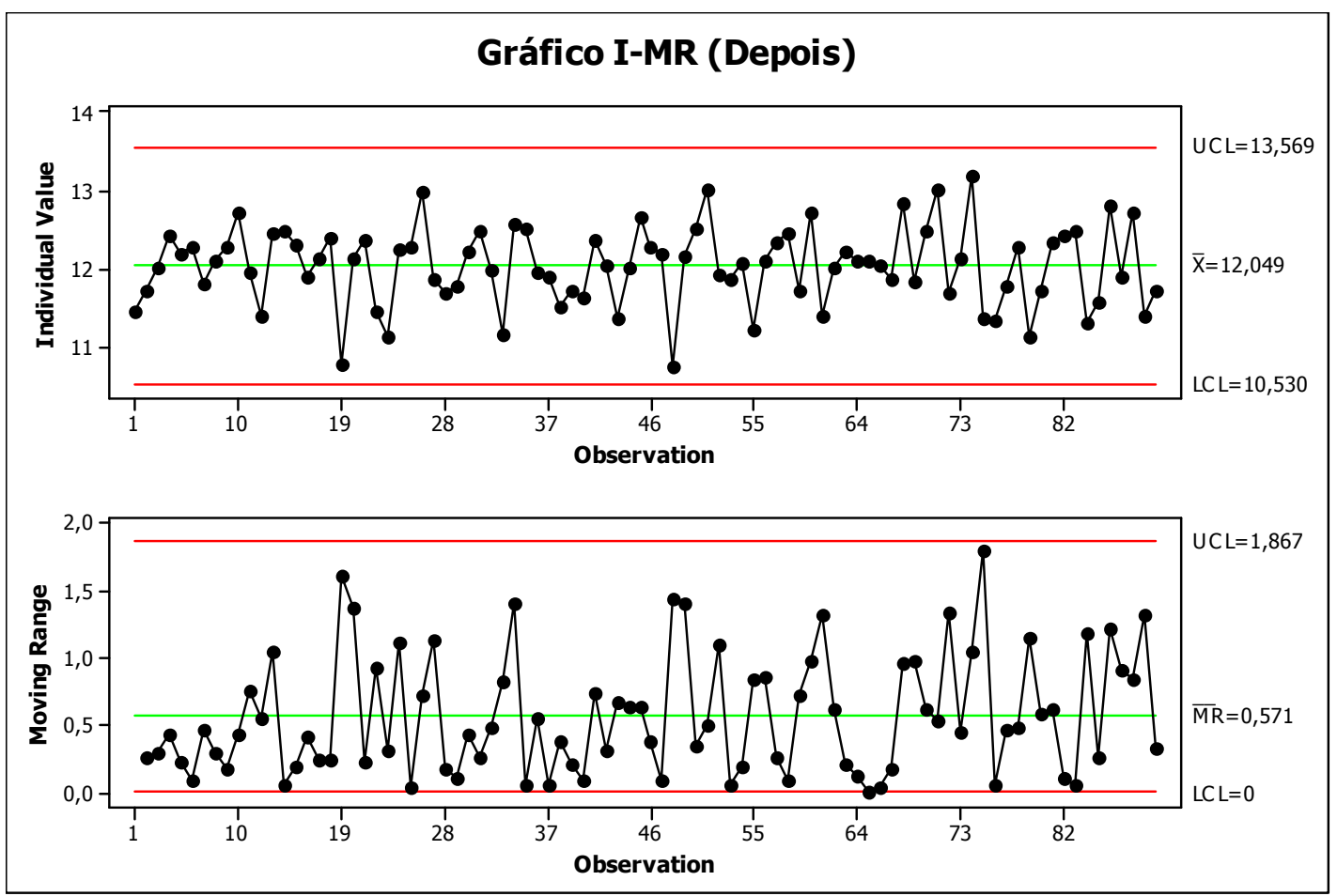

Figura 4.16 - Carta de Controle I-MR do processo de movimentação dos Die Cars na Troca do Ferramental após implementação da melhoria. Fonte: Autor. 


\section{CONCLUSÕES E TRABALHOS FUTUROS}

O estudo de uma metodologia para se estabelecer uma modelagem sistêmica do processo de melhoria contínua de processos industriais utilizando o Seis Sigma e redes de Petri vem de encontro a uma necessidade das empresas de dominar os processos e serem competitivas. Um modelo representativo de determinado processo industrial permite que se possam desenvolver análises por meio de simulações e, desta forma, otimizar tal processo, validá-lo, bem como estabelecer técnicas de controle que atendam as necessidades produtivas, sendo uma excelente ferramenta para desenvolvimento de projetos Seis Sigma ou de qualquer outro método de melhoria contínua.

Focou-se no desenvolvimento e validação dessa dissertação por meio do método Seis Sigma - método de melhoria contínua mais em voga na atualidade. Em vista da empresa objeto do estudo de caso não possuir nenhum processo da área de Estamparia já modelada e abordando o sistema de Die Set como uma classe de sistema a eventos discretos que permite a utilização de técnicas como as Redes de Petris Hierárquicas e Temporizadas, se optou por modelar em HPSim apenas o processo mais crítico observado durante o desenvolvimento do projeto Seis Sigma que foi o processo de movimentação dos Die Cars. A estratégia de engenharia reversa - pois aplicamos o método proposto neste trabalho apenas após o projeto Seis Sigma ter sido finalizado - mostrou-se eficaz, sobretudo por conseguir estabelecer parâmetros claros de comparação entre o método tradicional e o método apresentado.

Ao longo do processo de estudo e modelagem constatou-se que o modelo pode tornarse bastante complexo a depender do tamanho do processo. Visto que foi modelada apenas uma das etapas do processo de Die Set, não foi necessária a utilização de redes de Petri hierárquicas, o que seria um importante recurso no caso da modelagem completa da Estamparia. A utilização de redes de Petri hierárquicas permitiria ao time Seis Sigma 
"explodir" apenas o processo de interesse para sua análise, porém uma das consequiências seria a exigência de um maior nível de abstração por parte das pessoas envolvidas na modelagem, visto que os modelos encapsulados passam a conter muitas informações não explícitas. Contudo, essa característica é menos relevante quando se leva em consideração a simplificação oferecida no processo de modelagem.

Existe um resultado prático deste trabalho que aponta para o tempo que geralmente se perde no ciclo de melhoria contínua, recompondo informações perdidas sobre os processos, pela não conformidade entre o sistema de melhoria contínua e sua documentação. Ou pior, propostas de melhorias sem sequer conhecer a documentação do processo, como foi constatado no estudo de caso. O estudo de caso se mostrou eficaz, principalmente, sob o ponto de vista da constatação de que a documentação do processo, quando apropriada e devidamente analisada, conduz os times de chão-de-fábrica a focar nos reais problemas do processo, entendendo o projetado em relação ao real e podendo realizar ajustes que podem ser de simples disciplina e revisão dos controles não demandando projetos complexos de melhoria contínua. Por outro lado, por mais simples que sejam as melhorias nos processos industriais, as mesmas devem ser documentadas estabelecendo-se uma forte integração entre times de projeto e produção que resultará numa documentação "viva" do processo e sobretudo, acessível. Esse conceito garante que o ciclo de conhecimento e de melhoria contínua da empresa seja fomentado, controlado e validado diariamente.

Outra consideração importante foi a validação da proposta de integração entre as ferramentas de modelagem e simulação com o ciclo de melhoria contínua, onde se teve resultados práticos bem positivos, principalmente pelo fato de levar ao time o conhecimento profundo do processo.

Como trabalho futuro o autor pretende desenvolver a partir dos requisitos da metodologia Seis Sigma sua modelagem em RdP. 


\section{REFERÊNCIAS BIBLIOGRÁFICAS}

AGUIAR, S. Integração das ferramentas da qualidade ao P.D.C.A. e ao programa Seis Sigma. Belo Horizonte: Editora DG, v.1, 2002.

AIAG, Automotive Industry Action Group, Measurement Systems Analysis (MSA) Reference Manual, Chrysler Corporation, Ford Motor Company, General Motors Corporation, Detroit Michigan, 1995.

AKAO, Y. Quality Function Deployment - QFD: Integrating Customer Requirements into Product Design. USA: Productivity Press., 1990. p. 12-47

AL-JAAR, R.; DESROCHES, A. Performance Evaluation of Automated Manufacturing Systems Using Generalized Stocastic Petri Net. IEEE Transaction on Robotic and Automation, Vol. 6, 1990. p. 621-639

ANDRADE, E. L. Introdução à Pesquisa Operacional. Rio de Janeiro: Livros Técnicos e Científicos, 1989, p. 156-171.

ARAKAKI, J.; MIYAGI, P.; SANTOS, D. Análise de sistemas integrados de manufatura baseada na metodologia MFG/PFS. Workshop Ibero-Americano de Sistemas Autônomos em Robótica - Robótica e Automatização: Revista de Informação Técnica e Científica. Lisboa, 1992., n.10. p.19-24.

ARIENTE, M.; CASADEI, M.; GIULIANI, A.; SPERS, E.; PIZZINATTO, N. Processo de mudança organizacional: estudo de caso do Seis Sigma. Revista da FAE - volume 6, nº1. Disponível em:

http://www.fae.edu/publicacoes/pdf/revista_da_fae/rev_fae_v8_n1/rev_fae_v8_n1_07.pdf

BASU, R; WRIGHT, N. Quality Beyond Six Sigma. São Paulo: Elsevier Butterworth Heinemann, 2003.

BERRYMAN \& ASSOCIATES. Design for six sigma clients. Disponível em: http://www.berryman-dfss.com. USA, 2001.

BESSANT, J.; CAFFYN, S.; GILBERT, J.; HARDING R; WEBB, S. Rediscovering continuous improvement. Technovation. v. 14, n. 1, 1994, p. 17-29. 
BESSANT, J., CAFFYN, S.; GALLAGHER, M. An evolucionary model of continous improvement behaviour. Technovation. v. 21, n. 1, 2001, p. 67-77.

BRAZ, M.A. Tópicos especiais em controle de qualidade: Seis Sigma metodologia. São Caetano do Sul, 2002.

CARY, A.; GUPTA, P.; WILSON JR., C. Six Sigma deployment. São Paulo: Butterworth Heinemann, 2003.

CASSANDRAS, C. Discrete event system: Modeling and performance analysis. Boston: Irwin Publications, 1993.

CHENG, L. QFD: Planejamento da Qualidade. Rio de Janeiro: Fundação Christiano Ottoni, 1995.

CLARK, K.B.; FUJIMOTO, T. Product development performance: strategy, organization, and management in the world auto industry. Boston: Havard Business School Press, 1991.

CLARK, K.B.; WHEELRIGHT, S.C. Revolutionizing product development: quantum leaps in speed, efficiency and quality. New York, The Free Press, 1992.

DESROCHES,A.A.; AL-JAAR, R.Y. Applications of Petri Nets in Manufacturing Systems. IEEE Press, 1995.

DALE B.; SHAW P. Failure mode and effects analysis in UK motor industry: a state-of-art study. Quality Progress, Setembro 2003. p. 46-50.

DENHAM, M. Petri net approach to discrete event control: Proceedings of the IEE Colloquium on Modelling, Simulation and Control of Discrete Event System. Digest No. 146. London, 1989.

DER JENG, M., DI CESARE, F. A Review of Synthesis Techniques for Petri Nets with Applications to Automated Manufacturing Systems, IEEE Transactions on Systems, Man and Cybernetics, Ed. 3. 1993. p. 301-312.

ECKES, G. A revolução Seis Sigma: o método que levou a GE e outras empresas a transformar processos em lucros, Rio de Janeiro: Campus, 2001. 
ENOKI, C. Gestão de Processos de Negócio: Uma contribuição para avaliação de soluções de Business Process Management (BPM) sob a ótica de estratégia de operações. Dissertação (Mestrado em Engenharia) - Escola Politécnica, Universidade de São Paulo, São Paulo,2006.

FEIGENBAUM, A.V. Controle da qualidade total. São Paulo: Makron Books. v.1-4, 1994, p.98

FIORAVANTI, A. Aplicação da metodologia “Design for Six Sigma” (DFSS) em projetos automotivos. Dissertação (Mestrado em Engenharia) - Escola Politécnica, Universidade de São Paulo, São Paulo, 2005.

FERNANDES, J.M.R. Proposição de abordagem integrada de métodos da qualidade baseada no FMEA. Dissertação (Mestrado em Engenharia) - Pontifícia Universidade Católica do Paraná, Curitiba, 2005.

FLORENZANO, M.C. Gestão de desenvolvimento de produtos: estudo de casos na indústria brasileira de autopeças sobre a divisão de tarefas, capacidade e integração interunidades. Dissertação (Mestrado em Engenharia) - Universidade de São Carlos, São Carlos, 2000.

GINN, D.M.; JONES, D.V.; RAHNEJAT, H.; ZAIRI, M. The QFD/FMEA Interface. European Journal of Innovation Management, vol. 1, n.1, 1998, p. 7-20.

GIRAULT, C.; VALK, R. Petri Nets for System Engineering. Springer, 2003.

GRIFFIN, A.; PAGE, A.L. An interim report on measuring product development sucess and failure. Journal of production innovation management, v.10, n.2, September,1993. p.291-308

HARRY, M.J.; SCHROEDER, R. Six Sigma: a breakthrough strategy for profitability. Quality Progress, New York, May 1998.

JENSEN, K. Coloured Petri Nets - Basic concepts, analysis methods and pratical use, Berlin: Sringer Verlag, 1992.

JENSEN, K; HUBER, P.; SHAPIRO, R. M. Hierarchies in Coloured Petri Nets, volume 483. Springer-Verlag, 1990.

JURAN, J.M. A qualidade desde o projeto: os novos passos para o planejamento da qualidade em produtos e serviços. $1^{\mathrm{a}}$ ed. São Paulo: Pioneira Thimson Learning, 2002. 
KATO, E.R.R., MORANDIR, O., POLITANO, P.R., CAMARGO, H.A.C. Control Design Aproach for Complex Automatic Manufacturing Systems, IEEE, 2001.

KAMINSKI, P. C. Desenvolvendo produtos com planejamento, criatividade e qualidade. Rio de Janeiro: Ed. LTC, 2000.

LAFRAIA, J.M. Manual da confiabilidade, mantenabilidade e disponibilidade. $1^{\mathrm{a}}$ ed. Rio de Janeiro: Qualitymark, 2001.

LAWRENCE ASSOCIATES INC. Virtual Manufacturing Technical Workshop, 25-26 october, 1994.

LIN, E. Contribution to Virtual Manufacturing Background Research, 1995. Disponível em http://www.isr.umd.edu/Labs/CIM/vm/report/report.html. Acesso em 13 out. 2007.

LIU, W.; MIYAGI, P; SCHREEK, G. MFG/PFS Methodology in manufacturing industries. Studies in Informatics and Control. v.3, 1994.

MIYAGI, P. Control system design, analysis and implementation of discrete event production system by using mark flow graph. Tese (Doutorado em Engenharia) - Tokyo Institute of Technology. Tokyo, 1988.

MIYAGI, P. Controle programável: fundamentos do controle de sistemas a eventos discretos. São Paulo: Editora Edgard Blucher, 1996.

MURATA, T., Petri Nets: Properties, Analysis and Applications, Proceeding IEEE, vol. 77, No. 4, April, 1989.

NETTO, FRANCISCO S. Medição de Desempenho do Gerenciamento de Processos de Negócio - BPM no PNAFE: Uma Proposta de Modelo, Tese (Doutorado em Engenharia) Escola Politécnica, Universidade de São Paulo, São Paulo, 2006.

PALOMINO, R. C. Uma Abordagem para a Modelagem, Análise e Controle de Sistemas de Produção Utilizando Redes de Petri, Dissertação (Mestrado em Engenharia) - Universidade Federal de São Carlos, São Carlos, São Paulo, Agosto, 2005. Disponível em: http://www.eps.ufsc.br/disserta/palomino/indice/index.htm 
PANDE, P.; NEUMAN, R. P. e CAVANAGH, R. R. Estratégia Seis Sigma: Como a GE, a Motorola e outras grandes empresas estão aguçando seu desempenho. Rio de Janeiro: Qualitymark, 2001.

PENG, S., ZHOU, M. Conversion Between Ladder Diagrams and Petri Nets in Discrete Event Control Design, IEEE, 2001.

PEREZ-WILSON, M. Seis Sigma: compreendendo o conceito, as implicações e os desafios. Rio de Janeiro: Qualitymark Ed., 1999.

PETERSON, J. Petri Net theory and the modeling of systems. Engelwood Cliffs: Prentice Hall, 1981.

PINE II, B. J. Personalizando Produtos e Serviços - Customização Maciça - A Nova Fronteira da Competição dos Negócios. Makron Books, São Paulo, 1994, p. 184-231.

PORTER, L. Six Sigma Excellence. Quality world, 2000. p.12-15

PORTER, M. E.; MILLAR, V.E. How information gives you competitive advantage. Harward Business Review. Agosto, 1985

PORTO, A. J. V.; PALMA, J. G. Da Manufatura Virtual à Simulação e à Realidade Virtual. In: Fábrica do Futuro: entenda hoje como sua indústria vai ser amanhã, ed. Banas, 2000.

PUENTE, J.; PINO, R.; PRIORE, P.; FOUNTE, D. A decision support system for applying failure mode and effects analysis. International Journal of Quality \& Reliability Management, vol.19, n.2, 2002. p. 378-397.

PUGH, S. Creating innovative products using total design: the living legacy of Stuart Pugh. Haddison-Wesley Publishing Company, Massachusetts, 1996.

RAMADGE, P.; WONHAM, W. The control of discrete event system. Proceedings of the IEE. v.77, n.1. 1989.

RAMCHANDANI, C. Analysis of asynchronous concurrent systems by petri nets. In Project MAC, TR-120, Cambridge, MA: MIT, Fev.1974.

RECHULSKI, D.; CARVALHO, M. Programas de Qualidade Seis Sigma: Características Distintivas dos Modelos DMAIC e DFSS. Artigo apresentado no XI SIMPEP, Bauru/SP, 2004. 
REISIG, W. Petri nets an introduction. New York: Springer Verlag, 1985.

RIASCOS, L. Metodologia para detecção e tratamento de falhas em sistemas de manufatura através de Rede de Petri. Tese (Doutorado em Engenharia) - Escola Politécnica, Universidade de São Paulo, São Paulo, 2002.

ROTONDARO, R. G. Seis Sigma: estratégia gerencial para melhoria de processos, produtos e serviços. São Paulo: Atlas, 2002.

REIS, D. Seis Sigma: um estudo aplicado ao setor eletrônico. Dissertação (Mestrado em Engenharia) - Universidade do Rio Grande do Sul - Porto Alegre, 2003.

http://www.producao.ufrgs.br/dissert_mestrado/Delmar_Flemming.pdf

SETEC CONSULTING GROUP. FMEA, apostila de treinamento, Julho, 2006

SHANNON, R. E. Introduction to the Art and Science of Simulation, in Proceedings of the 1998 Winter Simulation Conference, Washington, D.C., December 13 - 16. Disponível em: www.informscs.org/wscpapers.html.

SILVA, L. D.; PERKUSICH, A. Modelagem Sistemática de Sistemas Flexíveis de Manufatura. Congresso Brasileiro de Automática, Natal-RN, 2001.

SILVA, E. L.; MENEZES, E. M. Metodologia da pesquisa e elaboração da dissertação. Florianópolis: UFSC/PPGEP/LED, 2000.

SILVA, W. J. Um Ambiente de Suporte à Modelagem Hierárquica por Redes de Petri para Sistemas de Produção. Dissertação de mestrado, UFPE, Pernambuco, 2005.

SIMÕES, M. A. Modelagem dos Processos de Decisão em Operação de Sistemas de Produção com Redes de Petri e Teoria Fuzzy. Tese de doutorado, USP, São Paulo, 2000.

STAMATIS, D. H. Failure Mode and Effect Analysis: FMEA from theory to execution. 2. ed. ASQC, Milwaukee: Quality Press, 2003. 494 p.

TUBINO, Dalvio Ferrari. Manual de Planejamento e Controle da Produção. São Paulo: Atlas, 1997.

VALERI, SANDRO G. Estudo do processo de revisão de fases no processo de desenvolvimento de produtos em uma indústria automobilística. Dissertação de mestrado, USP, São Carlos, 2000. 
VASCONCELOS, N.; TEIXEIRA, F. Estratégia Competitiva e Impacto Local: A Indústria Automobilística na Bahia. Nexos Econômico. Salvador: UFBA-FCE-CME, 2000.

XIONG, H. H.; ZHOU, M.; CANDILL, R. J. A Hybrid Heuristic search Algorithm for Scheduling Flexible Manufacturing. Proceeding IEEE, 1996.

YAMADA, C. M., PORTO, A.J.V., INAMASU, R.Y., Aplicação dos Conceitos de Modelagem e de Redes de Petri na Análise do Processo Produtivo da Indústria Sucroalcooleira. Pesq. Agrop. Brás., Brasília, V.37, No. 6, p809-820, Junho 2002.

ZHOU, M., DICESARE, F., Petri Net Synthesis for Discrete Event Control of Manufacturing Systems, The Kluwer International Series in Engineering and Computer Science, Kluwer Academic Pub., New York, 1993.

WAVE Report. 3D - Points to Ponder. 2002. Disponível em: <http://www.wavereport.com>. Acesso em: 3 abr. 2008.

WERKEMA, M.C.C. Criando a cultura seis sigma. Qualitymark, Rio de Janeiro, 2002. 


\section{Apêndice A - WITNESS e o Seis Sigma}

O WITNESS é uma solução de simulação desenvolvida pelo Lanner Group que tem auxiliado grandes indústrias a prever os resultados de mudanças nos seus negócios.

WITNESS pode ajudar na maioria das fases dos projetos Seis Sigma. Na fase definir ele pode ajudar a identificar onde as mudanças de um processo podem ter mais impacto e assim auxiliar na seleção dos projetos mais apropriados. Durante as outras fases do projeto WITNESS pode prover detalhes estatísticos no efeito de alguma mudança proposta em termos de produção, cargas, atrasos etc.

WITNESS oferece mais funcionalidade para definir e medir o desempenho de um processo com exatidão. Caso o processo seja de manufatura ou serviços, o WITNESS permite modelos precisos para serem construidos rapidamente com total detalhe matemático de tal forma que o desempenho atual ou futuro possa ser avaliado adequadamente.

Modelos em WITNESS permitem incluir aspectos tais como alocação de recursos, distribuição de tempos, rotas completas e programação e taxas de trabalho. Permitem fácil uso de dados do banco de dados e do Microsoft Excel, sendo possível definir dados no modelo e exportar para o Excel para cálculos futuros ou produção de gráficos com facilidade.

É importante em muitos projetos Seis Sigma ser capaz de medir taxas de refugos e retrabalhos dentro de um modelo de processo ou produção e o WITNESS pode gerenciar isto com facilidade. O elemento refugo permite analisar as taxas e razões pelas quais defeitos nos produtos ocorrerão. WITNESS capturará toda informação de defeito durante uma corrida de simulação e então automaticamente traduzirá isto para o nível sigma do processo para cada peça ou entidade no modelo. Estas são apresentadas com outras informações estatísticas essenciais na tela de relatório da peça. 


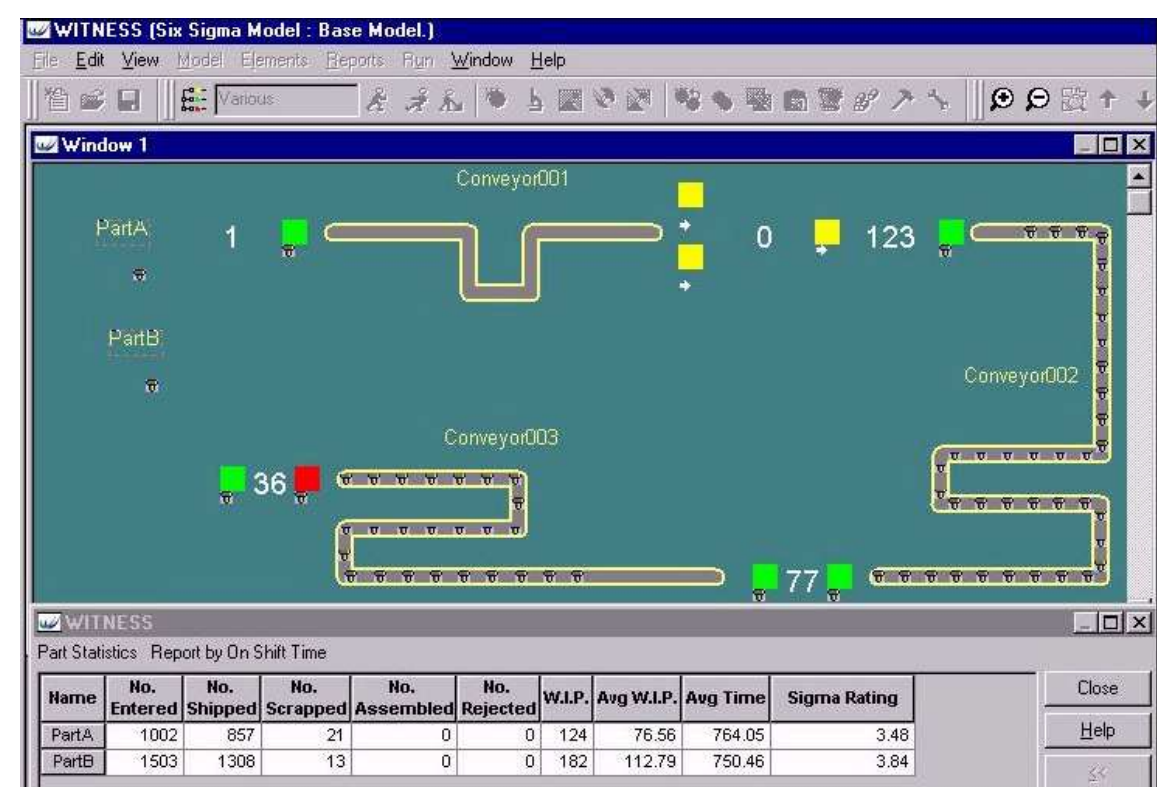

Figura A. 1 - Modelo em WITNESS com tela de resultados mostrando o nível Sigma

Os relatórios do WITNESS utilizam, normalmente, o nível Sigma ajustado em 1,5 desvios padrão devido a variação a longo prazo.

WITNESS também permite a inclusão de outros defeitos no desempenho da produção, tais como retrabalhos e reclamações de garantia que podem ser incluidas em qualquer modelo e o nível Sigma incorporado desses fatores pode ser calculado e mostrado automaticamente usando a função "Sigma Rating" incluída no WITNESS para permitir essa flexibilidade. Tais como medidas de retrabalho, scrap e garantia, pode-se aplicar o nível Sigma para medir, por exemplo, tempo de execução de um serviço ou "jobs per hour" - por exemplo, um processo pode ter um objetivo definido de doze minutos para completar um determinado serviço. $\mathrm{O}$ número de entidades processadas acima desse tempo, pode ser chamado de "defeito" e ser atribuído ao processo um nível Sigma da mesma forma dos defeitos de produtos.

A rigorosa análise requerida pelo Seis Sigma inclui muitos testes estatísticos. Freqüentemente é importante checar se os dados são distribuidos normalmente de forma a validá-los em níveis Sigma. O praticante do Seis Sigma desejará produzir vários diferentes 
gráficos e o WITNESS oferece um link direto para exportação do software estatístico MINITAB - um produto de análise detalhada de dados, necessário ao programa Seis Sigma. Usuários podem escolher quando exportar dados de variáveis chave e podem também escolher exportar qualquer parte das páginas dos relatórios estatísticos gerados pelo modelo. WITNESS inclui um botão na barra de ferramentas que permite efetuar a transferência de dados onde os dados são colocados automaticamente dentro da planilha do MINITAB.

\section{- Suporte à Definição do Projeto Seis Sigma}

O time do Seis Sigma frequentemente necessita identificar as melhores áreas para projetos de melhoria. Para qualquer processo de produção existe diferentes focos pelos quais os projetos poderiam ser escolhidos. O Black Belt deve identificar quais projetos oferecem maior potencial de melhoria para escolhê-los e priorizá-los.

Modelos de simulação do processo são feitos de forma a mostrar quais melhorias são possíveis através de ajuste de equipamentos, recursos, layout e controle.

Por exemplo, numa dada linha de produção há vários itens de equipamento onde melhorias individuais poderiam ser realizadas. Tipicamente, a atual taxa de desempenho é comparada ao conjunto de padrão teórico de trabalho da máquina. Uma gama de experimentos de simulação deve ser executado ajustando confiabilidade e tempo de ciclo etc para avaliar o valor agregado de diferentes tipos de melhorias com uma única medida de saída para a linha como um todo, como por exemplo, "jobs per hour". Parâmetros que podem ser mudados para o experimento incluem taxas e tempos de quebra, perdas de ciclo, taxas de refugo, tempos de troca de ferramentas etc. 
Por meio do WITNESS estes experimentos podem ser executados interativamente com o modelo, explorando e avaliando todas as formas de mudanças nestas áreas e ilustrando as diferenças entre os cenários. Algumas entradas que são importantes e necessárias para a modelagem no WITNESS:

- Quais as respostas que se deseja obter do modelo?

- Processo (o que ocorre e quando)

- Layout (esboço dimensional da área a ser modelada)

- Jornada de Trabalho (número de minutos excluindo o descanso permitido por semana)

- Eficiência (qual a eficiência do processo, por exemplo 95\%)

- Volume/Produção (quantas peças deixam a linha por semana)

- Tempo de ciclo do processo (com que freqüência uma peça entra)

- Mix de Produção/Derivados (quantidade e mix de cada derivado que terá efeito no processo)

- Batch (tamanho do grupo de produção)

- Tamanho da Peça (dimensões da peça)

- Passo (distância entra as peças)

- Regras e Tempo de Correção (quando erros são notados quais pontos são corrigidos, onde são corrigidos e em que tempo)

- Tempo de Tato - Takt time (tempo em que a peça fica em cada estação)

- Atrasos (quais atrasos ocorrem antes da peça ser liberada)

- Velocidade da Esteiras/Transportadores (qual a velocidade de cada transportador)

- Quebras

- Changeovers (atrasos que ocorrem devido a mudança do derivado)

- Tempo de Set Up (tempo que leva para parametrizar uma estação e freqüência com que isto é feito) 
O modelo de sistemas de manufatura utilizando o software WITNESS pode ser utilizado para a análise/verificação de propriedades qualitativas assim como para estimativas de métricas de desempenho dos sistemas produtivos. Também é possível, a partir deste modelo, a geração do escalonamento das atividades nestes sistemas de produção. Estes modelos, do ponto de vista do usuário (engenheiro de produção) consistem em um conjunto de ícones interconectados que determinam a planta (com suas máquinas, equipamentos de transporte etc) e os roteiros de produção. Estes ícones são objetos de alto nível que não fazem referência a modelos formais permitindo assim, que o relacionamento entre os componentes do sistema sejam melhores visualizados, compreendidos e documentados. Dessa forma, o usuário não necessita conhecer a teoria de RdPs ou Teoria de Filas para poder utilizar a ferramenta.

\section{- Soluções de Negócio usando o WITNESS}

Uma das grandes questões que uma organização deve abordar ao introduzir a simulação é sobre quem deve realizar o trabalho de simulação. A decisão usualmente depende da estrutura organizacional, onde na estrutura está o atual defensor da simulação, a habilidade do staff disponível, e se a terceirização do trabalho de modelagem é ou não considerada.

A abordagem de construção do modelo da simulação adotado pela maioria das companhias pode ser classificado, de modo geral, de duas formas ou numa combinação delas. Essas abordagens são listadas a seguir:

a) Abordagem de Consultoria Interna, onde existe um departamento centralizado de especialistas em simulação atuando como consultores para os demais usuários na companhia. Estes usuários analisam os modelos construidos por esses consultores internos e implementam as soluções geradas. 
b) Abordagem distribuída, onde muitos modeladores constroem e analisam modelos de simulação além de implementar os resultados.

\section{ABORDAGEM DE CONSULTORIA INTERNA}

As vantagens de uma abordagem de consultoria interna são:

1. Os consultores internos tornam-se especialistas na ferramenta e isto encurta significativamente a fase de construção do modelo.

2. A metodologia e estatísticas usadas no projeto são mais prováveis de serem uma boa prática, por exemplo, número de corridas estocásticas, períodos de preparação.

As desvantagens são:

1. Os consultores precisam ser educados pelos especialistas do processo para entenderem como funciona realmente o processo.

2. Os consultores dependem freqüentemente dos seus clientes internos para fornecerem dados que suportem o modelo.

As organizações que seguem a abordagem de consultoria interna podem fazer vários modelos flexíveis seguindo os estágios mostrados na Figura A. 2.

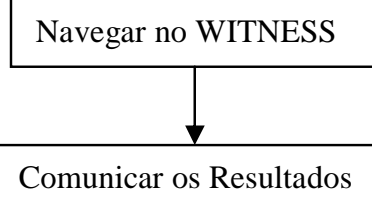

Figura A. 2 - Estágios da Modelagem. 


\section{- Navegando no WITNESS}

Esta técnica permite o construtor do modelo moldar o modelo finalizado dentro de um shell que permite ao usuário alimentar e mudar os dados, criando vários cenários de negócio sem ter que acessar os códigos detalhados de simulação.

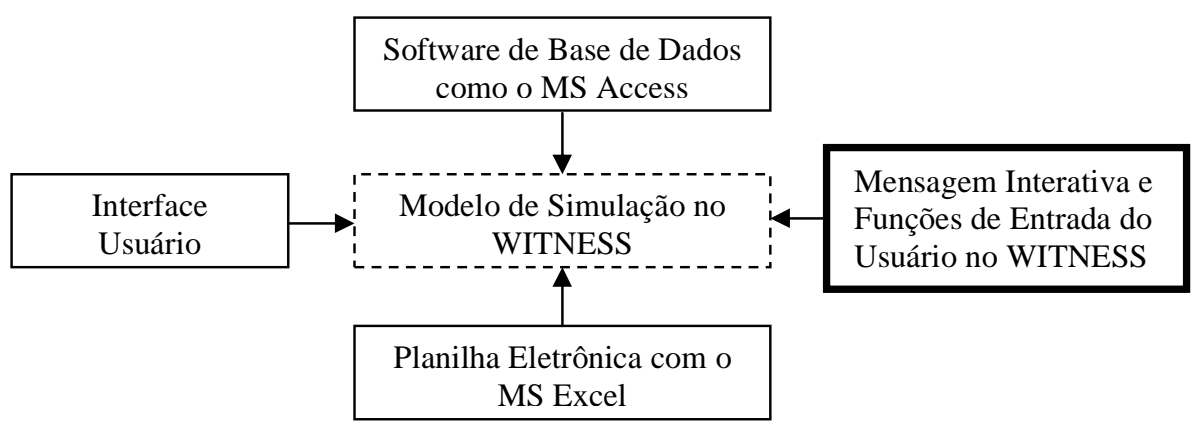

Figura A. 3 - Modelo de Simulação Navegando no WITNESS.

WITNESS é equipado com várias funções que podem ser usadas para aceitar entradas do usuário. WITNESS aceita a entrada e modificação de acordo com o modelo. O usuário pode, portanto, modificar o modelo e fazer análises "o que-se" sem ser especialista no WITNESS ou mesmo de simulação. As caixas de entrada são bem flexíveis e permitem escolhas de listas drop-down como também campos de entrada numéricas. Funções do sistema permitem ao usuário entradas para configurar o modelo.

O grupo Lanner tem realizado muitos projetos usando essa abordagem para prover uma solução personalizada aos clientes.

\section{- Comunicando os Resultados}


A abordagem de consultoria interna demanda que os resultados dos modelos sejam comunicados efetivamente. Algumas das capacidades do WITNESS de suportar esta comunicação estão listadas a seguir:

\section{Realidade Virtual}

Tem a capacidade de simular sem um ambiente virtual. Gráficos 2D são suplantados por um mundo que pode ser navegado através do mouse. Cameras podem ser localizadas na cabeça dos trabalhadores ou nas peças de forma que o usuário possa passeiar pelo modelo.

\section{Arquivod AVI}

WITNESS pode gravar a realidade virtual e simulações em 2D para um formato de arquivo de vídeo (.avi). Estes arquivos podem então ser distribuídos, por exemplo, para serem usados em ferramentas de apresentação.

\section{Voltando a Simulação}

WITNESS permite retornar para qualquer ponto anterior da simulação em qualquer momento. Isso facilita bastante a resolução do problema pelo grupo. A pergunta "Porque o tempo de ciclo aumenta de repente?" pode ser respondida retrocedendo um determinado período da simulação e visualizando novamente a corrida do modelo.

\section{Visualização do Processo}

Fornece uma visualização do fluxo do modelo para além da simples vista "geográfica"da simulação do modelo.

\section{Relatórios}

O usuário final do modelo de simulação precisa facilmente de relatórios acessíveis, flexíveis, graficamente interessantes e auto-explicáveis. Os relatórios são automaticamente gerados e 
apresentam os resultados num formato padrão. Uma variedade de opções de tabelas e gráficos estão disponíveis.

\section{ABORDAGEM DE MODELAGEM DISTRIBUIDA}

Essa abordagem baseia-se na utilização de um grande número de engenheiros ouu analistas habilitados pra usarem simulação para resolverem problemas no negócios os quais eles observam no dia-a-dia.

As vantagens dessa abordagem são:

1. Eles possuem excelente conhecimento do processo local

2. Os modelos tendem ser menores e focados em rápidos resultados.

3. Simulação é apenas uma de várias técnicas que o engenheiro ou analista pode empregar. Existe, assim, menor pressão para solucionar através da simulação problemas que não sejam adequados para tal aplicação.

As desvantagens são:

1. Uma pessoa que modela ocasionalmente, provavelmente tem menor conhecimento da ferramenta e levará mais tempo para criar um dado modelo.

2. É difícil evitar a existência de modeladores que continuamente "reinventam a roda" desenvolvendo modelos semelhantes.

O desafio é fornecer um correto ambiente de modelagem e funcionalidade da ferramenta para que as desvantagens desapareçam e que as vantagens de uma abordagem distribuida se sobressaia. 